\title{
Protocolos par-a-par para interligação de aglomerados em grades computacionais
}

\author{
Vladimir Moreira Rocha.
}

DISSERTAÇO APRESENTADA AO

INSTITUTO DE MATEMATICA E ESTATÍSTICA

DA LNIVERSIDADE DE SÃO PALLO

PARA OBTENCGATO DO GRAL DE

MESTRE EM CIENCIAS DA COMPUTACÃO

Área de Concentração: Ciência da Computação

Orientador: Prof. Dr. Fabio Kon

Sào Paulo. dezemoro de 200.j

Durane a elaboracio deste rahallo o antor Lepenen apoio finaneiro da CAPES. 



\title{
Protocolos Par-a-Par para Interligação de Aglomerados em Grades Computacionais
}

\author{
Este exemplar corresponde à redação \\ final da dissertação devidamente \\ corrigida e defendida por \\ Tladimir Moreira Rocha \\ e aprovada pela comissão julgadora.
}

São Paulo. dezembro 2005.

Banca examinadora:

- Prof. Dr. Fabio Kion (Orientador) - IMEE-tSP

- Prof. Dr. Narcelo Finger - IME-LSP

- Prof. Dr. Renato Cerqueira - PEC-Rio 


\section{Agradecimentos}

Ton começar por Dens, agradecer Ele por ter me dado a vida e por estar aqui. Ainda não sei muito bem qual o destino que Ele me deu. mas um dia rou concluí-lo. Aos meus pais, por seu apoio incondicional, pelos momentos vividos. pelo carinho. amor e por acreditar sempre em mi.

Agradeço profundamente ao professor Fabio Kon pelas suas orientaçoes sempre acertadas bem como pela sua amizade.

Agora aos amigos, quero agradecer aos meus "irmãos" da Republica e da vida, Edu. Thiaguin. Christian, Gordito e Karina. Com eles os momentos vividos e que vamos viver estarão sempre comigo. são inesquecíveis. Yrla. rocè merece um beijo especial.

Gostaria de agradecer também aos professores que participaram tanto na banca da defesa como da qualificação, Marcelo Finger, Renato Cerqueira e Alfredo Goldman.

É claro que não vou esquecer dos membros do GSD e do InteGrade. principalmente pelas reuniões. pelas comidas e pelos temas engraçados que as vezes abordáramos.

Finalmente agradeço ao LIE e a TSP por ter me dado a oportunidade de continuar meus estudos de pós-graduaço e a CAPES pelo apoio financeiro.

Enitersidade de Swo Paulo

De inmbro zomj 


\section{Resumo}

Neste trabalho são apresentados dois noros protocolos Par-a-Par que servirão para interligar aglomerados em uma Grade Computacional e localizar, nos gerenciadores desses aglomerados, os recursos oferecidos por eles.

O primeiro protocolo permite que os aglomerados de uma Grade Computacional se conheçam e que a latència entre eles seja a menor possível. Para isto utiliza-se a função de roteamento da camada de rede para descobrir noros aglomerados que estão dentro de uma rota entre dois aglomerados.

O segundo protocolo permite localizar informações nos diferentes aglomerados. A localização destas informações pode ser feita por intervalo de valores, e para isto é criada uma estrutura de lista distribuída ordenada pelos valores das informaçóes.

Os protocolos foram simulados e testados em relação a vários pontos críticos dos protocolos Par-a-Par como escalabilidade, tempo de ingresso e largura de banda utilizada. Mostramos que os resultados da simulação destas novas propostas cumprem com os objetivos de escalabilidade e eficiência. 


\section{Abstract}

In this work, we present two new Peer-to-Peer protocols that allow to intercomnect Grid clusters and to locate. in the clusters manager, shared resoluces.

The first protocol allows to link different Grid clusters and to organize them to obtain the less latency possible among them. To accomplish these objetives. we utilize the routing function present in the network larer. With that. it is possible to find new clusters present in a path between two clusters.

The second protocol allows to locate information shared by the Grid clusters. The location of these information could be made by a value range. In order to perform a location, a distributed list structure is created, ordered by the information values.

Finally. we simulate these protocols in many critical points of Peer-toPeer protocols like. scalability; join time and bandwidth used. Te show the results and prove that they satisfy scalability and efficiency goals. 


\section{Sumário}

Resumo iv

Abstract $\quad$ V

Sumário vi

Lista de Figuras ix

Lista de Tabelas $\quad$ xi

1 Introdução 1

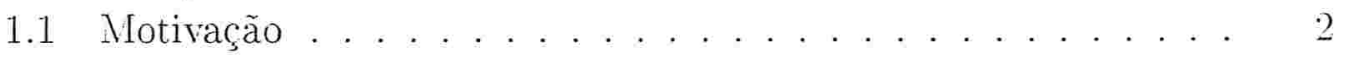

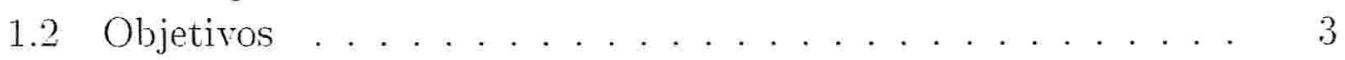

1.3 Contribuiçòes . . . . . . . . . . . . . . . . . . . . . . . 4

1.4 Estrutura da Dissertação . . . . . . . . . . . . . . . $t$

2 InteGrade 5

2.1 Arquitetura Intra-Aglomerado . . . . . . . . . . . 7

2.1.1 Protocolo de Disseminação de Informaçōes . . . . . . . 8

2.1.2 Protocolo de Execução de Aplicações . . . . . . . . . . . . 9

2.2 Arquitetura Inter-Aglomerados . . . . . . . . . . . . . 10

3 Redes P2P 12

3.1 Arquiteturas . . . . . . . . . . . . . . . . . . . . . . . . . . . . . . .

3.1 .1 Modelo Atomico . . . . . . . . . . . . . 13

3.1 .2 Todelo Centrado no Tsuário . . . . . . . . . . . 1.j

3.1.3 Modelo Centrado nos Dados . . . . . . . . . . . 17

3.1.4 Modelo Estruturado . . . . . . . . . . . . . 1 i

3.2 Exemplos de Serviços . . . . . . . . . . . . . . . . . . 19 
4 Localização Eficiente de Recursos 20

- 1 Características da Tabela de Hash Distribuida . . . . . . . . . 20

t.2 Estrutura de anel . . . . . . . . . . . . . . . . . . 21

4.3 Implenentaçòes . . . . . . . . . . . . . . . . . . . . . . . . . . . . . . . . . . . . . . . . . .

4.3.1 Chord . . . . . . . . . . . . . . . . . . 23

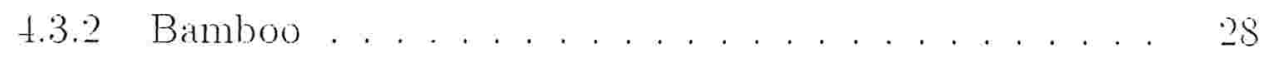

5 Protocolo de Interligação $\quad 32$

э.1 Visão Geral . . . . . . . . . . . . . . . . . . . . 33

5.1.1 Lsando e Armazenando a Informação dos Roteadores . 33

5.1.2 Repositório Local de Pares . . . . . . . . . . . . . . . . . . . . . . . . . .

5.2 Descrição do Protocolo . . . . . . . . . . . . . . . . . . . . . . . . . . . . . . .

5.2 .1 Adicionando um Par à Rede . . . . . . . . . . . 36

5.2 .2 Saída de um Par da Rede . . . . . . . . . . . . . . . . . . . . . . . . . .

5.2 .3 Processo de Atualização . . . . . . . . . . . . . . . . 39

6 Protocolo de Localização 42

6.1 Tipos de Recursos . . . . . . . . . . . . . . . . . . . . . . 12

6.2 Alternativas de Localização . . . . . . . . . . . . . . . . . . . . . . . . . . . . . . . .

6.3 Lista Distribuída . . . . . . . . . . . . . . . . 45

6.3.1 O Problema das Buscas nas tabelas de hash distribuidas t5

6.3.2 Estrutura Simplificada . . . . . . . . . . . . . . . 46

6.3 .3 Estrutura Estendida . . . . . . . . . . . . . . . . 47

6.3.t Buscas por Interralo . . . . . . . . . . . . . . . . . 49

6.3.5 Inserção de um Novo Recurso . . . . . . . . . . . . . . 49

6.3.6 Algoritmo de Estabilização da Estrutura . . . . . . . . 51

6.3.7 Algortimo de Estabilização da Tabela de Repeated Finger 51

7 Trabalhos Relacionados 54

7.1 Trabalhos Relacionados à Interligação . . . . . . . . . . . . . . jt

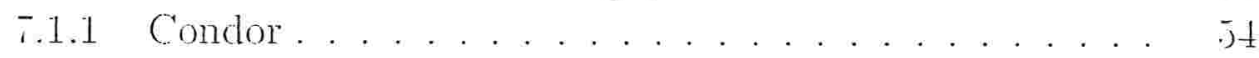

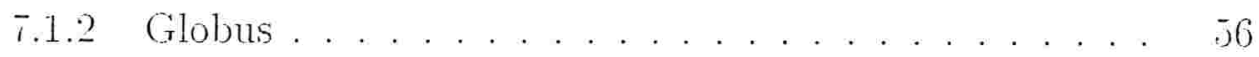

т.1.3 Gridbus .........................

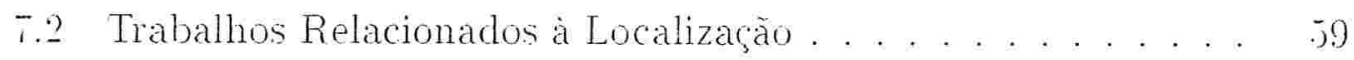

7.2.1 Plefit Hash Tiee . . . . . . . . . . . . . . . . . 59

T.2.2 Entended PHT ................ 60

72.3 Stip Graph ......................... 61 
8 Simulação $\quad 63$

8.1 Escolha e Implantação . . . . . . . . . . . . . . . . . . . 63

8.2 Resultados Experimentais da Intercomunicação . . . . . . . 6 6.5

8.2.1 Ambiente de Teste . . . . . . . . . . . . . 65

8.2 .2 Custo de Ingresso na Rede . . . . . . . . . . . . . . 65

8.2.3 Quantidade de pares espalhados . . . . . . . . . . . 66

8.2.4 Largura de Banda Usada . . . . . . . . . . . . . . 6 6

8.3 Resultados Experimentais da Localização . . . . . . . . . . . . 68

8.3.1 Ambiente de Teste . . . . . . . . . . . . 68

8.3.2 Custo de Inserir um Recurso . . . . . . . . . . . . . . . 68

8.3.3 Número de Recursos Visitados em uma Busca . . . . . 69

8.3.4 Largura de Banda usada pelo Protocolo . . . . . . . . . 70

8.3.5 Buscas por Intervalo . . . . . . . . . . . . . T0

9 Integração dos Protocolos ao InteGrade 73

9.1 Visão Geral . . . . . . . . . . . . . . . . . . . . 73

9.1 .1 Protocolo de Interligação . . . . . . . . . . . . . 73

9.1 .2 Protocolo de Localização . . . . . . . . . . . . . . . . . 74

9.2 Obtendo os LRMs . . . . . . . . . . . . . . . . . . .

9.2 .1 Utilizando a Vizinhança . . . . . . . . . . . 76

9.2 .2 Utilizando as LBIs . . . . . . . . . . . . . . 76

10 Conclusões e Trabalhos Futuros 78

10.1 Conclusòes . . . . . . . . . . . . . . . . . . . . . . . . . . . . . . . .

10.2 Trabalhos Futuros . . . . . . . . . . . . . . . . . . . 79

$\begin{array}{ll}\text { Referências Bibliográficas } & 81\end{array}$ 


\section{Lista de Figuras}

2.1 Arquitetura Intra-Aglomerado do InteGrade. . . . . . . . . . T

2.2 Protocolo de Execução de Aplicações. . . . . . . . . . . . . . . . . . 9 . . . . . . . .

2.3 Hierarquia de aglomerados. . . . . . . . . . . . . 11

3.1 .odelo Atomico. . . . . . . . . . . . . . . . . . . . . . . 14

3.2 Modelo Centrado no Lsuário. . . . . . . . . . . . . . . . 16

3.3 Modelo Estruturado. . . . . . . . . . . . . . . . . . . 18

4.1 Estrutura de anel com oito pares. . . . . . . . . . . . 22

t.2 Exemplo de uma tabela de hush distribuida. . . . . . . . . . . 22

4.3 Exemplo da tabela de roteamento do par número $25 . \quad \ldots . .25$

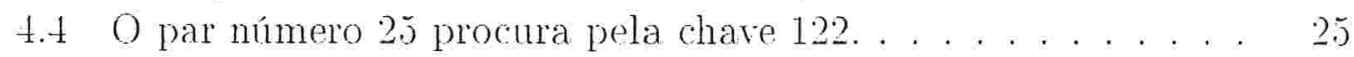

4.5 Atualização da tabela de roteamento identificando o par $27 . \quad$. 27

4.6 Transferência das chaves do par 28 para o par 27 . . . . . . 28

4.i Exemplo de uma tabela de roteamento do pastry. . . . . . . . 29

j.1 Estrutura de uma rede Par-a-Par geral. . . . . . . . . . . . 33

5.2 Rota da mensagem entre dois pares. . . . . . . . . . . . 34

5.3 Algoritmo para o ingresso de um par na rede. . . . . . . . . . 37

j.t Propagaça do uma mensagem pelos pares com o TTL $=3 . \quad . \quad 40$

6.1 Todos os pares atualizam num só par gerando uma arquitetura Cliente-Sertidor. . . . . . . . . . . . . . . 44

6.2 Exemplo de una busca simples com uma combinação de elementos atributo-ralor. . . . . . . . . . . . . . 46

6.3 Exemplo de buscas por intervalo de valores. . . . . . . . . . . 46

6.t A estrutura Lista para Buscas por Tuteralo sem valopes pepetidos. ti

6.5 A sestrurura Lista para Busca por Interalo com valores repetidos. 48

6.6 Algoritno usado para buscar os valores contidos em um intervalo. 49

6.7 Agoritmo para adicionar 1 m novo recurso. . . . . . . . . . 50 
6.8 Algoritmo que atualiza o predecessor e o sucessor de um recurso. 51

6.9 O método Estabiliza aplicado a diferentes recursos. . . . . . . 52

6.10 Algoritmo para estabilizar os valores repetidos. . . . . . . . 52

¡.1 A estrutura Skip List. . . . . . . . . . . . . . . . 61

8.1 Custo em segundos da entrada de um par na rede. . . . . . . . 66

8.2 Quantidade de pares espalhados nos processos de entrada de um par e de atualização do repositório. . . . . . . . . . . . 67

8.3 Consumo de largura de banda usada nos processos de entrada de um par na rede e de atualização do repositório. . . . . . . 68

8.4 Custo de inserir um recurso usando ou não a tabela de fingers. 69

8.5 Quantidade de recursos visitados em uma busca. . . . . . . . T0

8.6 Largura de banda usada pelos processos de registro estabilização. 71

8.7 Quantidade de recursos devolvidos dada uma busca por intervalo. it

9.1 Configuraçào da rede formada pelos GRMs. . . . . . . . . . Tt

9.2 Estrutura do Recurso armazenado na LBI. . . . . . . . . . . . T5

9.3 Très LBI. uma para a memória RAM, uma para o processador e outra para o disco rígido. . . . . . . . . . . . i5

9.4 Algoritmo utilizado para buscar os LRMs nas LBIs dado um requisito para a execução de uma tarefa. . . . . . . . 76 


\section{Lista de Tabelas}

3.1 Aplicacòes Par-a-Par. . . . . . . . . . . . . . . . . 19

4.1 Definiçào da tabela de roteamento de um par $p . \ldots .24$

5.1 Exemplo de um Repositório local de Pares . . . . . . . . . . 35

5.2 Lista de pares estáveis a ser armazenada em uma página Web. 37 


\section{Capítulo 1}

\section{Introdução}

Seja no ambito comercial, industrial ou de pesquisa, faz-se necessário apresentar e distribuir alguns serviços para as pessoas. Com a chegada da Internet, passou a ser possivel acessar estes serviços de qualquer parte do mundo através de um computador. Só é preciso saber como encontrar as máquinas que estão conectadas à rede e que disponibilizam tais serviços.

A arquitetura computacional mais utilizada que permite expor esses serviços é a cliente/ servidor. Nesta arquitetura, cada computador cumpre um papel bem definido. Se o computador é um servidor, então possui certas características, como por exemplo, ser um computador poderoso em termos de velocidade de processamento armazenamento e administração dos pedidos dos clientes para eritar congestionamentos e conseguir oferecer os serriços com qualidade. Se for um cliente, ele pode acessar os serviços disponiveis pelo servidor para seu aproveitamento.

Como exemplo, desde o começo dos anos 90. existiam servidores que ofereciam arquivos de música e outros documentos para compartilhamento e eram acessados por um número pequeno de clientes. Ouando a Internet foi se massificando, surgiram problemas de como administrar o crescimento exponencial do número de clientes que requisitaram estes arquiros e como distribuir e localizar as informações disponibilizadas pelos milhares de noros servidores que apareceram.

Para atender estes problemas foram desenrolvidos dois ambientes. que surgiram de diferentes comunidades e portanto foram projetados para satisfazer diferentes necessidades: as redes Par-a-Par e os sistemas de Computaräo em Giade.

As redes Par-a-Par smgiran para atender a necesidade le compartilhar arquiros entre milhares de computadores sem precisa dos serridores. 
Cada um destes computadores possui as mesmas responsabilidades e capacidades. podendo ser ao mesmo tempo servidor e cliente. Isto era uma proposta muito diferente da arquitetura cliente servidor que se tinha ate o momento |et01|. Neste tipo de rede, a comunicaçào é feita diretamente entre computadores e nào por intermédio de servidores. Estes computadores são chamados pares. Assim, se um cliente precisa de um serriço. simplesmente busca outros pares que o ofereçam.

Dentro dos protocolos de commicação Par-a-Par. existem diversos aspectos que foram abordados nos últimos anos. No entanto, os pesquisadores têm se concentrado na construçào de sistemas e arquiteturas que descobrem e localizam recursos que existem em um outro computador: tais como documentos e arquivos de música. e na escalabilidade do sistema para milhares de pares conectados.

Yo caso dos sistemas de Computação em Grade eles surgiram nos anos so para atender a necessidade do compartilhamento de recursos para o 1150 intensiro da computação. para processamento de dados, simulações. etc. Para aproveitar e melhorar esta nova idéia, os pesquisadores da área desenvolveram serviços sofisticados que conectam vários computadores para prover uma maior capacidade de processamento na execução de tarefas.

A localização dos recursos neste tipo de sistema não apresenta problemas quando são poucos os computadores envolvidos. Mas. com o crescimento de sistemas de grade computacionais, passou a ser possível a computação distribuída entre aglomerados de computadores geograficamente distantes. Assim não só é possivel executar uma tarefa em um outro aglomerado, como também acessar os seus recursos.

\subsection{Motivação}

O InteGrade [GIG-0t] [Int] é um sistema de Computaçào em Grade que interliga computadores com a finalidade de usar a capacidade ociosa de cada um deles em tarefas de computaçào de alto desempenho.

Sua arquitetura basicamente se resume a máquinas que fazem parte de 1 m aglomerado e um nó gerenciador responsável por administrá-los. Os módulos que coletam as informaçòes disponíreis sobre um nó como memoria R.A.H. Disco Rigido e Sistema Operacional. sào chamados LR I (Local Resource Manoyer). O módulo gerenciador. chamado GRX (Global Resource Manager) wleta as informacoues dos LR.I. 
No atual estágio do sistema. as aplicacões são executadas em un só aglomerado. Se a tarefa não pode ser executada no aglomerado local, a solicitação de execução da tarefa tem que ser enviada posteriormente até poder ser realizada.

A motivação do presente trabalho é criar um novo protocolo para redes Par-a-Par que servirá para interligar aglomerados no InteGrade. Com esses protocolos será possível fazer com que os GRAs de diferentes aglomerados possam se conhecer e localizar, nos GR.Ms da rede, informações que são modificadas periodicamente, as quais chamaremos de informaçôes dinàmicas.

No caso da interligação de GRMs. o objetivo é que a comunicação entre eles tenha baixa latência. Assim. se uma tarefa não pode ser executada num aglomerado, poderá ser transferida para outro com uma perda de desempenho relativamente menor. No caso da localização. as informações podem ser recursos disponíveis coletadas pelos LRMs. Com isso um usuário do sistema poderá encontrar, por exemplo, 64 máquinas (LRM) que tenham como mínimo 256 IB de RAM disponível, no momento, para executar uma multiplicação de matrizes.

\subsection{Objetivos}

Os principais objetivos do presente trabalho são:

- Criar um protocolo que permita estruturar os pares de uma rede de forma que a comunicação entre eles seja a mais rápida possível. (Protocolo de Interligação).

- Criar um protocolo que permita localizar os recursos disponibilizados pelos pares da rede. As buscas por estes recursos poderào ser definidas para um intervalo dos valores desses recursos. (Protocolo de Localização).

Os objetivos específicos traçados são:

- Os protocolos desenvolvidos para redes Par-a-Par poderão se adequar aos sistemas de Computação em Grade e vice-rersa. Por tanto. esses protocolos deveriam ter as seguintes características: independencia de um administrador central. suporte para buscas baseadas em atributos e escalabilidade [IF $\times 02$ ].

- Ctilizar uma estrutura Pur-qu-Pur que permita a busca de um recurso em tempo sub-linear. Esta estrutura selá a tabela de hash distribuíla. 
- Araliar a escalabilidade dos protocolos desenrolvidos. utilizando um simulador de redes de grande área.

\subsection{Contribuições}

As contribuiçoes deste trabalho correspondem aos protocolos criados para cumprir os objetivos traçados na sua concepção.

Io caso do Protocolo de Interligação. é inovador a utilização da função de roteamento da camada de rede para que um par possa encontrar novos pares que possam estar mais perto em termos de latência.

Em relação ao Protocolo de Localização. foi desenvolvida uma nova estrutura que permite uma busca pelo intervalo dos valores dos recursos. Esta estrutura. baseada na tabela de hash distribuída, corresponde a uma lista distribuída, ordenada pelos valores dos recursos e que é mais simples de administrar que as estruturas baseadas em árvores.

\subsection{Estrutura da Dissertação}

Esta dissertação está organizada cono a seguir. No Capítulo 2 apresentamos a arquitetura do InteGrade que utilizará os protocolos para localização e comunicação entre aglomerados. O Capítulo 3 é dedicado à descrição das redes Par-a-Par. No Capítulo 4, descrevemos como funciona a estrutura que será a base do protocolo e que permite uma localização em tempo $O(\log (n))$ de informaçòes espalhadas pela rede. No Capítulo j. descrevemos o Protocolo de Interligação que propõe resolver o problema de como obter uma comunica(̧ão eficiente entre os pares. No Capítulo 7 apresentamos alguns dos sistemas existentes relacionados ao Protocolo de Interligação. O Capítulo 6 descreve o Protocolo de Localização, que servirá para buscar nos GRMs informações dinamicas dos LR.M. Alguns dos sistemas existentes relacionados ao Protocolo de Localização são apresentarlos no Capitulo 7.2. O Capítulo 8 mostra os resultados da simulaça dos protocolos apresentados. em redes de grande area. Finalmente as conclusoes e trabalhos futuros a serem desenvolvidos como continuaça deste trabalho sào apresentadas no Capítulo 10. 


\section{Capítulo 2}

\section{InteGrade}

O InteGrade [Int] é um sistema de computação em grade desenvolvido por várias universidades brasileiras: IME USP, DCT UF.IS. DI PLC-Rio, DEINF LFMA e que tem por objetivo o compartilhamento de computadores pessoais de maneira a permitir a utilização de sua capacidade ociosa em tarefas de computação de alto desempenho, sem nenhum custo adicional em termos de hardware, nem exigindo nenhuma mudança drástica na instalação de software nas máquinas.

O InteGrade está sendo construído usando uma implementação de uma arquitetura padronizada. CORBA. que permite a objetos distribuídos se comunicarem [Gro02]. Na arquitetura CORBA são descritos serviços, como Serviço de Nomes, Serviço de Negociação e Serviço de Transações os quais já estão implementados, testados e que ajudam a diminuir a complexidade do sistema e custos de manutenção do software, permitindo que o desenvolvimento do projeto somente fique concentrado na domínio da aplicação.

Segue abaixo um resumo dos diferentes aspectos dentro do InteGrade que formam a arquitetura interna do sistema e que permitem o seu funcionamento.

- Detecção e Análise de Padrões de Uso

O modulo de Análise e Deteç̧ão de Padrōes de Lso é o encarregado por coletar longas séries de informaçöes referentes ao uso de recursos de cada uma das máquinas da Grade. Ele fornecerá. ao escalonador de aplicaçōes. informações que melhorarão a sua capacidade de decisão de onde alocar a tarefa a executar. Por exemplo. se uma determinada máquina pertencente à Grade é usada de mancira intormitente ao longo do dia. estando ociosa apenas em breres príodos. o escalonador analisará que 
é ponco eficiente escalonar uma tarefa que precisa de um longo período de execução. resultando no cancelamento ou migração da tarefa. Entretanto, convém lembrar que esse módulo somente fornecerá dicas, ou seja, at chance do padräo sugerido ocorrer tende a ser grande. mas de maneira alguma representa uma certeza.

\section{- Segurança}

L'm dos problemas sérios que temos em aplicaçòes e sistemas que usam as redes é a segurança. Esse módulo pretende assegurar que as máquinas da grade sejam protegilas contra ataques; preservando assim a integridade dos dados da mácquina do provedor de recursos. Com isso, evita-se que un usuário possa tentar roubar dados sigilosos e arquivos pessoais. prejudicar ou impedir o correto funcionanento da mácquina e também instalar programas que cansem perdas de arquivos e dados. Assim, são necessários medidas que impeçam que tal tipo de ataque ocorra.

\section{- Suporte a aplicações paralelas}

O suporte de aplicações paralelas consiste em permitir o uso de aplicações paralelas que precisam de uso simultàneo de vários recursos e que geralmente são executadas em sistemas de computação em grade. No momento. poucos sistemas de grade oferecem suporte à execuçăo de aplicações paralelas fortemente acopladas. especialmente quando não há nenhuma garantia sobre a disponibilidade dos recursos. InteGrade oferece suporte ao modelo BSP (Bulki Synchronous Parallelism) [Tal90] com o objetivo de que as aplicações já existentes possam rodar na Grade. Assim. junto com o módulo de Análise e Deteç̧ão de Padrões de Uso, o InteGrade poderá oferecer uma previsão muito provável sobre a disponibilidade de recursos em cada máquina do sistema.

\section{- Checkpointing}

O mecanismo de checkpointing prore recuperação por retrocesso para aplicações sendo executadas na Grade. Isto é muito importante devido ao fato de máquinas poderem ficar inacessiveis ou mudar seu estado de ocioso a ocupado rapidamente comprometendo a execuçào das aplicaçòes nussas mádninas, O mecanismo consiste em armazenar periodicamente o estado de um processo. de modo que este estado possa ser recuperado em caso de falha em sua execucato. 
A arquitetura do InteGrade é composta por aglomerados interligados. Cada aglomerado contém normalmente entre duas e 100 máquinas. Tamos descrever a arquitetura de um aglomerado típico e a arquitetura entre aglomerados.

\subsection{Arquitetura Intra-Aglomerado}

A Figura 2.1 apresenta os elementos mais importantes de um aglomerado do InteGrade. Existem vários tipos de nós no aglomerado. O Nó Dedicado é uma máquina reservada à computação em grade, assim como se fosse um nó em um aglomerado dedicado tradicional. Tais máquinas não são o foco principal do InteGrade, mas tais recursos podem ser integrados aos aglomerados se desejado. O Nó Compartilhado é aquele que pertence a um usuário que compartilha seus recursos ociosos com a grade. Finalmente, o Nó de Lsuário é aquele que possui a capacidade de submeter aplicações para serem executadas na grade. O Gerenciador de Aglomerado é responsável pela execução de módulos responsáveis pela coleta de informaçöes e escalonamento. É importante destacar que um nó pode pertencer a várias categorias simultaneamente, por exemplo, um nó que tanto compartilha seus recursos ociosos quanto é capaz de submeter aplicações para serem executadas na grade.

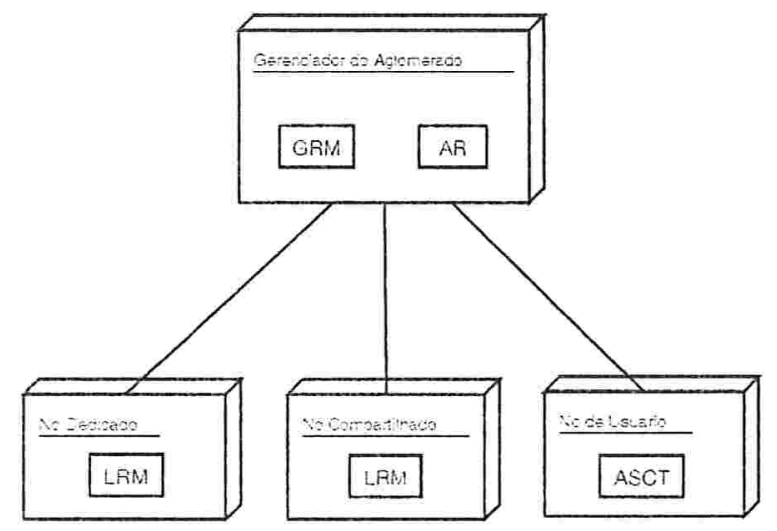

Figura 2.1: Arquitetura Intra-Aglomerado do InteGrade.

Os módulos apresentados na Figura 2.1 são responsáveis pela execucão de diversas tarefas necessárias à Grade daremos a seguir uma descrição deles.

O ASCT (Application Submission und Control Tool) e uma ferramenta que permite aos nsuários da Grade submeter aplicaços que serão executarlas 
na mesma. Com essa ferramenta é possivel estabelecer certas condições de excuçăo. como: sistema operacional. configuraçoes de hardware e software. etc. e preferencias. como recursos necessários (por exemplo quantidade de memória RA.M mínima) para melhorar o desempenho da execução da aplicação. Essa ferramenta também disponibiliza ao usuários o controle, monitoramento - recuperação dos resultados da execuça da tarefa. O LRII (Local Resource Manager) é executado em todas as máquinas que compartilham seus recursos com a Grade é responsável pela coleta de informaçoes sobre a disponibilidade de recursos em un dado nó. Também è responsável por exportar os recursos desse nó à grade permitindo à execução de aplicações submetidas por usuários da grade. O GR\I (Global Resource Manuger) geralmente é executado en um nó que gerencia o aglomerado e é responsável por coletar as informaços dos LRM. assin como tomar decisoes de escalonamento baseadas em tais informações [GKG-0-t]. O AR (Applicution Repository) é o responsável por armazenar as aplicaçòes submetidas pelos usuários e que serão executadas na Grade. Esse repositório de aplicaçoos fornece também outras funcionalidades como por exemplo o registro de meta-dados da aplicação, como nome, tipo de aplicação e sistema operacional onde pode ser executado. Finalmente, existem outros módulos como o LLPA. GLPA e o NCC que saem do escopo deste trabalho. mas que são analisados em [Gol0t].

A colaboracão entre esses módulos é dada pelos protocolos responsáveis pela disseminação de informações e pela execuçào de tarefas e que são derivados dos protocolos utilizados pelo sistema operacional distribuido $2 \mathrm{~K}[\mathrm{KC} \mathrm{C} \div 00]$.

\subsubsection{Protocolo de Disseminação de Informações}

Este protocolo permite a um aglomerado do InteGrade manter atualizadas as informações dos recursos disponibilizados nas diversas máquinas do aglomerado. Essas informaçōes podem ser dados estáticos (arquitetura da máquina. sistema operacional. memória total disco rígido. etc.) ou dados dinamicos (porcentagem de CPL ociosa. memória R.A.I disponírel no momento. etc.) e que permite que o GR.I escalone as tarefas da forma mais adequada aos requisitos da aplicação submetida.

Para manter os dados do aglomerado atualizados. periodicamente cada LRM rerifica a disponihilidade dos sene recuros. Caso exista alguma mudanca significatira entre a infomaca atual a infomaço anterior o LR.l envia

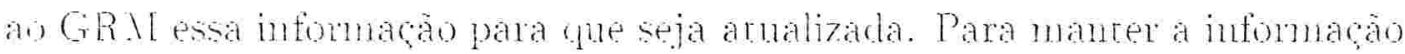
das máninas do aglomerado que esta no ar. cala LRM enria periodicanente 
ao GRMI uma mensagem de vida (keep-alive).

\subsubsection{Protocolo de Execução de Aplicações}

Este protocolo têm por objetivo a execução de uma aplicação submetida sobre recursos compartilhados da Grade. A Figura 2.2 apresenta os passos necessários para executar uma aplicação. Depois que a aplicação foi submetida ao repositório de aplicações através do ASCT. o usuário pede a este a execução de uma tarefa o qual é encaminhada ao GR.Y (1). O GR.I. com as informações coletadas da Grade, procura os nós candidatos que cumprem com os requisitos da tarefa (2). Caso existam nós disponíveis, o GRM verifica se eles realmente possuem os recursos necessários para a execução da tarefa e pede para executá-la nesses nós (3). Deremos lembrar que o GR.Y somente tem uma visão aproximada da Grade. O LR.M que aceita a execução da tarefa pede para o Repositório de Aplicações o arquivo executárel da aplicação (4) e para o nó requisitante os arquivos de entrada (j). Finalmente executa a aplicação (6).

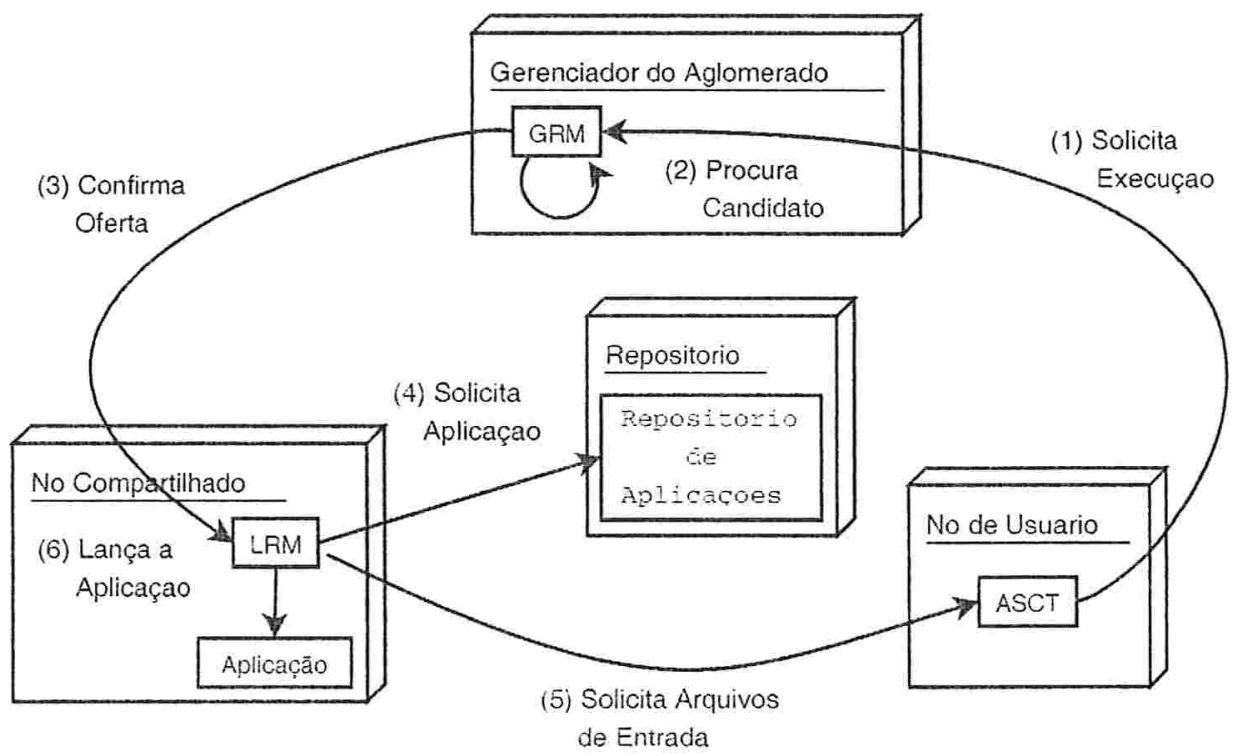

Figura 2.2: Protocolo de Execução de Aplicações. 


\subsection{Arquitetura Inter-Aglomerados}

Lma primeira proposta para interligar eficientemente diversos aglomerados do InteGrade foi a cle integrar os diferentes aglomerados em uma hierarquia de árore definida pelos administradores dos aglomerados, como mostra a Figura 2.3. Um dos problemas que esta alternativa apresenta é que a escalabilidade do sistema pode ser comprometida de duas formas: a primeira é que os administradores tem que conhecer os endereços dos gerenciadores do aglomerado para conectá-los manualmente e no caso de haver muitos gerenciadores pode ficar difícil de administrar. A segunda é que um nó mantém informações sobre a sub-árvore de sua hierarquia e, no caso dessa sub árvore ser muito grande. a atualização das informações nesse nó pode gerar uma carga muito alta. Nesmo assim. no caso de se ter centenas de aglomerados do InteGrade esta proposta parece ser muito eficiente.

Como um dos objetivos do InteGrade é implementar um sistema capaz de atender potencialmente milhares de máquinas conectadas através de uma rede de grande área como a Internet, é necessário estender a arquitetura para interligar vários aglomerados. O objetivo deste projeto é oferecer o máximo de escalabilidade e velocidade de comunicação entre eles.

A arquitetura Inter-Aglomerados, terá dois protocolos fundamentais para seu funcionamento: O Protocolo de Interligação e o Protocolo de Localização de Recursos. O Protocolo de Interligação como veremos na Seção 5 . conecta os Aglomerados de uma maneira eficiente. O Protocolo de Localizaçăo procura por nós dos aglomerados que satisfaçam certos critérios, descritos na Seção 6. 


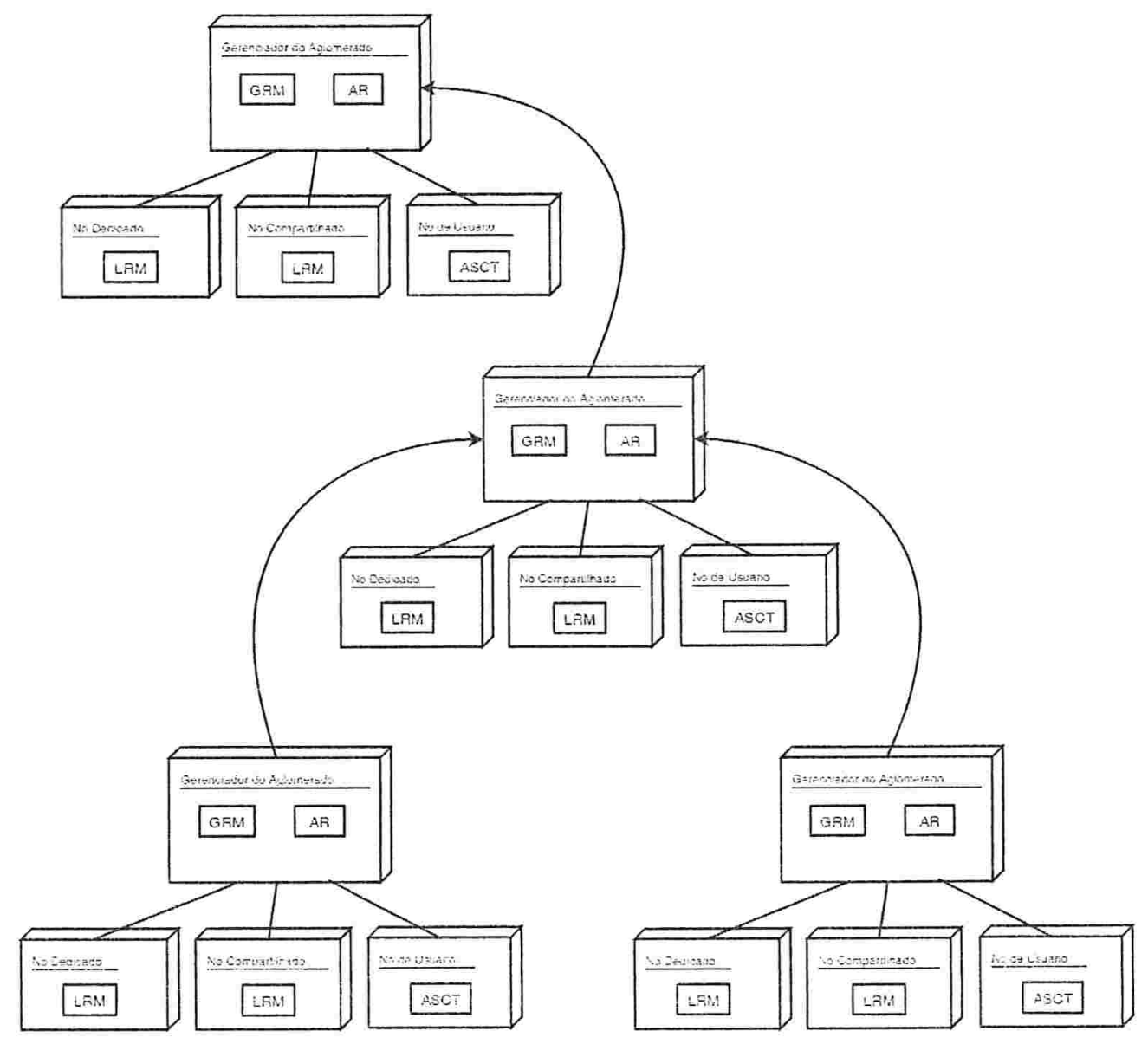

Figura 2.3: Hierarquia de aglomerados. 


\section{Capítulo 3}

\section{Redes P2P}

O termo Par-a-Par (P2P ou Peer-to-Peer) como conceito foi usado pela primeira vez por vendedores de redes locais em meados dos anos 80 para descrerer a conectividade de uma arquitetura de uma rede local [Leu02].

Yesmo que algumas aplicações Par-a-Par existam descle os finais dos anos 70 . como a Usenet, que permitia o compartilhamento de notícias nas comunidades LXIX. foi só no ano 2000, com o surgimento de uma aplicação que compartilha arquiros de música chamada Napster. que o conceito começou a se generalizar e ser conhecido [STDG01]. Desde então, em meios não acadêmicos, Par-a-Par virou quase um sinonimo de aplicaçòes para compartilhamento de arquiros.

Daremos a seguir uma definição do que é uma rede Par-a-Pur. Como conceito, estará dividida em vários aspectos que juntos formarão una definição compreensivel.

- Comunicaçuo diretu entre os pares: A commicação entre os pares, que podem ser pessoas, máquinas ou programas, não possui um mediador central que a controle. É possivel ter uma comunicação entre dois pares quaisquer pertencentes à rede Par-a-Par.

- A conectividade é usualmente transitória e năo permanente: Cada par pertencente à rede Par-a-Par tem uma período de vida curto (normalmente poucas horas [GDS-03. SGG02. CLL02]). Isso implica que nesta topologia. os serviços oferecidos e a comunicaça são variáreis e intermitentes.

- Esta focado principalmente em pessons e recursos: As redes Par-a-Par proporcionan os meios necessarios para obter qualquer tipo de recuso 
que é oferecido pelos seus pares. Cada par tem um identificador global que o caracteriza como único.

- Alternativa às estruturas baseadas em servidores: A maioria das tecnologias criadas para as redes Par-a-Par tem como objetivo evitar as arquiteturas onde o par só atua como cliente ou só como servidor.

\subsection{Arquiteturas}

Existem vários modelos arquiteturais para redes Par-a-Par [Min01]. A seguir serão mostradas as características, rantagens, desvantagens, ingressos e buscas de quatro desses modelos que consideramos como os mais usados e conhecidos.

\subsubsection{Modelo Atômico}

O modelo atòmico é chamado pelos puristas de "a verdadeira rede $P$ ar-a-Par". Este modelo apresenta algumas características que diferem totalmente das arquitetura baseadas em servidores. Primeiro, não existem servidores centrais que possam ter informação completa da rede e dos seus usuários, de modo que todos os pares são por sua vez clientes e servidores. Segundo, a estrutura de conexão formada por eles é aleatória, uma vez que um par pode se conectar potencialmente a qualquer outro par da rede. Terceiro, cada par é autonomo e administra seus próprios recursos e suas próprias conexões. Nesse caso, cada um deles mantém contato direto (conexão direta) com alguns outros, mas a comunicação pode ser estabelecida com qualquer outro par da rede (conexão virtual), como mostra a Figura 3.1.

Jos últimos tempos, algumas pesquisas em redes $P(u r-a-P a r$ têm utilizado uma variação do modelo a tómico. Essa variação consta da criação de uma nova camada de pares, conhecidos como super pares, que tem como característica una melhor capacidade de processamento, armazenamento, conectividade e confiabilidade. Com essa variação se tenta criar uma estrutura de pares que permita melhorar o desempenho nas buscas.

Escalabilidade é uma questăo importante nos modelos arquiteturais das redes Par-a-Par onde a quantidade de pares que a utilizam é muito grande. - Hgumas pesquisas |Rit01| mostram que aplicaços que utilizam este modclo. como Guntella 1. sào cscalóxeis no máximo a algums milhares de pares conecrados. Passado onse valor. o desmpenho nas buscas. devido à sobrecarga na 


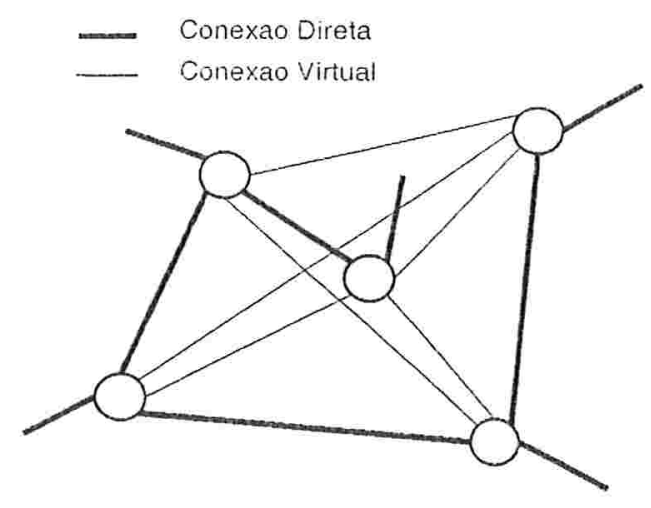

Figura 3.1: Modelo Atómico.

rede. começa a degradar exponencialmente até a rede ficar indisponível. Existem dois tipos de alternatiras ao problema mencionado acima. A primeira é estruturar os pares como veremos na Seção 3.1.4 e a segunda é utilizar uma propagação controlada na comunicação entre pares, mostrado em "Buscas na rede" deste modelo.

Ingresso na rede. To modelo atomico, como não existe um servidor central de onde poder-se-ia obter outros pares com os quais se comunicar, existe um problema fundamental de como se unir à rede.

Existem dois métodos tradicionais para resolver em parte esse problema. cada $1 \mathrm{~m}$ deles usado para diferentes propósitos. A primeira é propagar uma mensagem de pedido de ingresso usando broddcast para obter respostas de pares que estejam escutando esse tipo de mensagens. Essa proposta é muito utilizada e eficiente para redes locais. onde determinar os pares que estão escutando uma requisição de ingresso não é difícil. A segunda alternativa é se conectar a pares cujos endereços săo conhecidos. geralmente utilizada nos casos onde os pares estão espalhados em uma rede grande. por exemplo uma MAX (Wide Area Netuork). A propagação de uma mensagem de ingresso explicada na primeira alternativa pode resultar em um grande consumo de largura de banda. pois a mensagem será propagada pela rede para todos os pares sem considerar se eles estão. on nào. escutando pela requisição.

Buscas na rede A base de todas as buscas por recursos neste modelo a a propagaço da mensagen de busca nos pares la rede. Cma das prineinas 
alternatiras utilizadas nos protocolos de busca foi propagar a requisiça a todos" os pares da rede. chamado de flooding. A desvantagem desta alternativa se produz quando a quantidade de pares que utilizam a rede aumenta. Neste caso, a quantidade de mensagens de busca aumenta de forma exponencial e a rede fica inutilizada rapidamente pela sobrecarga. Surgiu então uma variaçào desta alternativa que utiliza uma variável TTL (Time To Live) que define o tempo de vida da mensagem, ou seja limita a propagação. O valor desta rariável diminui em cada propagação da mensagem, o que controla a quantidade de mensagens que utilizam a rede. Com esta proposta, apesar da melhora do problema da sobrecarga da rede, não podemos ter certeza se o recurso existe ou não. Como a propagação da mensagem é controlada. ela somente alcança um certo nível de pares que podem não conter o recurso procurado e que pode estar além da barreira definida pela TTL. Outras alternatiras mais recentes. como a do protocolo do Gnutella 2 [gnua], propõem que um par (conhecido como super par ou hub peer) armazene os nomes dos recursos dos seus conhecidos. Com isso, quando a esse par chega uma mensagem de busca por um recurso $x$, este encaminha diretamente ao par que possui $x$, o que evita, de certa forma, a propagação da mensagem e melhora o desempenho de algumas buscas.

\subsubsection{Modelo Centrado no Usuário}

O modelo centrado no usuário, diferentemente do modelo atomico, é gerenciado por um servidor central que atua como mediador para ingresso e buscas de pares da rede, como mostra a Figura 3.2. Esse servidor contém um diretório, que mantém os endereços (chamado de links persistentes) dos pares conectados na rede e que possibilita a procura por eles. $\dot{E}$ atualizado enviando periodicamente uma mensagem de rida (heartbeat) aos pares conectados. Essa arquitetura é uma das mais utilizadas devido à facilidade de conhecer os outros pares conectados à rede e por ser bem parecida com a arquitetura Cliente. Servidor.

A escalabilidade deste tipo de modelo é dada pela sobrecarga exercida no servidor central. Para saber se o modelo pode ser considerado escalável. ou não. para uma quantidade grande de pares conectados, deremos analisar qual é a função do administrador central. Se a função dele for somente a de permitir o ingresso de pares à rede. então torlas as transferencias de mensagens foomo as de busca) seráo entre os pares envolvidos. Veste caso o modelo é totalmente escalárel. Se o administrador central for também o responsárel pela busca de recursos nos pares armazenados no diretório. existirá mma sobrecarga maior 


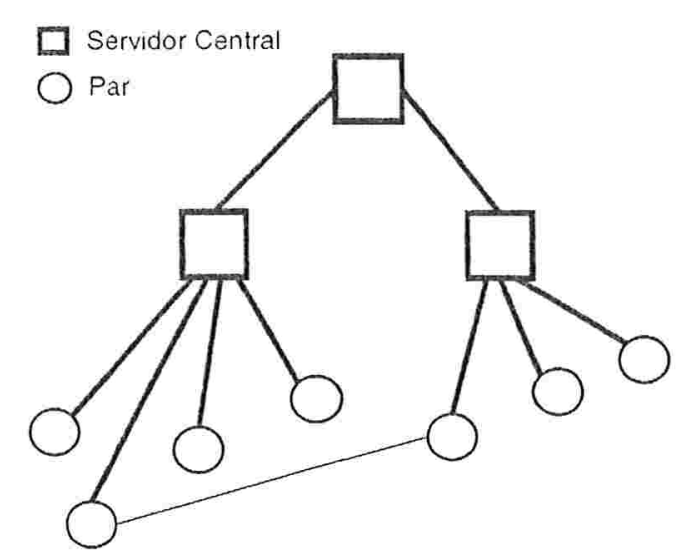

Figura 3.2: Modelo Centrado no Lsuário.

porque todas as buscas serão feitas utilizando este administrador. Neste caso, o modelo fica pouco escalável e será necessário criar réplicas desse administrador. como no caso das aplicações Kazaa [kaz] ou Napster [nap].

Ingresso na rede. Para um par se conectar à rede. deve primeiro contatar o servidor central (com endereço conhecido) e pedir permissão para se conectar. Quando o administrador central permite o ingresso. este registra no seu diretório o novo par disponibilizando sua conexão com os outros pares da rede. Uma rez registrado, um par pode procurar no diretório por pares que correspondam aos critérios de busca dados pelo diretório. Devemos deixar claro que esse critério será a característica do par e não os recursos que ele disponibiliza. A informação recebida será os endereços desses pares e a transferência de informação será sempre entre os pares envolvidos e não afetará o administrador central.

Buscas na rede. A busca por pares conectados está implícita no diretório do administrador central. mas a busca por recursos terá que ser parecida com a do modelo atomico. ou seja, pela propagação da busca. Lma altemativa é ter diretórios dos recursos disponibilizados pelos pares da rede como verenos na seça seguinte. 


\subsubsection{Modelo Centrado nos Dados}

Esse modelo é muito parecido com o modelo centrado no usuário. A diferença principal é que o servidor mantém um índice dos recursos ao invés de usúrios. Vesse modelo, as políticas de segurança e regras de conexão com os pares são mais estritas que no modelo centrado no usuário. Nem sempre é permitido o acesso aos recursos, especialmente no ambito empresarial.

A escalabilidade desse modelo é menor que a do Centrado nos Usuários derido à quantidade de recursos disponíveis ser muito maior que a quantidade de pares. As mensagens de atualização de recursos disponiveis e as de busca por recursos podem sobrecarregar o administrador central provocando uma queda no desempenho. Como no caso do modelo centrado nos usuários. uma alternativa é usar réplicas destes administradores de modo a dispersar as mensagens de ingresso e busca.

Ingresso na rede Para o ingresso de um par nessa rede, é necessário verificar a segurança uma rez que alguns recursos podem não estar disponíveis para certos pares. De modo similar ao modelo centrado nos usuários. o par se contata com o administrador central pedindo permissão para se conectar. Quando o administrador central permite o ingresso, este registra no seu diretório todos os recursos disponibilizados pelo par que esta ingressando e as políticas de segurança desses recursos.

Buscas na rede Para buscas por recursos o par envia uma mensagem de busca para o administrador central. Este por sua rez procura os recursos disponíveis no seu diretório e devolve os endereços dos pares que o disponibilizam e que permitem o seu compartilhamento, segundo as políticas de segurança do recurso. O mapeamento entre recursos e endereços está no diretório do administrador central.

\subsubsection{Modelo Estruturado}

Este modelo foi um dos últimos a surgir no cenário dos modelos Par-a-Par. A idéia principal é a de construir redes estruturadas de modo a melhorar a eficiencia das buscas por recursos nos pares da rede que o armazenam. Esse tipo de modelo e chamado de redes sobrepostas (overlay neturks). reja Figura 3.3. Com isso. tenta-se eritar que a busca por um recurso seja propagada sem controle em pares que nào tém o recurso. como no caso do modelo atomico. 
Existem diferentes estruturas criadas para armazenar e procurar recursos em redes Par-a-Par, tais como: listas distribuidas [ASO3|. árores distribuídas $|\operatorname{Cos} 97|$ e tabelas de hash distribuídas $\mid \mathrm{S}:\left[\mathrm{K}^{-0} 03 \mid\right.$.

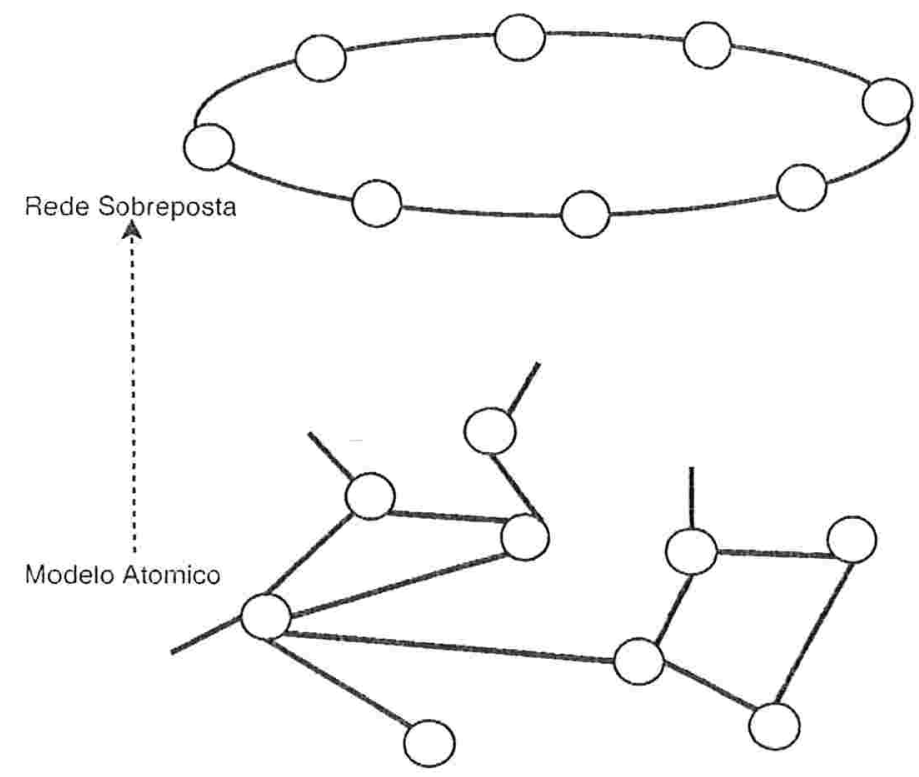

Figura 3.3: Modelo Estruturado.

A escalabilidade deste modelo, segundo as simulações feitas [RGRL04. $\mathrm{S.MK}^{-03}$. RFH ${ }^{-01]}$ foi demonstrada para milhares de pares unidos à rede. Mesmo assim ainda não existem experimentos para casos onde a quantidade de usuários é parecida com as aplicaçôes reais. ou seja centena de milhares.

Ingresso na rede. Da mesma forma que no modelo atomico. aqui também nào existe um servidor central ao qual se conectar à rede e portanto se tem os mesmos problemas e alternatiras de conexáo apresentadas naquele modelo.

Buscas na rede. Devido a estrutura formada pelos pares, a procura por recursos sempre devolverá um resultado positiro caso exista o recurso. A idéia é que o caminho seguido (chanado de roteamento) pela mensagem para procurar o par que armazena o recurso é o mais eficiente possirel. É importante destacar que todas essas estrutuas utilizan $O(\log n)$ troca de mensagens para localizar o recurso fonde 11 é a quanticlade de pares da rede). 


\subsection{Exemplos de Serviços}

Wostramos na Tabela 3.1 algumas das aplicações Par-a-Par mais conhecidas.

\begin{tabular}{|c|c|c|}
\hline Tome da Aplicação & Domínio & Arquitetma \\
\hline $\mathrm{ICQ}$ & Serviço de mensagens & Centrado no usuário \\
\hline Jabber & Serviço de mensagens & Centrado nos dados \\
\hline Napster & $\begin{array}{l}\text { Compartilhamento e transfe- } \\
\text { rència de arquivos XP3 }\end{array}$ & Centrado nos dados usuário \\
\hline Gnutella & $\begin{array}{l}\text { Compartilhamento e transfe- } \\
\text { rència de arquivos }\end{array}$ & Atomico \\
\hline Freenet & Persistencia de arquivos & Atomico \\
\hline Groove & $\begin{array}{l}\text { Ambiente de trabalho colabo- } \\
\text { rativo }\end{array}$ & Centrado nos dados \\
\hline JXTA & $\begin{array}{l}\text { Persistencia, mensagens, tra- } \\
\text { balho colaborativo, etc. }\end{array}$ & Atomico \\
\hline Chord & $\begin{array}{l}\text { Persistencia, indexação de in- } \\
\text { formações, trabalho colabora- } \\
\text { tivo, etc. }\end{array}$ & Estruturado \\
\hline CAN & $\begin{array}{l}\text { Persistencia, indexação de in- } \\
\text { formaçōes, trabalho colabora- } \\
\text { tivo, etc. }\end{array}$ & Estruturado \\
\hline BitTorrent & $\begin{array}{l}\text { Compartilhamento e transfe- } \\
\text { rència de arquiros }\end{array}$ & Centrado nos dados \\
\hline MSN & Serviço de mensagens & Centrado no usuário \\
\hline Tiazaa & $\begin{array}{l}\text { Compartilhamento e transfe- } \\
\text { rencia de arquivos }\end{array}$ & Centrado nos dados/usuário \\
\hline
\end{tabular}

Tabela 3.1: Aplicações Par-a-Par. 


\section{Capítulo 4}

\section{Localização Eficiente de Recursos}

No ambito das redes Par-a-Par as aplicações estão baseadas em características como: armazenamento. seleção do servidor mais próximo, buscas. autenticação. entre outras $\left[\mathrm{SMK}^{+} 03\right]$. Yesses últimos anos. diversas pesquisas se concentraram no principal problema de todos os sistemas Par-a-Par, que é a localizaçào eficiente do membro que armazena o recurso procurado.

Para resolver o problema acima, diversas estruturas distribuídas foram criadas (ver Seção 3.1.4), mas a tabela de hash distribuída teve efeitos revolucionários no desempenho e escalabilidade. A tabela de hash distribuída é uma estrutura que permite a realização das funções de uma tabela de hash normal, ou seja. nela pode-se armazenar um valor dada uma chave e procurar por esse valor utilizando a chave [Tan02].

Lma das caracteristicas importantes sobre as tabelas de hash distribuidas é que o armazenamento e as operações de busca são distribuídas entre as máquinas que pertencem à rede $P a r-a$-Par. Diferentemente das arquiteturas cliente servidor existentes, os membros podem se unir e sair da rede livremente. Apesar do caos evidente que poderia acontecer com essas mudanças na estrutura da rede, o funcionamento da tabela de hash distribuida garante a qualidade de serviço nas operações de busca.

\subsection{Características da Tabela de Hash Distribuída}

As tabelas de luash distribuidas apresentam algumas características como:

- Balanceamento de Carga. É utilizarla una fumçào de hash para distribuir ignalmente as chaves a serem armazenadas entre os pares da tabela 
de hush distribuída. Com isso: a probabilidade que um par fique sobrecarregado é muito baixa.

- Descentralização. Seguindo as propriedades das redes Par-a-Par, nenhum par nesta tabela é mais importante que outro, isso implica na melhoria da robustez comparado com alternativas baseadas em servidores derido à pouca organização deste tipo de redes.

- Escalabilidade. O custo das buscas só aumenta logaritmicamente com a quantidade de pares pertencentes à rede. Essa quantidade pode ser considerada constante mesmo para aplicações com um número muito grande de pares. Portanto, qualquer aplicação que seja baseada na tabela de hash distribuída pode ser desenvolvida sem se preocupar em colocar restrições que afetem o crescimento da rede.

- Disponibilidade. Essa característica impõe que toda chave será sempre encontrada, inclusive se o sistema está em um estado de mudança contínua. A tabela de hash distribuída preocupa-se com as entradas e saídas aleatórias dos pares da rede.

- Flexibilidade de nomes. As chaves a serem criadas pelos usuários da tabela de hash distribuída não precisam ter um formato específico.

- Eficiência. A tabela de hash distribuída provè mecanismos para o ingresso/saída de um par e para encontrar uma chave armazenada. Esse mecanismo somente precisa de uma troca de mensagens de ordem logarítmica em relação à quantidade de pares pertencentes à rede.

\subsection{Estrutura de anel}

A estrutura das tabelas de hash distribuidas pode ser vista como uma variação de uma lista circular duplamente encadeada onde cada nó dessa lista corresponde a um par da rede. Como a estrutura é circular. ela é chamada de anel. Na Figura 4.1 podemos obserrar uma estrutura de anel já formada com oito pares.

Cada par pertencente à estrutura tom uma informagào única que o distingue por exemplo à uniào do IP com o númcro da portà onde está escutando as requisiçoes. A essa informação única é aplicada una função de hak que devolve um identificador ínico se a informaço do par é inica, o numero gerado pela funça tera una al ta probabilidade de ser úncol o gual é inserido na 


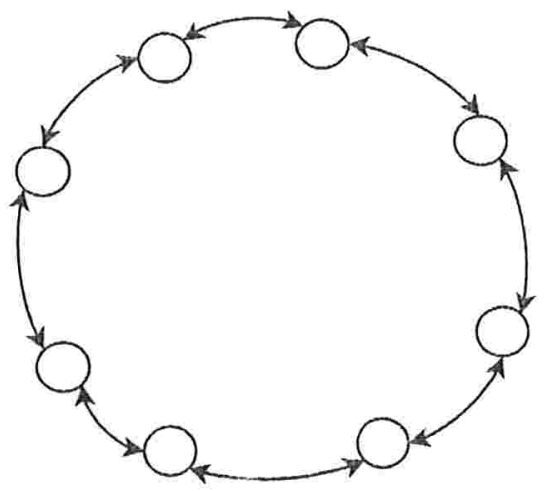

Figura 4.1: Estrutura de anel com oito pares.

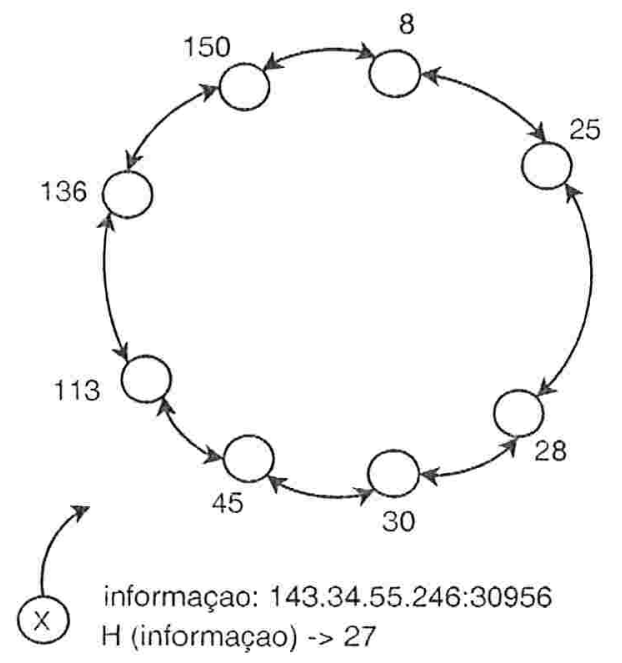

(a) Transformação da informação do par X

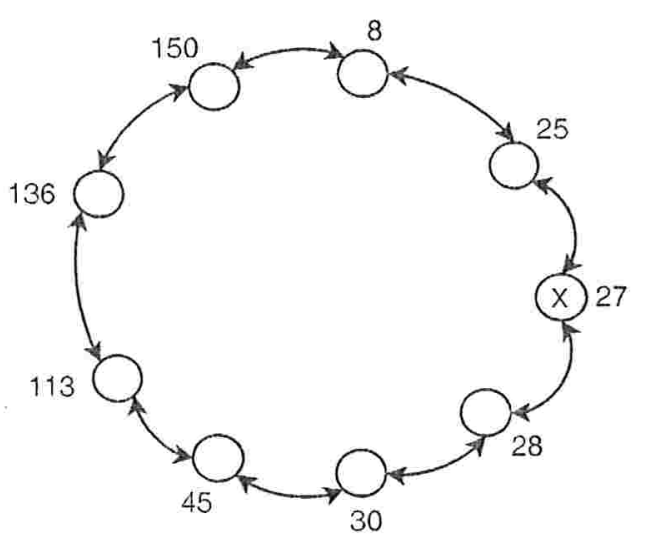

(b) Inserção do Par X na estrutura

Figura 4.2: Exemplo de uma tabela de hash distribuída.

estrutura de forma que o anel fique sempre ordenado de forma crescente pelos múmeros. Na Figura t.2(a) podemos obserrar que ao par I que está ingressando e dado o identificador 27. o qual será inserido entre os identificadores 25 e 28 (Figura t.2(b)).

Sobre a responsabilidade dos pares a respeito das chares armazenadas. cada par da estruma será respousarel por mu interalo de chaves. compre- 
endido desde o identificador do predecessor, sem contar com ele, até o seu identificador. Por exemplo, na Figura 4.2(a) o par com identificador 25 será responsável pelas chaves 9 (o primeiro número após o seu predecessor) até o 25 .

A transformação de uma chave em um número, que servirá para conhecer que par será responsável por essa chave, é feita de maneira análoga ao ingresso dos pares. A chave a ser armazenada é aplicada uma função de haısh. a qual devolverá o número que será armazenado em algum par da estrutura responsável pela chave. Por exemplo, na estrutura como da Figura 4.2(a), uma chave com ralor 32 será armazenada no par com identificador 4.5 .

To caso de colisões das chaves. é a implementação da tabela de hash distribuída a responsável por administrar esse problema. Geralmente, as implementações inserem informações adicionais que permitem que a chave a inserir seja única com uma alta probabilidade. Logo, estruturas internas da tabela de hash distribuída possuem referèncias a essas colisōes. Por exemplo. se tivermos uma chave $X$ a ser inserida duas vezes, a implementação insere na tabela $X, X 1$ e $X 2$ ( $X 1$ e $X 2$ são as chaves criadas a partir de $X$, que contém informações adicionais). Finalmente, o par responsável por $X$ terá também referências às chaves $X 1$ e $X 2$.

\subsection{Implementações}

Como mencionamos no começo do capítulo, a estrutura em anel é duplamente encadeada, ou seja, cada par tem ponteiros para seu predecessor e para seu sucessor. Lma busca por uma chave nesse tipo de estrutura, portanto. requer tempo de ordem linear (a busca passará por cada par seguindo o sucessor até localizar o par responsável pela chave). Para que a eficiencia de uma busca nas tabelas de hash distribuídas seja de ordem logarítmica, precisamos de uma estrutura adicional, chamada de tabela de roteamento, que permite conhecer pares que estão mais a frente que o sucessor imediato. Mostraremos a seguir duas implementaçoes da tabela de hash distribuída: a primeira baseia sua tabela de roteamento em uma lista com ponteiros que seguem uma fórmula matemática e a segunda em uma estrutura de árore de prefixos.

\subsubsection{Chord}

Chord [Cho] é uma implementação na linguagem C - de uma rabela de hash distribuida feira nos laboratónos do .IIT. O protocolo especifica como localizar 
as chaves entre os pares da rede. como novos pares se unem à rede e. finalmente. como os pares saem da rede.

Tabela de Roteamento Suponhamos que temos. em um dado momento, a seguinte estrutura de anel mostrada na Figura 4.3. Cada par com identificador $p$ tem $u$ tabela de roteamento local que aponta para pares que estão mais na frente que ele no anel e que ajuda na localização eficiente dos recursos. Esta tabela de roteamento. que é chamada de fingers pelo Chord, é definida da seguinte maneira (Ter Tabela t.1):

- Há no máximo $\log n$ ponteiros registrados ( $n$ é a quantidade de pares na estrutura) evitando com isso um excesso de informação. Se tivéssemos todos os pares registrados tornaríamos o protocolo pouco escalável.

- Cada entrada $i$ da tabela de roteamento de p contém o identificador do primeiro par no anel cujo valor seja maior ou igual a $p+2^{i}$ e menor que o identificador do último par da tabela de hash distribuída. Por exemplo. na Figura 4.3. a entrada $i=3$ tem como identificador o par tj que é o primeiro par encontrado cujo valor é maior que $33\left(p+2^{i}=25+8=33\right)$.

\begin{tabular}{|c|l|}
\hline Entrada & Definição \\
\hline 0 & ponteiro ao successor de $p$ \\
\hline$i$ & ponteiro ao primeiro par $s$ no \\
& anel tal que \\
& $p+2^{i} \leq s$. \\
& $1 \leq i \leq \log _{2}($ id do último par \\
& $-p)$ \\
\hline
\end{tabular}

Tabela 4.1: Definição da tabela de roteamento de um par $p$.

Busca por um recurso. A busca por um recurso dada uma chave é feita da seguinte maneira. Quando um par envia uma mensagem em busca de uma chave. é aplicada a ela uma funçào de hash que devolve um valor $x$. $h(c h a r e)=r$. A seguir. a tabela de roteamento fornece o identificador $p<r$

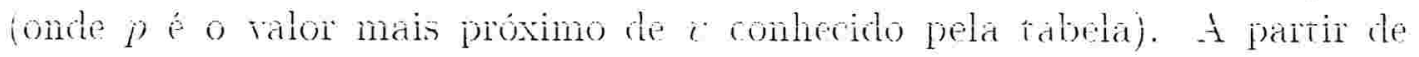
p. o processo se repete de maneira recursiva. passando essa mensagem até se encontrar o valor 2 . Este processo é completado com O(log n) troca de mensagens. 


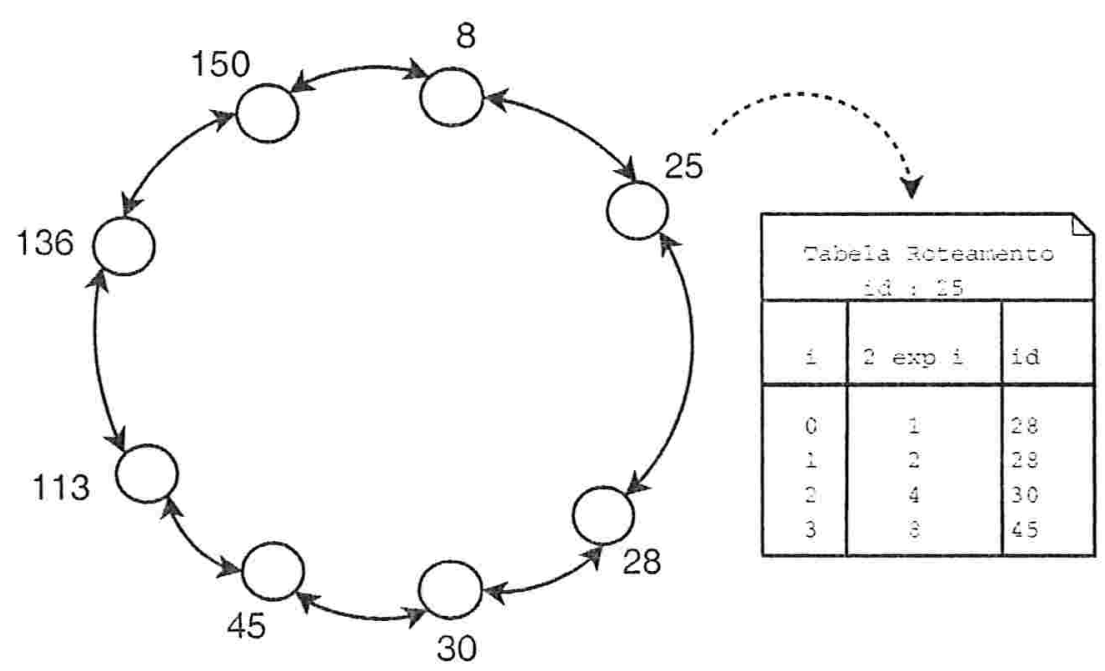

Figura 4.3: Exemplo da tabela de roteamento do par número 25.

Para dar um exemplo consideremos a seguinte situação: suponha que um par identificado com o número 25 precisa procurar a chave cuja função de hash derolveu o valor 122. Os passos seguintes se manifestam na Figura 4.4.

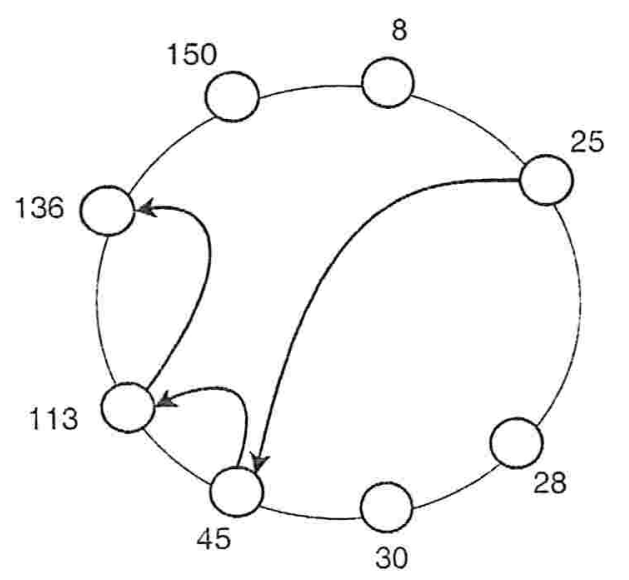

Figura 4.4: O par número 25 procura pela chave 122.

O par 2.5 verá. em sua tabela de roteamento. que existe um par com identificador mais próximo à chave procurada. neste caso o par 4.j. A busca será repassada ao par t.j que por sua vez verá em sua tabela de roteamento 
o par mais próximo à chare procurada. que é o par 113. A busca é repassada noramente com o qual se chegará ao par 136. responsável por manter as chaves do 114 ao 136.

A quantidade de troca de mensagens utilizada para executar essa busca $O(\log n)$. pois as entradas das tabelas de roteamento eritam que uma mensagem passe por todos os pares da estrutura $\left[\mathrm{CJK}^{-}\right.$-01|.

Ingresso de um par na tabela de hash Em um ambiente dinàmico como as redes Par-a-Par: o ingresso de um par na estrutura pode acontecer a qualquer momento. Para manter as propriedades da tabela de hosh distribuida. faz-se necessário levar em conta as seguintes considerações:

- Alocação do noro par.

Primeiro dere-se encontrar o lugar exato onde incluir o novo par. Para isso, faz-se uma busca (perguntando a qualquer par da tabela de hash distribuída) pelo identificador do novo par. O ponto final do caminho traçado por essa busca permitirá saber qual é o par mais próximo da posiça onde teremos que inserir o novo par (Na Figura 4.2(a). o par com identificador 28 é o mais próximo do novo par). A quantidarle de troca de mensagens necessária para executar a alocaçăo é $O(\log n)$. que seria a busca da posição mais a inserção do par, que leva tempo constante.

- Atualizar os registros dos outros pares já existentes na tabela de hash distribuída.

A primeira atualização é feita sobre o par sucessor s e o par predecessor $p$ do novo par ingressado. que chamaremos de $n$. $n$ contata o sen sucessor $s$ indicando que atualize seu ponteiro predecessor (que agora apontará para $n$ ). O mesmo processo é feito para o predecessor de $p$, o ponteiro sucessor de $p$ agora apontará para $n$.

A segunda atualização corresponde às entradas das tabelas de roteamento dos outros pares para que estes tenham conhecimento do noro par que ingresson. Para cada entrada é feita uma procura pelo valor. segundo a formula da Tabela t.1. sem considerar o valor que a tabela de roteamento contém. La Figura t.j. podmos observar que a cntrada $i=1$ depois de executar este processo vai apontar para o par 27 e nào para o que rem atualmente (identificador 28). Lembremos que segundo as regras da tabela: $n-2^{i}=25+2^{i}=27$ 


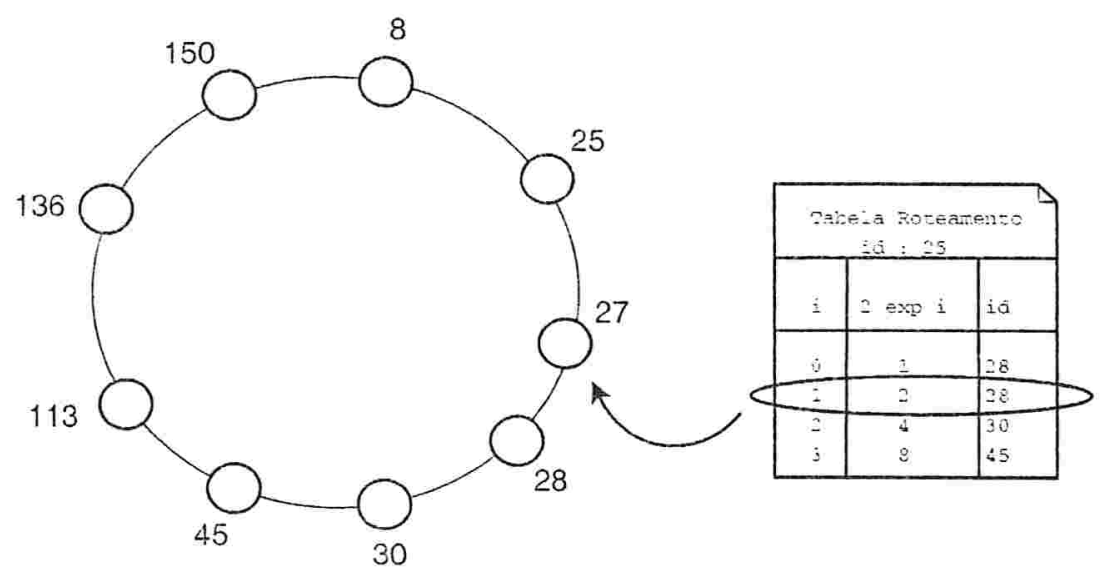

Figura 4.5: Atualização da tabela de roteamento identificando o par 27.

As duas atualizações apresentadas são executadas com uma troca de mensagens de ordem logarítmica [SMK $\left.\mathrm{K}^{+} 03\right]$.

- Transferència das chaves ao novo par

Esta última operação move as chaves (identificadas como $k$ ) que agora serão de responsabilidade do novo par ingressado. Somente se precisa extrair do sucessor imediato do novo par as chaves do intervalo entre o identificador do novo par até a do identificador do sucessor. Este processo é mostrado na Figura 4.6 na qual podemos observar que as chaves $27 \mathrm{e}$ 26 são transferidas para o par 27 .

Saida de um par da tabela de hash Da mesma forma que para o ingresso de um par na estrutura, para a saída de um par, que pode ser planejada ou não, devemos considerar os seguintes aspectos:

- Atualizar os registros dos outros pares já existentes na tabela de hash distribuída.

É necessário atualizar a tabela de roteamento dos outros pares para que estes tenham conhecimento do par que saiu da estrutura. Para isso é itilizado o niesmo processo de dtializaça quando tim par ingressa na rede. Primeiro se irá procurar o identificador do par para cada entrada da tabela de roteamento. Essa atualizaça é executada com uma troca de mensagens de orden logarimica [S:IK-1):3]. 


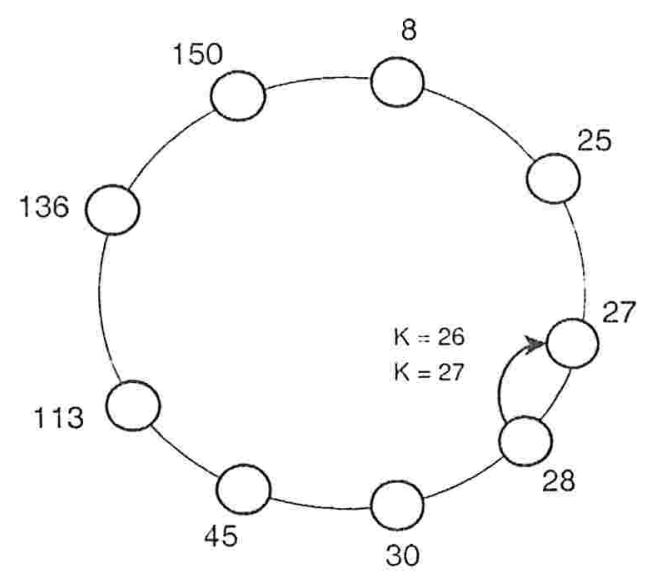

Figura 4.6: Transferencia das chaves do par 28 para o par 27 .

- Transferência das chaves ao sucessor do par que saiu.

Esta última operação move as chaves do par que saiu da estrutura para o sucessor imediato dele, já que agora serão de responsabilidade do sucessor.

\subsubsection{Bamboo}

Bamboo é uma implementação da tabela de hash distribuída na linguagem Java desenvolvida na Universidade da California em Berkeley. A equipe do Bamboo direcionou os esforços de desenvolvimento no melhoramento do desempenho e estabilidade da rede quando os pares entram e saem dela com uma alta probabilidade [RGRK04]. O protocolo descreve como achar as chares entre os pares da rede como novos pares se unem à rede e o processo de atualizaçào da estrutura.

Tabela de Roteamento A tabela de roteamento do Bamboo que, como no caso do Chord. tem ponteiros a pares que estão na frente no anel e ajudam a melhorar a eficiencia nas buscas por uma chave. utiliza uma versăo da tabela mulo parecida como utilizado pelo algoritmo Pastry |RD01| que é baseado em uma estrutura de árvore de prefixos.

Essa tabela contém os identificadores de outros pares pertencentes à tabela de hush distribuída e consiste em uma matriz con $\log n$ filas e $2^{b}$ colunas icomeçando de zero) no qual 2"'e a base numerica do identificador. geralmente 
$\operatorname{com} b=2$. Com isso, qualquer numero que esteja na base 10 (ou outra base) será transformado na base 4 .

Na Figura 4.7(a) temos a tabela de roteamento do par com identificador 10123102 (base 4) ou 19410 (base 10). Como podemos observar, cada célula fila. coluna da tabela de roteamento corresponde a um identificador de um par. Este identificador está dividido em três partes:

1. um prefixo do identificador formado pela união de todas as células sombreadas até a fila -1

2. o valor da coluna

3. um sufixo que, na união com os outros dois valores acima, corresponde a um identificador válido de um par pertencente à estrutura.

Se essa célula estiver vazia quer dizer que a tabela não conhece nenhum par com esse prefixo. Para dar um exemplo. vemos que na Figura 4.i(a) e 4.7(b): a célula da fila 4 coluna 2 têm como prefixo 1023 , como sufixo 121 e a união do prefixo-coluna-sufixo representa a o par com identificador 10232121 . Nó caso da ultima fila, podemos observar que está vazia, significando que não existem pares com o prefixo 1023310.

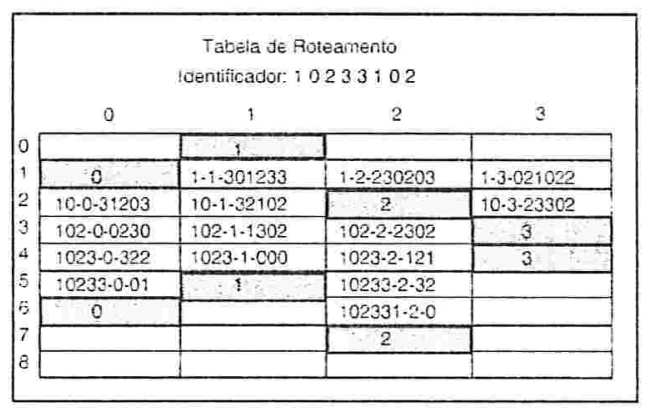

(a) Tabela de roteamento para o par conn identificador 10233102

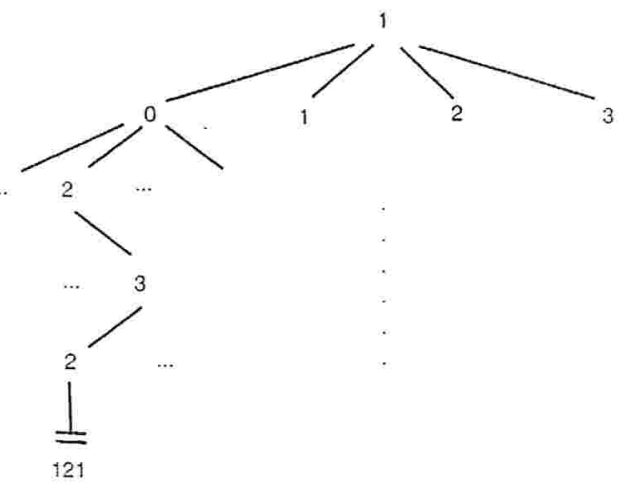

(b) Arrore de prefixos para o identificador 10232121

Figna 4.7: Exemplo de uma tabela de roteamento do pastry. 
Busca por um recurso. A busca por um recurso é feita da seguinte forma. Quando um par envia uma mensagem em busca de uma chave. será aplicada uma função de hash à chave que devolverá um valor $v$. A tabela de roteamento devolverá então o identificador do par que tenha o prefixo mais longo comparado com 2 (ramos supor que esse par tem como valor $p$ ). A partir de p. o processo se repete de maneira recursiva, passando essa mensagem até se encontrar o valor $c$. Para efetuar esta busca é necessário $O(\log n)$ troca de mensagens.

Por exemplo, vamos supor que estamos procurando pelo valor $v=$ 10232123. A tabela de roteamento da Figura $4.7(a)$ devolverá $p=10232121$ (segundo a Figura 4.7(b) o prefixo conhecido mais longo é 10232). A partir de p esse processo se repete até localizar o valor 10232123.

Ingresso de um par na tabela de hash Como acontece com Chord. faz-se necessário levar em conta algumas consideraçòes para o ingresso de um par na estrutura do Bamboo:

- Alocação do novo par.

O lugar na tabela onde será inserido segue as mesmas regras que no Chord. ou seja. faz-se uma busca pelo identificador do novo par até localizar o valor do sucessor mais próximo a esse identificador. Essa será a posição correta na tabela de hash distribuida onde será inserido o noto par. A diferença com Chord está em que, neste processo, ao novo par é dado uma tabela de roteamento inicial, com valores muito parecidos com a tabela de roteamento do seu sucessor.

- Atualizar os registros dos outros pares já existentes na tabela de Hash distribuídla.

A atualização é dada da seguinte forma. Primeiro se escolhe de forma aleatória uma célula ( fila. coluna) da tabela de roteamento de um par. Essa célula tèm associado um ralor $c$ (dado pelo prefixo da célula mais o valor da coluna) o qual será procurado na tabela de hash distribuída da seguinte maneira: a mensagem de busca. por esse valor $u$ e e repassada ao primeiro identificador do par desta tabela de roteamento que pertença à mesma fila da célula e columa $=i$ com $($ coluria $>i \geq 0)$.

Para dar $u$ exemplo. vamos supor que de foma aleatória escolhemos atualizar a célula (5.3) da tabela de roteamento da Figura t.7(a). Segundo anteriormente mencionado. o ralor 2 procurado será um par que 
tenha prefixo 102333 (prefixo 10233 mais a coluna $=3$ ). Agora, para encontrar um par ao qual repassar a mensagem de busca teremos que ir diminuindo o valor da coluna. A célula $(5,2)$ contém o par 10233232. To caso dessa célula estar vazia a mensagem será repassada ao par 10233001. ou seja, para a célula $(5,0)$.

Saída de um par da tabela de hash Quando um par sai da estrutura faz-se necessário atualizar as tabelas de roteamento dos outros pares já existentes na tabela de hash distribuida. Para isso, utiliza-se o mesmo processo de atualização de registros, ou seja. escolhe-se uma célula que tem associado um valor e procura-se pelo valor como definido anteriormente na atualização quando ingressa um novo par. 


\section{Capítulo 5}

\section{Protocolo de Interligação}

Esta seção apresenta o protocolo que permitirá montar uma estrutura de pares que seja eficiente na comunicação. Chamaremos este protocolo de Protocolo de Interligaçào. Esse protocolo. baseado no modelo atomico (vide Seção 3.1.1). risa interligar os pares mais próximos entre si em termos de latència. Antes de descrever os detalhes do protocolo, vejamos quais são os principais motivos pelo qual se faz necessário criá-lo.

Primeiro. existe uma necessidade no InteGrade de interligar os GRMIs dos diferentes aglomerados. Com isso. no caso em que uma tarefa não possa ser realizada localmente. teremos a possibilidade de requisitar a execução desta tarefa a outros GRMs.

Segundo. nos protocolos Par-a-Par existentes, como no caso de Gnutella [gnub] ou do Gisp [Kat02] do JXTA [jxt], a informação que um par disponibiliza (como por exemplo un arquivo de música) somente é encontrada. em alguns pares. Em nosso caso, as informações que um par compartilha (como sua quantidade de memória RAM disponível) devem estar na maioria dos pares.

Terceiro. na maioria das redes $P a r-u-P a r$ que utilizam o modelo atômico. a estrutura e formação dos pares é criada de forma aleatória em relação a seus vizinhos ${ }^{1}$. Para o nosso trabalho. o tempo de latencia entre um par e seus vizinhos é um requisito importante. que não é considerado nos protocolos desenrolvidos até agora.

Veremos agora como o nosso protocolo resolve os problemas anteriormente mencionados. É importante destacar que esse protocolo. desenvolvido para redes Par-a-Par. é uma generalizaçào da necessidade do InteGrade de interligar os GRMs. Com isso. se queremos incluir o protocolo no InteGrade

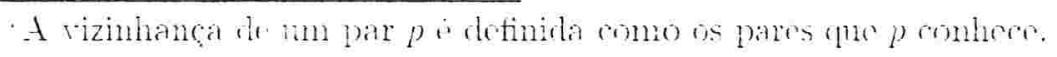


teremos que tratar cada GR.I como se fosse um par.

\subsection{Visão Geral}

Como mencionado no modelo atômico da Seção 3.1.1, as redes Par-a-Par não têm uma estrutura de conexão estabelecida, ou seja, não seguem nenhum padrão definido, como mostrado na Figura う.1. Para que um par possa melhorar o desempenho no envio e recepção das mensagens, se faz necessário que ele se conecte com o par mais próximo considerando o tempo de latência e não com outro qualquer. No caso do InteGrade, a melhora no desempenho da comunicação serviria para que um GRM possa repassar, de forma eficiente, uma tarefa que não pode ser executada localmente. A seguir veremos como resolver esse problema usando a função de roteamento da camada de rede.

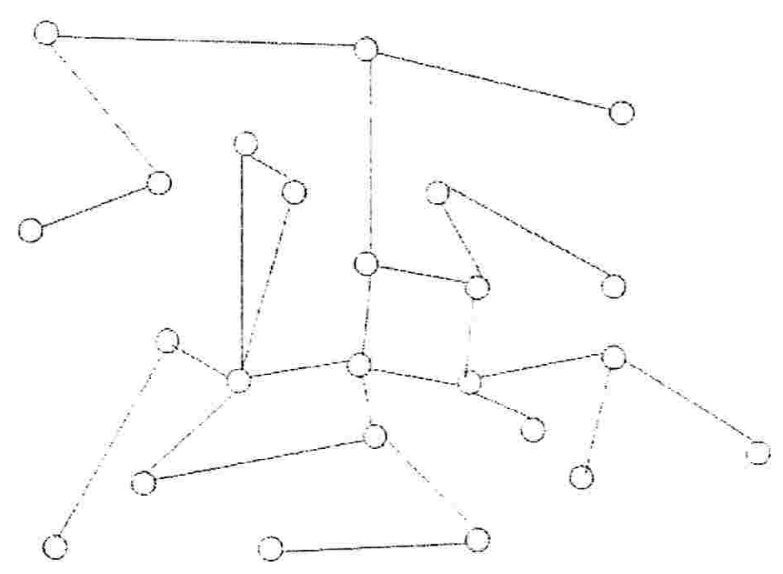

Figura 5.1: Estrutura de uma rede Par-a-Par geral.

\subsubsection{Usando e Armazenando a Informação dos Roteadores}

A camada de rede tem como função entregar pacotes de um lugar a outro arravés de uma infra-estrutura de redes interconectadas [Sta03]. Para isso. os protocolos lisados nesta camada fazem a dererminaço de caminhos 1011 
roteamento) entre destinos o que permite estabelecer a rota de preferencia para o envio de pacotes.

A compreensão da rota seguida por um pacote pode ajudar a descobrir que pares estão próximos em termos de latencia. Conforme ilustrado na Figura 5.2 . se o par $p 1$ envia uma mensagem para o par $p 2$. o pacote enviado segue uma rota $r 1$ determinada pela camada de rede. Suponhamos que em $u$ dos roteadores dessa rota exista outra rota $r 2$ para o par p3. que não é conhecido e que está mais perto de $p 1$. em termos de latència. do que $p 2$. Se pudéssemos conhecer $p 3, p 1$ poderia se comunicar com p3, assim, a commicação entre eles provavelmente seria mais rápida do que a commicação entre pl e p2.

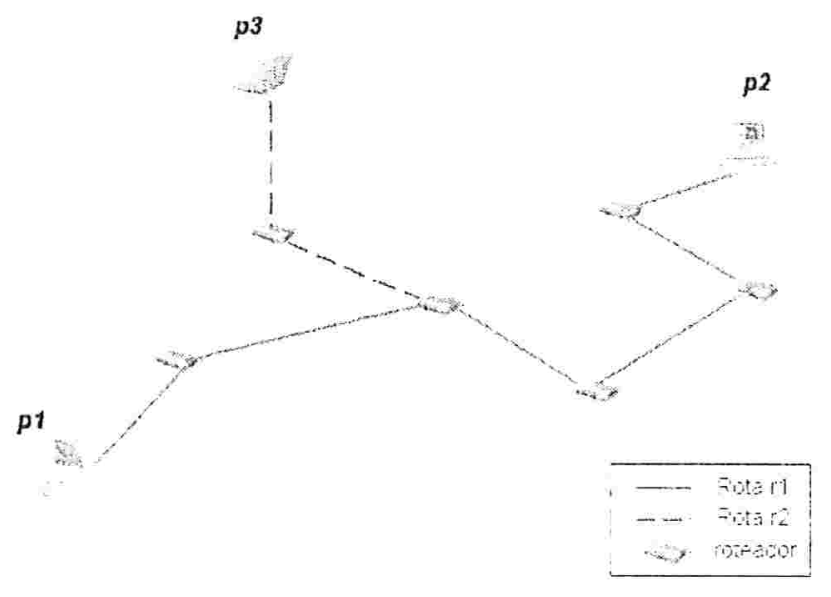

Figura 5.2: Rota da mensagem entre dois pares.

Nosso protocolo usa e armazena as informaçoes de latencia e das rotas la seguinte maneira:

- Informaços sobre cada roteador presente em una rota entre dois pares serao armazenadas na Tabela de Hash Distribuida (DHT). A DHT armazenará em uma estrutura. que chamaremos de "objeto roteador", a latencia e o identificador do par mais proxino a cle.

- Tsaremos as informaçòes armazenadas nos objetos roteadores no ingresso de um par na rede. detalhado na Seça j.2.1. 


\subsubsection{Repositório Local de Pares}

No Protocolo de Interligação, o repositório é um componente muito importante, já que com ele podemos armazenar conhecimento sobre os vizinhos de um par. Esse conhecimento corresponde a uma lista de identificadores dos pares, ordenada em ordem crescente de latência, armazenada num arquivo local ào par. Os pares, junto com sua latência, são atualizados periodicamente pelo processo de atualização do repositório (vide Seção 5.2.3). O identificador do par deve ser único e depende do implementador escolher de que tipo vai ser. Geralmente usa-se o endereço IP e a porta na qual o par recebe as requisições.

\begin{tabular}{|c|r|}
\hline PeerID & Latência(ms) \\
\hline $217.73 .145 .120: 2411$ & 10.01 \\
\hline $164.109 .41 .38: 1475$ & 10.33 \\
\hline $69.2 .200 .183: 3352$ & 12.87 \\
\hline $212.40 .5 .72: 2463$ & 12.87 \\
\hline $209.203 .253 .95: 2674$ & 12.98 \\
\hline $198.65 .117 .133: 4213$ & 13.53 \\
\hline $83.97 .42 .2: 80$ & 15.08 \\
\hline $205.217 .153 .53: 1113$ & 15.48 \\
\hline $195.95 .30 .170: 3442$ & 17.65 \\
\hline
\end{tabular}

Tabela 5.1: Exemplo de um Repositório local de Pares

\a Tabela 5.1, vemos que o repositório de um par proporciona informação sobre pares vizinhos (endereço IP : porta) e a latència entre eles. No caso do par se desconectar da rede e voltar a entrar, o repositório será muito útil na obtenção dos seus antigos vizinhos. Na implementação do repositório. deveria se usar uma quantidade de não mais que 10 vizinhos, que evita que a atualização periódica gere uma sobrecarga na rede pela quantidade de informação a atualizar.

\subsection{Descrição do Protocolo}

Para garantir a interligação usando a proximidade de laténcia. nosso protocolo dere considerar trés situaçós do par $p 1$ : a entrada na rede. a saida da rede e as atualizaçòes das referèncias dos outros pares com $p 1$. A seguir detalharemos cada una dessas situacões. 


\subsubsection{Adicionando um Par à Rede}

Segundo o detalhado na Seção 3.1.1, em um modelo arquitetonico atomico como o nosso protocolo, o par que quer ingressar na rede precisa conhecer "outros pares" quaisquer aonde se conectar. Para isso. podemos identificar duas opçòes:

- É a primeira vez que o par se conecta à rede: obteremos esses outros pares de uma fonte na Internet. como por exemplo uma página Web.

- O par já tinha ingressado antes e deseja voltar a se conectar na rede: obteremos esses outros pares do repositório local (vide Seção j.1.2) que os armazena.

Primeira vez. A solução proposta é ter o endereço de alguns pares, mais estáveis, em um local fixo. por exemplo, uma página Wéb que todos conheçam. Estes pares "estáveis" devem ter como característica o fato de a probabilidade de saírem da rede ser baixa. Outra possibilidade é a busca através de Broadcast esperando que alguém atenda à requisição. mas isto é claramente não escalável.

Uma das características da solução usando a página Web é que ela deve conter uma quantidade pequena de pares (no máximo algumas dezenas), evitando com isso uma demora no processamento da página. Outra característica é que esta página nào seja necessariamente única, ou seja, podem existir outras páginas organizadas por grupos, países. etc. que permitiria uma maior escalabilidade. Na Tabela 5.2 vemos um exemplo de uma possível página Web que armazena os endereços e portas onde os pares recebem as mensagens.

Já tinha ingressado. Neste caso, não deremos nos preocupar em procurar os pares na página Web descrita anteriormente. Agora simplesmente os obtemos do repositório de pares.

Na Figura 5.3. apresentamos o algoritmo de ingresso de um par pl na rede. É importante destacar que este algoritmo é executado no par que está ingressando na rede. Detalharemos o seu funcionamento a seguir.

1. Obtemos uma quantidade constante de possíveis identificadores de pares com os quais o noro candidato ( $p 1$ ) poderia se conectar. Esses identificadores serão obtidos do processamento da página Teb. se for a primeira rez que o noro candidato se conecta. ou do repositório local de pares. se já tinha ingressado antes (Linha 3 e j). 


\begin{tabular}{|c|r|}
\hline PeerID & Porta \\
\hline 193.154 .180 .100 & 80 \\
\hline 63.211 .182 .17 & 156 \\
\hline 66.250 .128 .130 & 80 \\
\hline 4.22 .66 .35 & 1225 \\
\hline 69.31 .132 .42 & 678 \\
\hline 209.203 .253 .95 & 2674 \\
\hline 164.109 .41 .38 & 1475 \\
\hline 195.95 .30 .170 & 3442 \\
\hline 212.40 .5 .72 & 2463 \\
\hline 217.73 .145 .120 & 2411 \\
\hline 198.65 .117 .133 & 4213 \\
\hline 83.97 .42 .2 & 80 \\
\hline 69.2 .200 .183 & 3352 \\
\hline 205.217 .153 .53 & 1113 \\
\hline 209.59 .152 .158 & 80 \\
\hline
\end{tabular}

Tabela 5.2: Lista de pares estáveis a ser armazenada em uma página Wẻb.

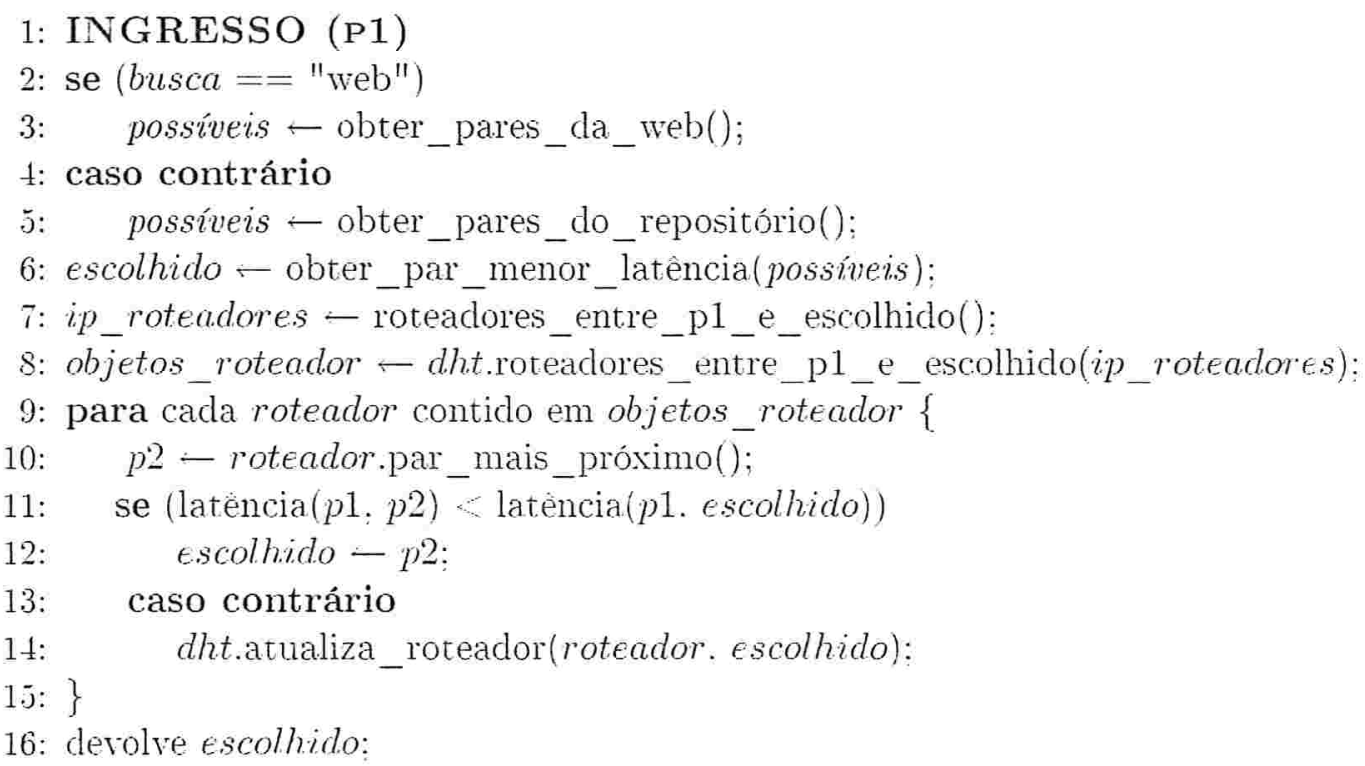

Figura 5.3: Algoritmo para o ingresso de um par na rede.

2. É escolhido o par com menor latencia entre $p 1$ e os pares obtidos acima. deixando registrado no repositorio de pares de $p l$ as latencias obtidas 
(Linha 6). O registro dos pares no repositório segue certas regras que foram descritas na Seçào J.1.2.

É importante destacar que existem diversas formas de obter a latencia. Em nosso caso. o protocolo utiliza o IC.MP (Internet Control Message Protocol) [Pos81] através de seu comando Ping, que obtém. do teste de conexão. o tempo necessário para que uma mensagem atinja o seu destino e retorne à origem.

3. Com o mais próximo dos pares encontrados (o escolhido) usamos os recursos físicos de rede que permitirão encontrar o melhor caminho entre pl (o par que esta se unindo à rede) e o escolfhido. Para isto, temos que obter os endereços IP de todos os roteadores do caminho entre o p1 e o escolhido (Linha 7). Para a obtenção desses roteadores; podemos usar por exemplo, o comando traceroute do Lnix. com o qual obteremos também a latência de $p 1$ a cada roteador encontrado por este.

4. Para todos os endereços IP dos roteadores encontrados acima, consultamos na Tabela de Hash Distribuída se existe alguma informação sobre esses roteadores (Linha 8). O tipo de informação armazenado nos objetos_roteador foi explicado na Seção 5.1.1.

5. Obtido o par p2 armazenado no objeto roteador (Linha 10), verifica-se se a latência entre $p 1$ e $p 2$ - obtida da fómula: latência ( $p 1$, roteador) - latência (roteador: $p 2$ ) - é menor que a latência entre pl e o escolhido (Linha 11). Caso seja menor; 12 será o novo escolhido por estar mais perto de p1 (Linha 12). Caso contrário, o escolhido está mais perto de p1 e, portanto, devemos atualizar o par armazenado no roteador (Linha $14)$.

6. Finalmente. o algoritmo devolve o escolhido com o qual pl se conectará (Linha 16).

\subsubsection{Saída de um Par da Rede}

Veste processo. o par se desconecta da rede. A desconexão pode ser prorocada por dirersos motiros entre eles:

- Saída roluntária

- Saida por problemas récnions 
De acordo com Anderson et al. [ASSW03], deremos estar cientes de que a queda de um par é possível e provável. Então, quando um par sai da rede, o protocolo deve: (1) atualizar as referências que os pares conectados a ele timham quando saiu e (2) atualizar os objetos roteadores que tinham armazenado informações sobre o par sendo desconectado. É importante destacar que essas atualizações são feitas periodicamente e não necessariamente no momento em que $1 \mathrm{~m}$ par sai da rede. Por ser um processo que ocorre de forma independente. as atualizações serão mostradas na próxima seção.

\subsubsection{Processo de Atualização}

Nosso protocolo realiza o processo de atualização de referèncias periodicamente e independente de um par entrar ou sair da rede. Existem três tipos de atualizações que serão mostradas a seguir. As duas primeiras são as atualizações de referências que dizem respeito à estrutura lógica das conexões entre os pares e a última corresponde à atualização do repositório que diz respeito à forma de obter novos pares.

Atualização de Referências. A atualização de referências pode ser feita quando um par (o escolhido) entra ou sai da rede. De qualquer forma, caso um par $p$ tenha como referència o escolhido, $p$ é responsável por verificar, periodicamente, se o canal de comunicação entre eles está funcionando. Caso não exista uma comunicação, $p$ terá que se conectar com o primeiro par do seu repositório de pares. Se não existir nenhuma referència no repositório, então ele terá que se conectar novamente usando o algoritmo para conectar-se à rede. explicado na Seção 5.2.1.

Atualização de Objetos Roteadores. A atualização dos objetos roteadores ocorre quando um par sai da rede. Aqui é necessário remover a referència contida no objeto roteador. Para isso, cada objeto roteador verificará se o par que mantém armazenado está funcionando (com o mesmo teste de conexão mostrado no item 2 da explicação do algoritmo de ingresso). Caso não exista comunicação. o par e o objeto roteador serão removidos da Tabela de Hash Distribuida.

Atualização do Repositório de Pares Essa atualizaçào consiste em atualizar as referencias aos pares do repositório que nào estejam disponíveis e em obter nowos pares. To prineiro caso o protocolo rerá que verificar. com un teste 
de conexão. se os pares do repositório estão funcionando ou não. Caso o par esteja funcionando, é atualizada sua latência e caso não esteja funcionando. é eliminado do repositório. Para a verificação de conexão. tem-se que enviar e receber mensagens de todos os pares do repositório. o que pode resultar em uma saturação da largura de banda para aplicaçóes con centenas de milhares de pares.

To segundo caso, ou seja, na obtenção de novos pares, pergunta-se a algum dos vizinhos tomado de forma aleatória se ele conhece outros pares (que nào existam no repositório) que cumpram com o requisito de estar entre as primeiras $T$ posições do repositório em termos de latência ( $\mathrm{T}$ é um valor determinado pelo usuário do protocolo). Como vimos na Seção j.1.2 o repositório é uma lista ordenada de pares pela latência. No caso de não encontrar nenhum par que esteja entre as primeiras $T$ posiçòes, propagaremos o pedido de novos pares aos vizinhos. Essa propagação terá uma profundidade determinada pelo valor de uma rariárel TTL (Time to Live) que diminuíra a cada propagação. Ia figura 5.4. podemos observar o caso no qual TTL $=3$. Os números dentro dos quadrados representam o valor do TTL que vai diminuindo em cada nivel de propagação.

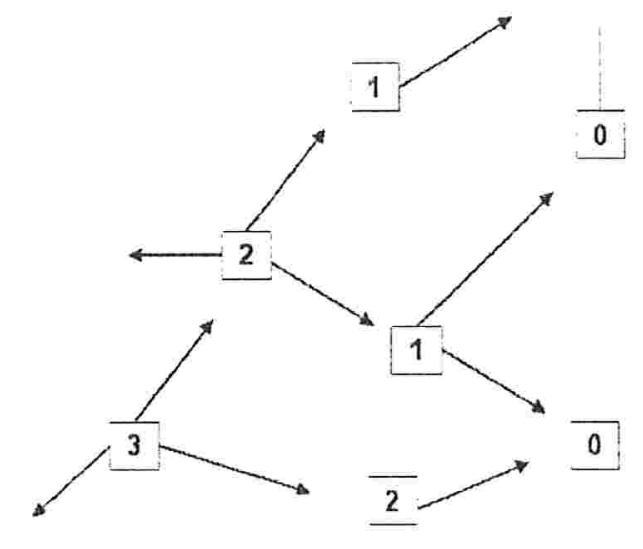

Figura j.4: Propagacão de uma mensagem pelos pares com o TTL $=3$.

L'm detalhe importante é como evitar a geraça de ciclos entre os pares. ou seja. como evitar que a pergunta seja refeita para um mesmo par. Lma 
alternativa é enviar na mensagem uma lista dos pares que já foram visitados. A outra é deixar que ciclos aconteçam e o par que fez a requisição descarte os que são iguais. 


\section{Capítulo 6}

\section{Protocolo de Localização}

Esta seção apresenta o protocolo que servirá para localizar as informações disponibilizadas pelos pares. No caso específico do InteGrade. existe a necessidade de localizar nós de diferentes aglomerados que atendam aos requisitos para a execução de uma tarefa. Por exemplo, como mencionado na Seção 1.1. encontrar $6+$ máquinas que tenham um mínimo de 256 \. IB de R.A. disponível para executar uma aplicação de multiplicação de matrizes.

Para resolver esse tipo de buscas, foi criado o Protocolo de Localização. que permite a busca de informaçòes de forma a obter a maior quantidade de pares que satisfaçam um certo requisito baseado nas informações publicadas.

\subsection{Tipos de Recursos}

Antes de detalhar o protocolo, vejamos quais são os tipos de recursos publicados por um par que poderão ser localizados pelo protocolo:

\section{- Recursos estáticos}

São recursos onde os atributos tendem a năo mudar com o tempo, por exemplo. um documento PDF. um programa de multiplicação de matrizes. um arquiro de configuração do protocolo, etc.

\section{- Recursos dinâmicos}

São recursos onde algum dos seus atributos mudam de valor freqüentemente por exemplo. a memória R.A.I disponivel. percentual live do processador ou o espaço live em disco rígido de um computador.

Io primeiro caso. a busca pelos recursos é resolvida usando diretamente a Tabela de Hash Distribuída. on seja. porle-se deixar. em pares distribuidos. 
referências para os recursos a compartilhar. Para isso, pode se criar uma chave com os dados relerantes do recurso, como o nome do arquivo, e armazená-la na tabela. O segundo caso é mais complicado. Como a informação pode mudar sem um padrão definido, temos que ter alguma forma de poder acessá-la. Mostraremos a seguir quatro diferentes propostas de solução.

\subsection{Alternativas de Localização}

Existem diferentes alternativas para localizar os recursos disponibilizados pelos integrantes de uma rede Par-a-Par.

1. Uma primeira alternativa seria deixar um par como administrador central que controlasse a informação dinamica de todos os pares, ou seja, que recebesse uma requisição e devolvesse uma resposta. Isso é impraticável em uma rede muito grande pois não é escalável, devido à sobrecarga do par que mantém a informação.

2. A segunda alternativa seria perguntar à rizinhança do par se eles conhecem o recurso. Como mostrado na Seção j, com a estrutura formada pelos pares, asseguramos que a troca de mensagens será feita entre pares com uma latência mínima, o que permite um bom desempenho. Neste caso. seria preciso levar em conta as seguintes considerações:

- A vizinhança do par pode ser obtida através do repositório de pares, ou perguntando diretamente ao par conhecido mais próximo. A partir deste vizinho a mensagem de busca pode ser propagada.

- No caso da propagaçào da mensagem, temos que evitar os ciclos gerados quando se pergunta novamente a um par e a propagação sem controle consumindo a largura de banda de forma desnecessária.

O problema de perguntar à vizinhança é que não podemos ter certeza se o recurso existe. A propagação tem que ter limites para evitar congestionamento da rede pelas mensagens trocadas e para o bom desempenho (não podemos esperar que a busca seja repassada a todos os pares). Com isso. se o recurso existe além do nivel da propagação. pode nào ser encontrado.

3. A terceira alternativa. estudada por diferentes grupos de pesquisa [Lui0t] [Jun0t]. seria a de se manter una árore distribuida onde cada no da árvore representaria um interralo de valores (como una árore B [Kini-3]) 
de disponibilidade de recursos. o que permitiria uma busca eficiente dos recursos. Cada intervalo seria uma chave armazenada na tabela de Hash distribuída. A deficiencia dessa estrutura ocorre quando todos os valores pertencem somente a um intervalo. nesse caso teremos uma sobrecarga no par responsárel por ele gerando uma arquitetura cliente servidor. Desse modo o desempenho cai drasticamente. tornando o protocolo pouco escalável.

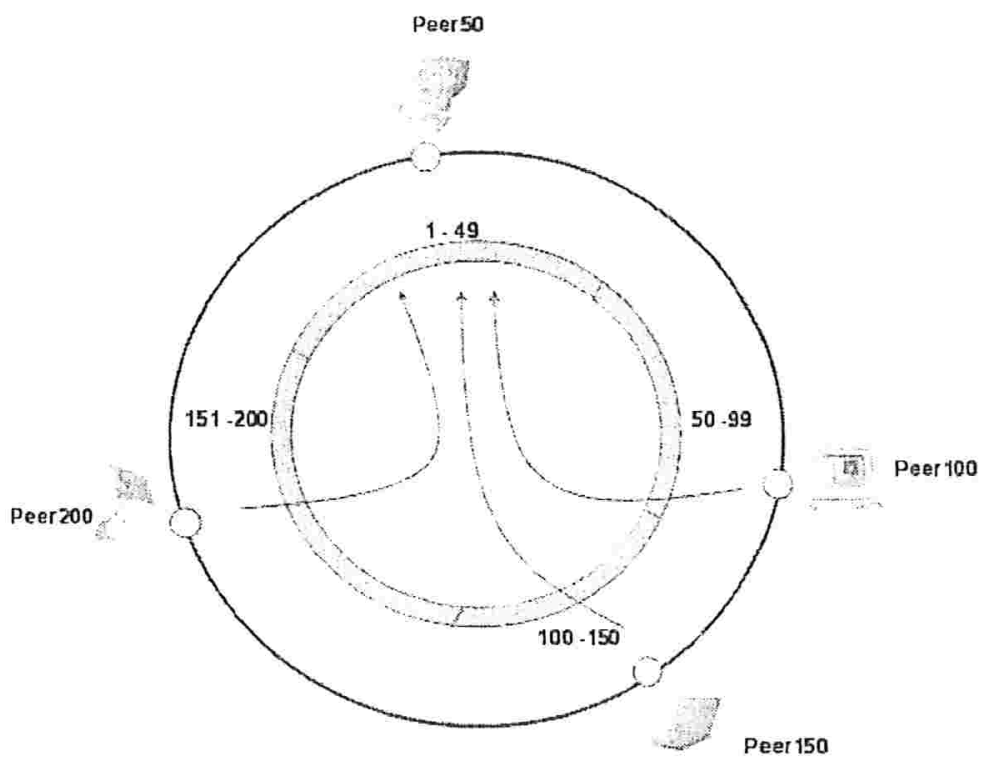

Figura 6.1: Todos os pares atualizam num só par gerando uma arquitetura ClienteServidor.

Essa solução está ilustrada na Figura 6.1. onde podemos observar que o par com identificador jo é o responsável pelo intervalo de ralores de memória R.A. disponível entre 1 e 49 \. To caso de todos os pares estarem dentro desse interralo. teríamos problemas de desempenho na resposta à requisiçōes derido à sobrecarga em um único nó.

Além disso. existe $1 \mathrm{~m}$ problema relacionado à vizinhança dos pares. A resposta que teriamos de uma busca nesse interralo seriam pares que năo necessariamente cstariam perto do cliente cue foz a pergunta. Com isso. 
a troca de mensagens poderia ter um custo maior.

4. A quarta alternativa propõe criar uma estrutura baseada em uma lista distribuída ordenada para o armazenamento das informações dinàmicas e que poderá ser usada na busca eficiente de recursos [RR.0j]. Esta alternativa, que utiliza também a tabela de Hash distribuída, pode diminuir a quantidade de objetos armazenados, em comparação com a solução da árvore, e portanto diminuir também a quantidade de mensagens trocadas para manter esse tipo de estrutura. Esta estrutura será detalhada na próxima seção.

\subsection{Lista Distribuída}

Como mencionado anteriormente, a última alternativa utiliza a tabela de hash distribuída para o armazenamento dos recursos a serem localizados. Entretanto, um dos problemas das tabelas de hash distribuídas é que elas não foram desenvolvidas para permitir buscas por intervalo de identificadores, onde um intervalo é definido pelos valores que estão entre um limite superior e um inferior. Para resolver este problema, propomos um novo mecanismo que é simples, eficiente e escalável. Esse mecanismo é baseado em uma lista distribuída ordenada pelos valores dos identificadores, que denominamos Lista para Busca por Intervalos (LBI).

\subsubsection{O Problema das Buscas nas tabelas de hash distribuidas}

Nas tabelas de hash distribuídas existem dois tipos de buscas possíveis: busca simples e busca por intervalo.

Uma busca simples é definida como a obtenção de um dado específico armazenado pela tabela de hash distribuída, a partir do identificador deste dado. Esta funcionalidade é encontrada explicitamente nas implementaçôes das tabelas de hash distribuídas. Existem algumas propostas, como o uso de elementos com formato (atributo,valor) [BBK02] ou a decomposiçào do identificador $\left[\mathrm{HHB}^{-0}\right.$-3]. que manipulam os identificadores de forma a melhorar a eficiencia das buscas. L'm exemplo onde este tipo de busca é aplicado são as Grades computacionais como o InteGrade [Int. GiGG-04]. onde $1 \mathrm{~m}$ usuário pode estar interessado em localizar computadores com certos recursos disponíreis. como mostrado na Figura 6.2. 
Obter máquinas onde:

$$
\begin{aligned}
& \text { os Aame }=\text { Linux dit } \\
& \text { processor. Mhz }=500 \text { : }
\end{aligned}
$$

Figura 6.2: Exemplo de uma busca simples com uma combinação de elementos atributo-valor.

Uma busca por intervalo consiste em encontrar o conjunto de todos os dados que estão contidos em um determinado intervalo de identificadores. Por exemplo. suponha que $11 \mathrm{~m}$ usuário deseja obter uma lista de computadores que possuam uma quantidade mínima de memória R.A.M. Este tipo de busca não é oferecida diretamente pelas tabelas de hash distribuidas e é representada como uma desigualdade no elemento (atributo-valor). mostrado em negrito na Figura 6.3.

$$
\begin{aligned}
& \text { Obter máquinas onde: } \\
& \text { os `ame = Linux \&idt } \\
& \text { availableRAM } \geq \mathbf{5 1 2} \text {; }
\end{aligned}
$$

Figura 6.3: Exemplo de buscas por intervalo de valores.

Para resolver em parte esse problema, Gao [GS04] apresentou duas propostas. A primeira consiste em registrar na tabela de hash distribuída um identificador para cada valor contido no intervalo. Por exemplo, se o identificador é "RA.W" e o intervalo está entre $r_{\text {inicio }}$ e $r_{\text {fim }}$, a quantidade de identificadores será $d=$ fim - inicio representado por R.AM-rinicio, R.A.M$r_{\text {micio-1 }}$.... R.A.M-r $r_{\text {fim. }}$. A segunda proposta se resume em aplicar uma função de espalhamento diretamente no identificador, ou seja. somente existirá "R.A." como identificador.

Na próxima seção, apresentamos nossa proposta para o problema de buscas por intervalo nas tabelas de hash distribuídas. que se baseia na combinaçào das duas abordagens acima mencionadas.

\subsubsection{Estrutura Simplificada}

A estrutura. que denominamos Lista para Busca por Interralo (LBI). é uma lista distribuída ordenada por um ralor e que permite buscas simples e por interralo. As buscas e inserçòes de itens. dado $\mathrm{um}$ identificador. utilizam 
$O(\log n)$ trocas de mensagens, onde $n$ corresponde à quantidade de itens armazenados na LBI. Esses itens são indexados por um valor e inseridos na posição correta da LBI de modo que a lista esteja sempre ordenada de forma crescente. Nos referiremos aos itens armazenados na tabela de hash distribuída como recursos.

Na Figura 6.4, mostramos a estrutura com oito recursos e identificadores não repetidos. Cada recurso armazenado tem seu respectivo identificador (definido como a união do nome do recurso e o valor) e ponteiros para seu predecessor, seu sucessor e uma tabela de ponteiros (fingers) para outros recursos, usada para acelerar as buscas.

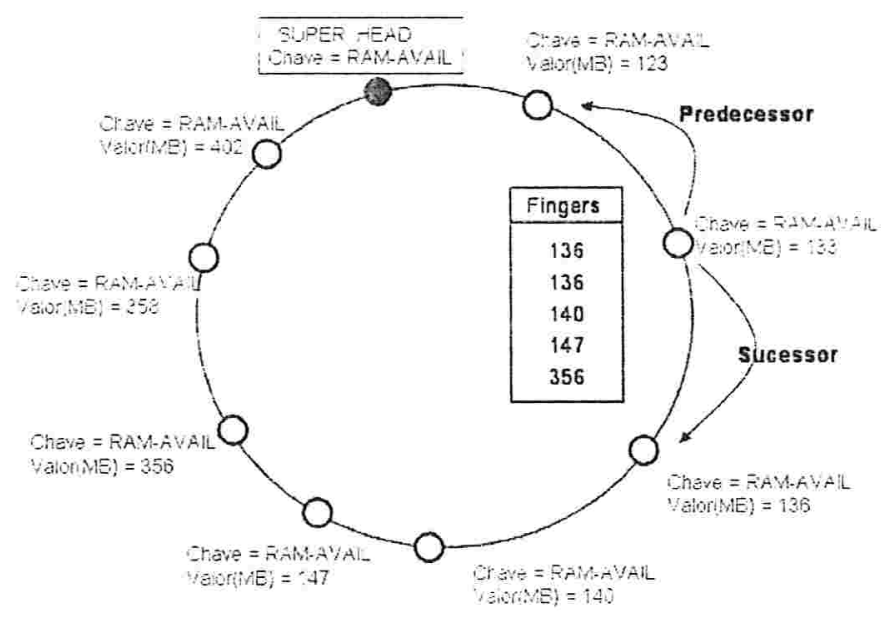

Figura 6.4: A estrutura Lista para Buscas por Intervalo sem valores repetidos.

A tabela de fingers de um recurso $r$ é um conjunto de identificadores onde cada registro $i$ dessa tabela corresponde ao recurso que sucede $r$ com um valor maior ou igual a $r+2^{i-1}$ (explicado na Seção 4.3.1). Finalmente, a LBI possui uma cabeça de lista chamada super head que mantém o nome do recurso armazenado, sel sucessor e a tabela de fingers. É usada nas buscas e inserções de recursos como reremos na Seçào 6.3.4.

\subsubsection{Estrutura Estendida}

Em sistemas reais. e bastante comum encontrar situaçoes em que a busca por um valor. dado $u$ identificador: tenha como resposta vários recursos. Por exemplo. supondo que o identificador é a pessoa e o valor è a idade deseja-se 
buscar todas as pessoas com 17 anos de idade. Até o momento da escrita desta tese. nenhum outro trabalho |A.T02. GSO4. IBOt. RHS03| parece solucionar este tipo de problema.

Como mostra a Figura 6.5. para comportar os casos onde existe repetiçào de ralores. a estrutura simplificada foi estendida de duas maneiras: (1) recursos com valores repetidos são adicionados de modo a formar uma nova lista ligada a partir da original e (2) uma outra tabela. que denominaremos (repeuted fingers). é inserida para permitir que em una busca sejam derolvidos os recursos com valores repetidos com troca de mensagens em $O(\log n)$, como mostrado na Seção 6.3.4. Sem essa tabela, o retorno de todos os valores será de ordem linear.

Na lista para valores repetidos, os recursos não estão ordenados de forma alguma e somente é criada se o valor é repetido e é apagada se ela não contém mais recursos repetidos. Finalmente, a tabela de repeated fingers para um recurso $r$ contém as entradas $i$ que representam recursos s que estão a uma distancia (quantidade de recursos entre $r$ e s na lista de valores repetidos) igual a $2^{i}$. Na Figura 6.5, vemos que o recurso com valor 133 tem em sua tabela de repeated fingers o par com ID $=\mathrm{D}$, que representa o recurso que está a uma distancia (do recurso com valor 133) igual a 4 . ou seja $2^{i} \operatorname{com} i=2$.

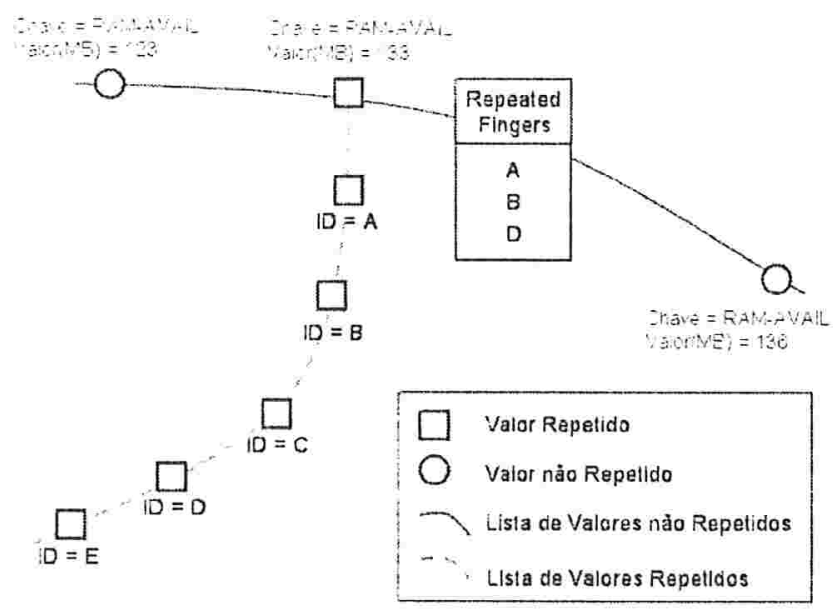

Figura 6.5: A estrutura Lista para Busca por Intervalo com ralores repetidos. 


\subsubsection{Buscas por Intervalo}

A Figura 6.6 mostra o algoritmo utilizado para buscar recursos pertencentes a um intervalo $[i, e]$. O primeiro passo antes de se chamar a função SEARCH é obter a cabeça da lista de identificadores chamada super_head. Em posse deste recurso, chama-se a função SEARCH(i, e, super_head) que devolverá os recursos contidos no intervalo [i,e]. A busca por intervalo requer $O(\log n)+$ $m$ troca de mensagens. onde $m$ é o número de recursos devolvidos. Esta quantidade de troca de mensagens é devida a iteração da linha 4. que envia a mensagem de busca para cada recurso da tabela de fingers. Esses recursos, por sua vez, repetem o processo de envio da mensagem, o que produz que a busca passe por todos os recursos do intervalo. Como conseqüência, a busca é assintoticamente linear ao número de recursos devolvidos.

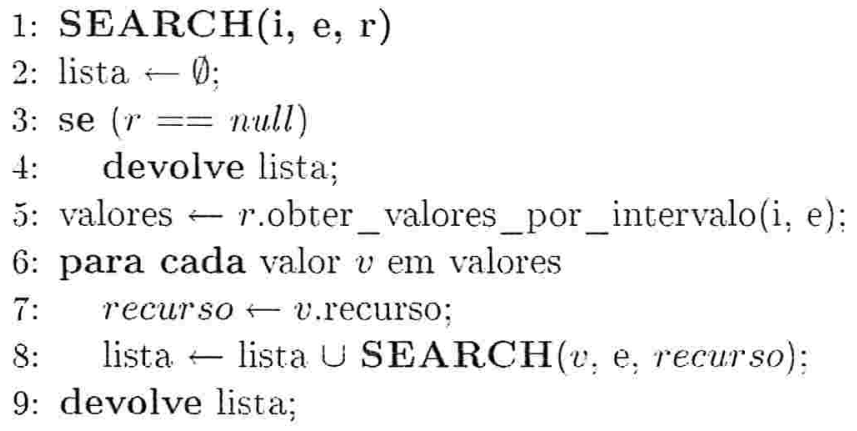

Figura 6.6: Algoritmo usado para buscar os valores contidos em um intervalo.

O algoritmo começa verificando se o recurso $r$ é null (Linha 3), significando isto que $r$ é o final da LBI. Se for null, não é necessário continuar o algoritmo e derolve-se uma lista vazia (Linha 4 ). Depois de obter do recurso $r$ os valores contidos no intervalo $[i, e]$ (Linha 5 ), ocorre uma iteração sobre esses valores para obter noros valores (Linhas 6-8). Finalmente, o método SEARCH devolve uma lista com todos os recursos encontrados (Linha 9). O método obter_valores_por_intervalo (Linha j) derolve todos os valores no intervalo [i.e], com seu respectivos recursos, mantidos nas tabelas fingers e repeated fingers de $r$.

\subsubsection{Inserção de um Novo Recurso}

A Figura 6.T mostra o algoritmo para inserção de um recurso $r$ : com valor $\because$. na posiça correta da LBI. lesta posiçâo. o sucessor de $r$ será o recurso com o ralor maior. mais proximo de $a$ 
O algoritmo começa verificando se o valor $\eta$ a inserir é repetido ou não (Linha 3). Se o valor nào for repetido, procura-se pelo super head do identificador e se ele náo existir é criada a lista de valores não repetidos (Linhas 4-7). Depois de procurar pelo melhor sucessor $s$ para o valor a inserir (Linha 8), é necessário fazer com que o predecessor de $s$ aponte para $r$ (Linha 10) e fazer com que o ponteiro sucessor de $r$ aponte para $s$ (Linha 11). No caso do valor estar repetido (Linha 14 ), é somente necessário obter o recurso topo com esse valor (Linha 16) e inserir $r$ no topo da lista ligada de valores repetidos (Linhas 1i-19). A quantidade de troca de mensagens necessária para inserir o novo recurso é $O(\log n)$.

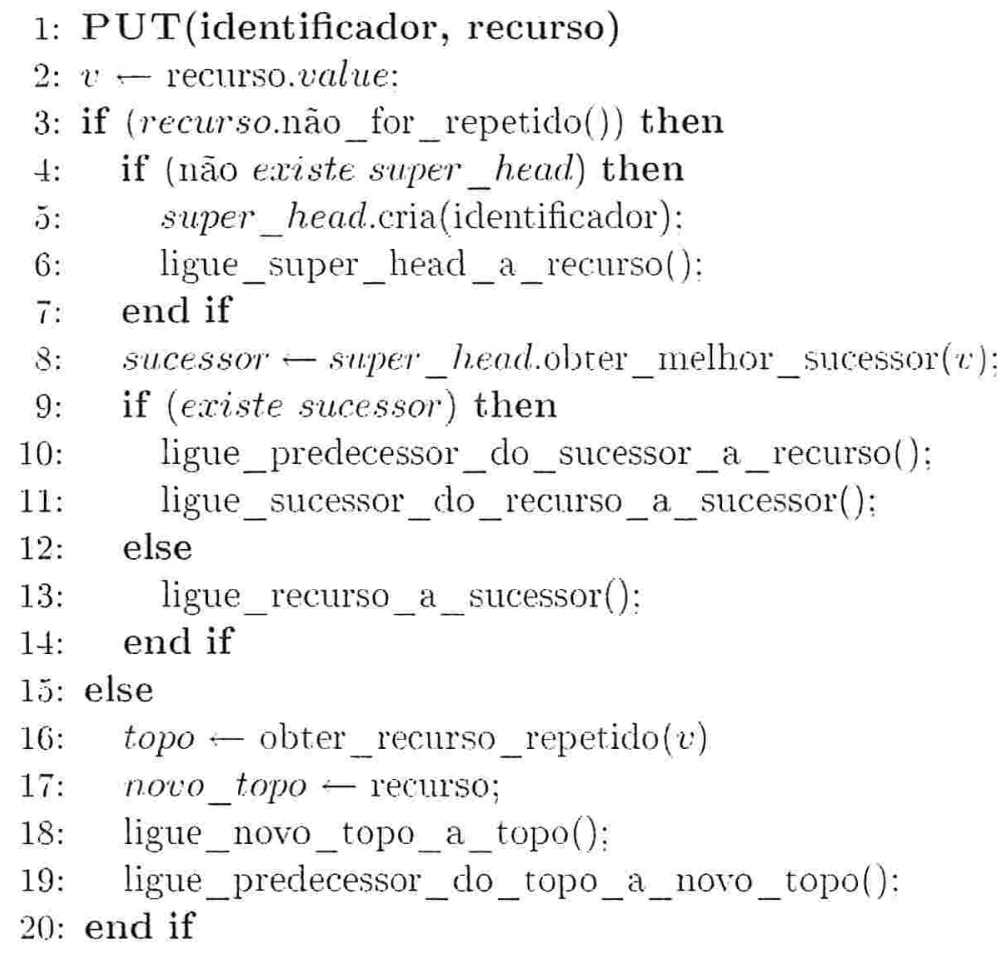

Figura 6.ĩ: Algoritmo para adicionar um novo recurso.

O método ligue_recursol_a_recurso2 faz com que o ponteiro sucessor do recurso 1 aponte para o recurso 2 e o predecessor do recurso 2 a ponte para o recurso 1. O método obter_melhor_sucessor(ralor_buscado) obtém o recurso com o ralor mais próximo do valor_buscado entre todos os recursos da estrutura LBI e é realizado em $O(\log n)$ passos [S\[K'03]. 


\subsubsection{Algoritmo de Estabilização da Estrutura}

Como rimos na seção anterior, o novo recurso, antes de ser inserido, deve procurar pela posição correta na LBI (sucessor): pois a LBI é uma lista ordenada. Quando finalizada a inserção, o predecessor desse sucessor não aponta para o novo recurso, nem o novo recurso aponta para o predecessor. Portanto, depois de executado este algoritmo, o sucessor e o predecessor de um recurso pertencente à LBI apontarão para o recurso certo (chamaremos isso de estabilização). O exemplo a seguir mostra porque um recurso precisa de uma estabilização.

A Figura 6.9(a) é o estado final atingido depois de inserir os recursos $p, s$ e $r$ (nessa ordem) com o algoritmo apresentado na Figura 6.7. Na Figura 6.9(a), podemos observar que o ponteiro predecessor do recurso $s$ está apontando para $p$ (sendo que deveria apontar para $r$ ) portanto, a estabilização se faz necessária cada vez que um recurso $r$ é inserido no meio da estrutura LBI. A estabilização da estrutura é realizada em tempo constante e é executada periodicamente sem a intervenção dos usuários.

A Figura 6.8 mostra o algoritmo para a estabilização que está baseado no trabalho de Stoica. [S.MK ${ }^{\top}$ 03]. Lma vez obtido o predecessor $p$ e o sucessor $s$ de um recurso $r$, seus ponteiros são atualizados.

Suponha que o recurso $r$ fosse adicionado à LBI como mostrado na Figura 6.9(a). Quando o método ESTABILIZA é chamado pelo recurso $r$, a execução das Linhas 6 e $T$ são mostradas nas ligações da Figura 6.9(b). Finalmente, quando o método ESTABILIZA é chamado por $p$, a execução da linha 5 é mostrada na Figura 6.9 (c) e a estrutura se estabiliza.

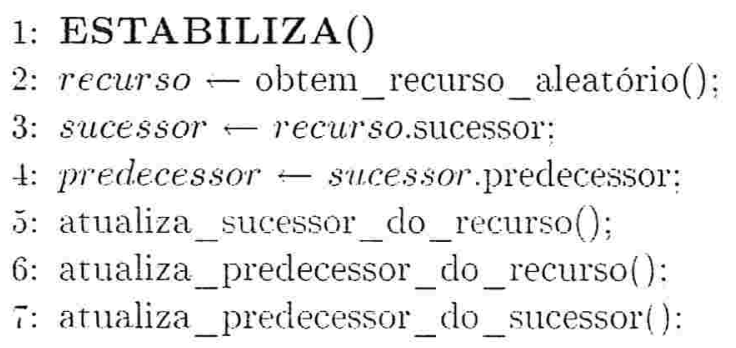

Figura 6.8: Algoritmo que atualiza o predecessor e o sucessor de um recurso.

\subsubsection{Algortimo de Estabilização da Tabela de Repeated Finger}

Esse algoritmo tom por objetivo atualizar a tabela repeated fingers de um recurso r e somente é executado quando r possui un valor repetido. Cada entrada i desta 


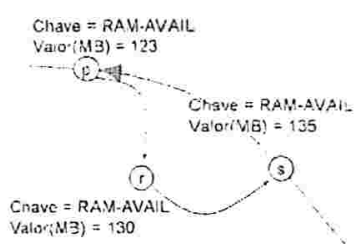

(a) O recurso $r$ foi adicionado entre $p$ es

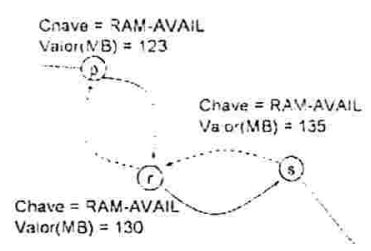

(b) Limhas 6 e $\vec{i}$ da Figura 6.8 quando o método Estabiliza é chamado por $r$

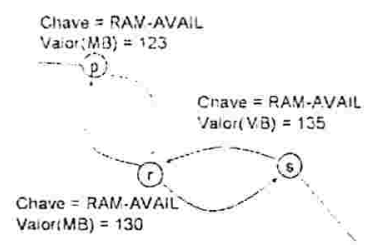

(c) Linha 5 da Figura 6.8 quando o metodo Estabiliza é chamado por $p$

Figura 6.9: O método Estabiliza aplicado a diferentes recursos.

tabela, quando finalizado este processo, terá o recurso que está a uma distancia de $2^{i}$. de $r$, na lista de valores repetidos.

O algoritmo desse processo é mostrado na Figura 6.10. A Linha 2 se encarrega de obter um recurso $r$. Existem diferentes formas de fazer isso, mas em nossa implementação preferimos obter, de forma aleatória, qualquer recurso pertencente à LBI e que está armazenado no par que está executando o processo. Se $r$ é um valor repetido (Linha 3) deremos obter o sucessor que está a uma distancia distancia_procurada de $r$ (Linha 6) e notificar $r$ sobre o sucessor encontrado (Linha 8).

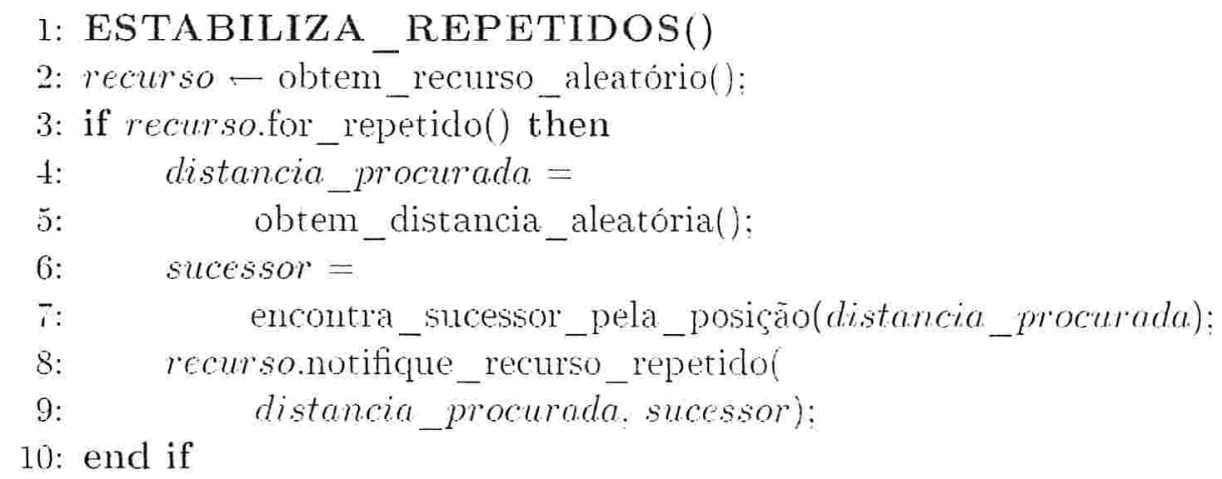

Figura 6.10: Algoritmo para estabilizar os valores repetidos.

Para entender melhor a notaçào do codigo: O método obtem_distancia_aleatoria obrem um ralor alearório porencia de 2. O netodo encontra_sucessor_pela_posino Limha $i$ derolve o identificador do recurso $p$ que esta associado a entrada $i$ da ra- 
bela de repeuted fingers: onde $i=\log$ (distancia_procurada $)-1$. A partir de $p$ : a distancia_procurada diminui em $2^{i}$ e o processo se repete de maneira recursiva até que a distancia seja zero. O método notifique_recurso_repetido (Linha 8) atualiza a tabela de repeated fingers de um recurso com o sucessor encontrado. 


\section{Capítulo 7}

\section{Trabalhos Relacionados}

Este capítulo apresenta alguns dos trabalhos relacionados aos protocolos descritos nas Seções ju e 6 . Deve-se salientar que os sistemas descritos representam apenas uma pequena fraçào dos sistemas existentes.

\subsection{Trabalhos Relacionados à Interligação}

Com o surgimento da Computação en Grade, diferentes sistemas foram desenvolvidos pela comunidade academica e pela indústria. Esta seção analisa alguns dos trabalhos representativos na descoberta e interconexão entre diferentes aglomerados de uma grade.

\subsubsection{Condor}

O sistema Condor [Con, LL.188] é um dos sistemas de grade mais antigos. Desenvolvido em 1988 pela Universidade de Wisconsin, prove uma arquitetura para realizar tarefas que necessitam um alto poder computacional usando os recursos ociosos dos computadores. Existem diferenças em relação ao InteGrade que são analisadas na dissertação de mestrado de Andrei Goldchleger [Gol04].

A arquitetura do Condor é formada por um aglomerado de computadores. chamado Condor Pool. que é monitorado pelo Administrador Central. O Administrador Central é o encarregado de coletar e distribuir as tarefas entre os computadores do aglomerado.

Para compartilhar recursos entre os diferentes aglomerados lo que é chamado de Flocking). Condor inclui mecanismos de descoberta de outros aglomerados baseado em configuraçòes estáticas feitas manualmente. O processo ocorre da seguinte forma: cada administrador central precisa conhecer outros administradores contrais ans quais podera enviar uma rarefa para ser executada. Devido an fato destes admi- 
nistradores mudarem suas configuraçōes constantemente em sua disponibilidade, seja de capacidade ou de endereço, este mecanismo limita a escalabilidade do Condor.

Para melhorar a escalabilidade no processo de descoberta, os pesquisadores do Condor apresentaram em 2003 um protótipo de sua nova arquitetura de organização de aglomerados baseadas em uma estrutura Par-a-Par [BZH03]. Nessa arquitetura, Condor usa a Tabela de Hash Distribuida baseada em Pastry ${ }^{1}$ para descobrir diferentes aglomerados Condor. Aqui, cada Administrador Central é registrado na estrutura com um identificador único.

Com esta nova arquitetura, Condor propõe três alternativas para obter os aglomerados aos quais pedir a execução de uma tarefa.

1. A primeira alternativa consiste em que o Administrador Central envie. através de broadcast, uma mensagem de pedido de execução de uma tarefa a todos os outros Administradores Centrais pertencentes à estrutura Par-a-Par formada pelos aglomerados do Condor.

2. A segunda alternativa consiste em usar a camada Par-a-Par para a localização eficiente dos outros aglomerados. Nessa camada, usarão especificamente os identificadores dos administradores registrados na tabela de roteamento do Pastry, que garante uma certa proximidade física entre os Administradores Centrais. Com isso, as tarefas executadas e as mensagens trocadas entre os administradores não percorrerão longas distancias.

3. A terceira alternativa é usar uma mensagem de requisição para buscar novos aglomerados e que será enviada a alguns dos Administradores Centrais registrados na estrutura. Essa mensagem será propagada por eles com um tempo de vida que irá se decrementando em cada propagação.

A primeira alternativa tem um sério risco de escalabilidade devido à sobrecarga na rede pela quantidade de mensagens trocadas. Devemos considerar também que se todos os administradores enviam uma mensagem de pedido a um só administrador; este ficará sobrecarregado.

Lm dos problemas de utilizar a tabela de roteamento do Pastry, como apresentado na segunda alternativa, é que os Administradores registrados nessa tabela estão próximos em termos das chares armazenadas e não em termos de latencia. Com isso podem existir outros Administradores que estejam mais próximos do que os obtidos,

No processo de descoberta de noros aglomerados, existem diferenças do Condor em respeito ao protocolo apresentado no Capitulo 5 . Nosso protocolo utiliza

\footnotetext{
Ver sobre o Pastry na Seção t.3.2
} 
uma modificação da segunda e da terceira alternativa. No caso da segunda alternativa, utiliza-se a camada de rede (e não a tabela de roteamento) para obter os aglomerados. To caso da terceira alternativa, nosso protocolo possui um repositório (vide Seçào j.1.2) que contém os aglomerados descobertos e que não necessariamente pertencem à tabela de roteamento. É importante destacar que este repositório pode conter aglomerados que estejam mais próximos cm termos de latencia que os da tabela de roteamento citada anteriomente.

\subsubsection{Globus}

Globus [Glo] é um sistema de Grade que tem o objetivo de ajudar na resolução de tarefas que requerem grande poder computacional usando os recursos de computadores distribuidos $\mathrm{cm}$ redes de grande área [FK97]. Atualmente é o projeto de maior impacto na área de Computação em Grade que envolve diversas instituições de pesquisa e grandes empresas tais como a IBM e a . Microsoft.

A arquitetura do Globus apresenta um conjunto de serviços que servem como uma infra-estrutura base para o desenvolvimento de aplicações de grade. Com esse fim, ele concentra-se principalmente em duas tarefas: a primeira corresponde ao desenvolvimento de mecanismos de baixo nível (comunicação, autenticação, etc.) que podem ser usados para implementar serviços de alto nível e a segunda, a técnicas que permitem que serviços observem e administrem as operaçōes dos mecanismos de baixo nivel (interfaces de programação paralela, escalonadores, etc.).

Dentro desses serviços, o Globus disponibiliza o serviço de descoberta e monitoramento (Monitoring and Discovery System), que é o responsável por reunir e monitorar os recursos disponiveis na Grade. A arquitetura do serviço de descoberta consiste em dois elementos básicos [CFFK01]:

- Lima grande e distribuída coleção de provedores de informação, Information Providers, cue permitem o acesso a informaçōes sobre uma determinada entidade como, por exemplo, recursos de um computador. tipo de rede utilizado, capacidade de transferencia, etc. At informação é estruturada em termos de um modelo de dados tomado do LDAP [ZSO4] onde cada entidade é descrita por um conjunto de objetos de tipo (atributo, valor).

- Serriços de alto nivel. coletores. administradores. indices e entidades que respondem a requisiçòes feitas pelos provedores de informação. Em particular. essas entidades chamadas de "diretório de agregado" (Aggregate Directories) facilitam a descoberta o monitoração de recursos.

O protocolo do cerviço de descoberta permite cue um provedor de informaço possa se registrar a um ou mais "diretorios de agregaclo" aos cuais poderá fazer 
requisiçōes e os diretórios se encarregam de se comunicar com outros diretórios. Então, quando um recurso quer ser disponibilizado na Grade deve se comunicar com um provedor de informação que será o responsável por esse recurso. Por sua vèz, esse provedor de informação se registrará em um (ou vários) "diretório de agregado".

A descoberta dos recursos de uma Grade começa quando o provedor de informação solicita, aos seus diretórios conhecidos, algum recurso. Os diretórios consultam em sua base de dados, implementado utilizando LDAP, se esse recurso é conhecido e o fornece caso o tenha. Caso não o tenha, o diretório pode propagar a consulta a outros diretórios.

Uma das restrições da arquitetura baseada em provedores de informação e diretórios de agregado é que a configuração dos serviços de informação pressupõe que os provedores conhecem os endereços dos diretórios aos quais devem se registrar. O Globus no momento depende de uma configuração manual, na qual os usuários e administradores do sistema configuram os provedores de informação com os endereços dos diretórios de forma estática. Essa abordagem tem sérios problemas de escalabilidade, mas é de fácil utilização no caso de poucos diretórios de agregados.

Existem diferenças do Globus em respeito ao protocolo apresentado no Capítulo j. Primeiro. nosso protocolo utiliza uma estrutura Par-a-Par que permite uma melhor escalabilidade no processo de descoberta. A melhor escalabilidade é dada devido a não dependència de servidores centrais ("diretórios de agregado") para obter novos aglomerados. Losso protocolo utiliza qualquer par para obtê-los, através da propagação de uma mensagem como vimos na Seção j.2.3. Segundo, a descoberta de novos aglomerados, pelo Globus, não prevè a latência entre eles, portanto, pode ocorrer de o aglomerado descoberto não ser a melhor solução para uma comunicaçào eficiente, como vimos na Seção 5 .

\subsubsection{Gridbus}

O Gridbus [gri]. desenvolvido pelo departamento de Ciência da Computação da Lniversidade de Melbourne, é um projeto voltado à criação de especificações. arquiteturas e serviços orientados à construção de aplicações científicas (eScience) e de comércio (eBusiness) que precisam de um alto poder computacional. O objetivo principal do Gridbus é a de regular a demanda por recursos da Grade provendo incentivos economicos para os provedores desses recursos. A idéia dos incentivos economicos visa atenuar o problema dos usuários que somente consomem mas não compartilham recursos [BT(0)].

A arcuitetura do Gridbus arualmente é composta por computadores que compartilham recursos. independentemente de se eles pertencem a um aglomerado. a una organizaça virtual. Virtual Oryanization. on a una empresa virtual Tirtual 
Enterprise [T TB03]. Esses recursos são registrados como provedores de serviços da Grade (Grid Service Providers) em un diretorio chamado de Grid Market Directory (G_ID), o qual permite a descoberta desses recursos para as máquinas pertencentes à Grade. Este modelo é muito parecido com o Sistema de Descoberta e Vonitoração do Globus.

O processo de descoberta de recursos funciona da seguinte forma: quando 1 m cliente (Grid Service Consumer) precisa de um recurso para a execução de uma rarefa. ele deve contatar o diretório onde estão registrados os recursos. Este. por sua rez. informará os recursos disponíreis na Grade e que poderão ser utilizados pelo cliente. É importante destacar aqui que os endereços dos diretórios devem ser conheciclos. o que gera um problema de escalabilidade no caso de existirem muitos diretórios.

Para melhorar o problema da descoberta de novos diretórios e recursos, Gridbus apresentou no final do 2004 uma arquitetura diferente. Neste modelo; chamado de Federação de Grades (Grid-Federation), a Grade consiste em aglomerados de computadores que estão unidos através de uma estrutura Par-a-Par o que permite a descentralização dos GMD da arquitetura anterior. Cada aglomerado terá como responsável um agente (Grid Federation Agent) que dissemina a descrição das características do cluster através da rede usando para isso o protocolo do Chord ${ }^{2}$ para o envio de mensagens e armazenamento de recursos.

O agente. além de disseminar a informação do aglomerado, permite a cooperação entre diferentes aglomerados, utilizando a camada Par-a-Par para a descoberta e registro de recursos da Grade. Assim, quando um usuário deseja executar uma tarefa. este agente verifica se esta pode ser executada localmente. Senão, através da federação, a tarefa pode ser transferida a um outro agente que satisfaz os requisitos da tarefa.

A busca por outros agentes é baseada na propagação da descrição de 1 moglomerado qualquer (quote) que é enviada a todos os agentes da Grade. Por exemplo, quando $u m$ agente entra na Grade e se registra na estrutura Par-a-Par, é enviada uma mensagem de broadcast a todos os outros agentes registrados na Grade. Com isso, um agente conhecerá os outros aglomerados e poderá enviar tarefas para serem executadas nestes. de acordo com o critério de busca. seja rapidez na comunicação. melhores máquinas. etc. L'ma desrantagem desta proposta é que enviar as caracteristicas a todos os outros agentes pode ser ponco escalárel no caso de haver mutos agentes.

No processo de descoberta de noros agiomerados. existem varias diferenças do Gridbus em respeito ao protocolo apresentado no Capitulo j. Entre elas: (1)

\footnotetext{
"Ter sobre o Chord na Seção t.3.1.
} 
nosso protocolo não faz broadcast das informaçōes a todos os pares da estrutura (que afeta diretamente a escalabilidade) e (2) os aglomerados descobertos tem uma proximidade em termos de latencia, que pode melhorar a rapidez da comunicaçăo entre eles, como vimos na Seção 5.1.

\subsection{Trabalhos Relacionados à Localização}

Esta seção apresenta alguns trabalhos relacionados a localização de recursos dado um intervalo de valores, a maioria usando a Tabela de Hash Distribuída para o armazenamento e busca destes.

\subsubsection{Prefix Hash Tree}

Uma das primeiras alternativas para buscar recursos por intervalos de valores nas tabelas de hash distribuidas foi desenvolvida conceitualmente por Ratnasamy et al [RHS03]. Nesse trabalho, é proposta a estrutura de árvore Prefix Hash Tree (ou PHT) na qual cada nó intermediário da árvore tem associado uma etiqueta que corresponde a um prefixo do domínio indexado e as folhas da árvore tem os dados do domínio. Esses prefixos estão armazenados na tabela de hash distribuída como (chave, valor $)=($ etiqueta,$n)$ e podem ser obtidos usando as funções de recuperação de chaves próprias das implementações das tabelas de hash distribuídas.

Para entender a estrutura PHT, podemos compará-la com um trie , geralmente utilizado para indexar palavras sobre um alfabeto. As folhas (ou seja as palavras completas) ficam penduradas em um nó intermediário que tem como etiqueta um prefixo comum a todas essas palavras. Por exemplo, as palavras cantar. canto, canticos seriam folhas penduradas a um nó intermediário com etiqueta "cant".

A busca por um intervalo de valores na PHT pode ser feito de duas formas: (1) começa-se perguntando à tabela de hash distribuída pelo nó raiz da PHT que contém a chave do dado indexado (por exemplo RAM-Disponivel). Esse nó devolve os nós pendurados que correspondem ao prefixo do intervalo procurado. Este processo é recursivo até chegar as folhas onde estão os dados que serão devolvidos. (2) Para cada ralor do intervalo procurado the é extraido seu prefixo. No caso desse prefixo existir na tabela de hash distribuida, esta devolve o nó responsável por esse prefixo e a busca para localizar as folhas começa desse nó. Isso melhora o desempenho comparado com a primeira alternativa porque não tem que se percorrer a árvore dosde a raiz para localizar os dados.

\footnotetext{
${ }^{3}$ Do termo retrieunl. o trie é uma estrutura eficiente para armazenamento e buscas de palatras com prefixo commin. Vista estrutura. as palarras săo armazenadas nas follhas [.11B.5.9].
} 
A diferença da nossa proposta é que a estrutura LBI não precisa de uma estrutura extra (o trie) para ordenar os valores dos recursos, porque a ordem é dada pela própria LBI. Além disso. as árvores apresentam um problema extra de manutenção. Por exemplo, se um filho de um nó sair da PHT. a estrutura tem que se adequar a esta saída organizando os nós intermediários de "todos" os prefixos do nó que saiu. Em nosso caso, somente as tabelas de finger, o sucessor e o predecessor de $11 \mathrm{~m}$ nó tem que ser atualizadas.

\subsubsection{Extended PHT}

To mesmo contexto das árvores, Gao et al. [GS0t] utilizam a PHT para indexar valores. Existem duas diferenças com respeito ao modelo apresentado na seção anterior. Primeiro. nesta extensão são utilizados os nós intermediários da PHT para armazenar os recursos. Com isso. para localizar os dados de um intervalo não é necessário chegar até as folhas. Segundo. cada nó desta árvore tem um conjunto de réplicas que evita que os nós fiquem sobrecarregados. Assim. mesmo que as buscas comecem pela raiz da estrutura, as réplicas mantém o desempenho distribuindo as consultas entre elas.

Para a busca dos recursos contidos em um intervalo utilizando a PHT, os autores explicam tres alternativas:

- Procurar na tabela de hash distribuída pelo identificador do dado armazenado: ou seja a raiz (por exemplo R.A.M-disponível). Esse nó terá como filhos todos os recursos e será responsável por devolver os dados armazenados nos filhos. Assim, a busca por qualquer intervalo sempre será constante pois a árvore tem somente um nivel.

O problema desta alternativa é que podem existir diferentes valores que compartilhem o mesmo identificador [RLS ${ }^{\top} 03$ ]: e mesmo que a função de hash forneça uma distribuição proporcional dos nós que armazenam os identificadores [KR04]: o nó responsárel pelo único identificador deverá ter problemas de sobrecarga. Para entender isso, ramos supor que o dado a ser indexado é R.A.. e que essa chave será armazenada em um nó $x$. Todos as máquinas que desejem ter sua R.MI indexada ou que procurem por um intervalo da chave terão que acessar o nó $x$ produzindo uma queda no desempenho da entrega das respostas derido à sobrecarga nele.

- Procurar na tabela de hash distribuida por cada valor do intervalo buscato. Se use valor existir na tabela entào é devolvido o recurso amazonado.

Esta altemativa raz alguns problemas: (1) a busca tera que ser dividida nos valores do intervalo. ou seja seräo realizadas $f-i-1$ buscas. Io caso do 
intervalo ser muito grande ou o intervalo ter poncos dados armazenados, este tipo de busca é pouco escalável e pouco eficiente respectivamente. (2) Se o intervalo contém valores contínuos (não discretos) a divisão do intervalo não pode ser definida.

- A proposta dos autores é uma combinação das duas alternativas mostradas acima. Com respeito à primeira alternativa, cada nó da estrutura tem associado réplicas que evitam a sobrecarga nas consultas. No caso da segunda alternativa, a busca é dividida nos valores do intervalo mas o nó responsável tem associado filhos aos quais a busca será propagada. Tessa propagação são encontrados os dados (sem ter que chegar às folhas) o que melhora o desempenho na devolução dos valores do intervalo.

\subsubsection{Skip Graph}

O trabalho que mais se assemelha com à estrutura apresentada na Seção 6.3, mas que não utiliza as tabelas de hash distribuídas para o armazenamento dos recursos. è o Skip Graph [AS03]. Skip Graph é uma estrutura Par-a-Par que estende a estrutura Skip List [Pug89] provendo tolerância a falhas e replicação de dados.

Para entender o Skip Graph devemos analisar antes o Skip List. Skip List. é uma estrutura de árvore balanceada e organizada como uma torre de listas esparsas encadeadas. Como mostrado na Figura 7.1, o nível zero da Skip List contém todos os valores em uma ordem crescente dada pela chave indexada. Lm valor de um nível $i$ aparece no nível $i+1$ dada uma probabilidade, ou seja, os níveis de cima são formados com recursos dos níveis de baixo que tem uma certa probabilidade de aparecer. Cada recurso de um nível do Skip List tem ponteiros a recursos posteriores na lista. O último nível do Ship List, muito parecido com a nossa estrutura, é formado por ponteiros que, no pior caso, podem resultar em uma busca linear.

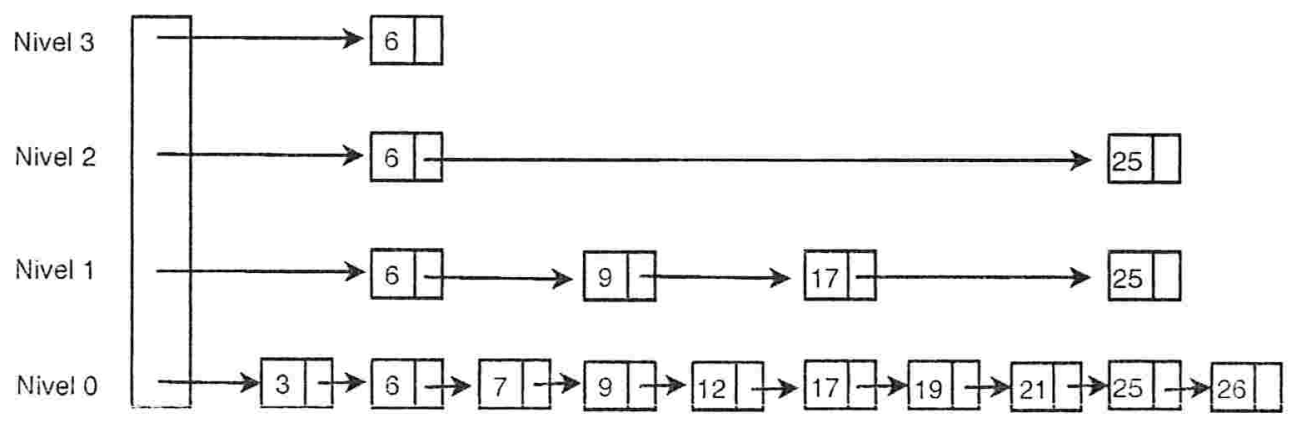

Figura 7.1: A estrutura Skip List. 
A idéia do Skip Graph è manter uma coleção de Skip Lists onde vão ser compartilhados os primeiros niveis. Com isso, cada nivel $i$ vai ter mais recursos onde efetuar as buscas (derido à uniăo dos niveis $i$ da coleção de Skip List) produzindo duas melhorias: (1) a probabilidade de que um recurso fique sobrecarregado é menor (2) a falha de um recurso, por exemplo o nó raiz do Skip List, năo afetará a estrutura.

Para buscas por intervalo neste tipo de estrutura se procede da scguinte mancira. Dado um intervalo [i.f] começa se perguntando aos recursos raiz do Ship Graph (note que existem tantos recursos quantos Skip List tenha o Skip Graph.) se o valor deles estâo dentro do intervalo procurado. Os recursos raiz devolvidos conterão ponteiros a outros recursos. Para para cada um desses recursos apontados. contimua se repetindo o processo até achar todos os valores. Com isto o processo faz $O(m \log n)$ troca de mensagens.

Como dito anteriormente, nós não temos uma estrutura adicional para ordènar os valores dos recursos e os ponteiros da tabela de fingers permitem realizar uma busca en tempo logarítmico. 


\section{Capítulo 8}

\section{Simulação}

Há inúmeros trabalhos que buscam investigar e desenvolver novas técnicas para construir serviços de Internet escaláveis e confiáveis, incluindo nisso redes Par-a-Par, redes sobrepostas (overlay), replicação em redes de grande área; etc. Esses sistemas são projetados para uma rede formada por um grande numero de nós distribuídos na Internet.

Para testar e avaliar tais sistemas, os desenvolvedores devem implantá-los em cenários realistas, como por exemplo em redes grandes, estruturadas ou ad-hoc. No entanto, é muito difícil implantar e administrar esses sistemas em nós espalhados em diversos sítios na Internet. Assim, os resultados obtidos dessa implantação, na prática, não são nem reprodutiveis nem previsíveis porque as condições e comportamentos mudam rapidamente e não estão sujeitos ao controle nem manipulaçào do pesquisador $\left[\mathrm{VYW}^{+} 02\right]$.

To caso de protocolos, um dos objetivos primordiais no seu projeto tem sido a robustez. Desde a era pré-Internet, a maioria dos esforços iniciais nesse aspecto foram os modelos a prova de falhas, onde a falha dos nós eram total e facilmente detectáveis por outros nós e podia ser corrigida. O protocolo IP. por exemplo, é robusto contra vários tipos de falhas usando pouquíssimos recursos.

As dificuldades de experimentação com redes reais de grande porte fazem com que a simulação tenha um papel importante na descoberta de possíveis problemas que o protocolo possa ter.

\subsection{Escolha e Implantação}

A simulaça do protocolo proposto em nosso rabaho rera o objetivo de verificar se ele atende a requisitos importantes de desenvolrimento deste tipo específico de aplicaça rais como: escalabilidade baixo tempo de resposta. pecpuena quantidade de mensagens trocadas etc. Para isso. o primeiro passo foi escoller uma ferramenta 
de simulação de redes de grande envergadura que permita analisar o protocolo e obter resultados dos tipos supracitados.

Para isso. foi escolhido o simulador do Bamboo [Bam], que foi desenvolvido com o objetivo de poder avaliar as aplicaçòes que usam a tabela de hash distribuída Bamboo. É importante destacar que foram feitas algumas adaptações no código do simulador para obter dados da simulação que serão analisados na Seção 8.2. As adlaptaçôes foram feitas de acordo com as recomendaçôes dadas pelo desenvolvedor do Bamboo obtidas através das interações feitas durante o desenvolvimento dos protocolos. A primeira adaptaçâo foi a de permitir a tabela de hash recuperar um recurso, dada somente a chave de indexação. como "RA.I" ou "CPL" (antes era necessário utilizar outros parametros, como a data em que foi criado, tempo de expiração, etc.). A segunda adaptação foi a de utilizar estruturas que armazenassem a quantidade de bytes enviados e recebidos pelos pares pertencentes à tabela de hash distribuída na troca de mensagens entre eles (ou seja, no ingresso de um par e nas atualizações mostradas na Seção j.2).

Os passos necessários para simular as aplicações e protocolos no simulador do Bamboo são:

1. O usuário especifica a topologia onde será testada a aplicação.

2. O usuário especifica os caminhos entre dois pares quaisquer da rede com sua respectiva latencia.

3. A aplicação ou protocolo a testar é instanciado pelo simulador.

To primeiro passo, utilizamos diferentes estruturas de rede, algumas criadas para casos específicos (como pares que estivessem muito perto uns dos outros e existissem poucos roteadores entre eles) e outras já criadas por outros desenvolvedores para testes.

To segundo passo, tivemos que colocar valores (que representaram a latència) aos caminhos entre dois pares. -leste passo. testamos com diferentes valores (a maioria eram dados de forma aleatória) nas estruturas criadas por nos. Tas estruturas criadas por outros desenvolvedores. algumas já rinhan com ralores próprios.

To terceiro passo. executado o simulador. onde se especifica a cuantidade $x$ de pares que terá a simulação. junto com a estrutura da rede e seus caminhos. $\mathrm{O}$ simularlor cria então $x$ instancias de pares em uma mácuina. mas simula a troca de mensagens como se estiressem em diferentes máquinas. 


\subsection{Resultados Experimentais da Intercomunicação}

Testa seção, avaliamos o Protocolo de interligação, apresentado na Seção j, usando o simulador do Bamboo que permite configurar o número de nós que terá a simulação. Nossa plataforma para simular o protocolo foi um computador com 1 GB de RAM e sistema operacional GNU Linux - Fedora Core 2. A seguir, mostraremos o modelo que usamos para simular o protocolo e os diferentes tipos de medições que foram feitas para verificar se o protocolo é escalável.

\subsubsection{Ambiente de Teste}

Nosso objetivo foi simular o protocolo para que funcionasse como se cada par fosse um GRM do InteGrade. Lsamos um modelo de rede com as seguintes características. Existem dois tipos de nós, os roteadores e os clientes. Os nós clientes somente podem se unir aos nós roteadores e um nó roteador deve estar unido a outros roteadores. Finalmente, para efeitos de simplicidade, a comunicação entre os nós é simétrica. Ou seja, se um nó a se comunica com um nó $b$, com uma latência $l$, então $b$ se comunica com $a$ com a mesma latência.

\subsubsection{Custo de Ingresso na Rede}

A medida do tempo levado por um par para entrar na rede, em função da quantidade de pares que já ingressaram é muito importante para verificar a escalabilidade. Teste experimento usamos de 47 até 750 nós clientes (simulando GRMs do InteGrade) e 300 nós roteadores. A simulação foi feita da seguinte maneira: a estrutura de rede da simulação estava composta por 47, 100, 300, 500 e 750 pares, os quais eram adicionados um a um. Nos últimos 10 ingressos foram medidos o tempo (em segundos) que o par ingressante demorou em encontrar a referéncia a um outro par e o tempo (em segundos) que demorou em encontrar um par mais próximo. Finalmente foi calculada a média de cada medida.

A Figura 8.1 mostra que o custo de entrar na rede se mantém quase constante. independente da quantidade de pares que já tenham ingressado. Como vimos na Seção j.2.1. para ingressar na rede o par só depende de una conexão lógica (referencia) com um outro. Para obter essa referencia, deve primeiro obter alguns pares (podemos considerar esse processo como constante) onde se conectar e depois obter a menor latencia. Supondo que a quantidade de pares obtidos é relatiramente pequena. o processo para obter a menor latericia (usando o método proposto no ponro 2 da Seçào 5.2.1) também pode ser considerado constante. É importante destacar. ciue a obtença e escolha de um par (Linha 2 e 3 da Figura 5.3 ) só demora 


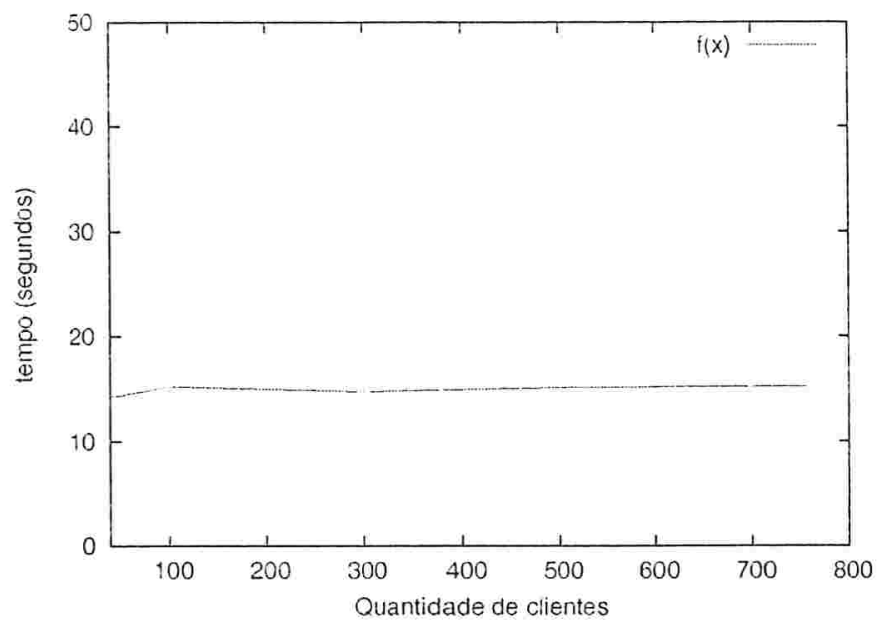

Figura 8.1: Custo em segundos da entrada de um par na rede.

3 segundos e que os outros 10 segundos são gastos em buscar um par mais próximo (Linhas 4-13 da Figura j.3).

\subsubsection{Quantidade de pares espalhados}

Quando um par ingressa na rede, o Protocolo de Interligação se encarrega de the dar vários pares aos quais poder se conectar. Como esses pares são obtidos de forma aleatória, existe uma probabilidade de que os pares da rizinhança estejam distantes em termos de latencia. Definimos então. como par espalhado. o par onde a maioria da. sua vizinhança são referencias a pares distantes. em termos de latencia. O Protocolo de Interligação, apresentado na Seção 5.2, mostrou que a vizinhança de um par pode ser atualizada, tanto no processo de entrada de um par na rede, como na atualização do repositório. Neste contexto, temos que analisar essas duas possibilidades.

A simulação foi feita da segunte maneira: a estrutura inicial da rede estava composta por $4 \bar{\tau}$ pares e dai se agregou outros pares até completar os 750 . Testa simulaçá, foi medido quantos pares săo espalhados respeito ao total de pares pertencentes à rede. A Figura 8.2 (a) mostra que no processo de entrada existem muitos pares espalhados, pelo fato do par escolhido para se conectar estar distante em termos de latencia. Como mostrado na Figura 8.2(b), essa quantidade diminui quando o processo de atualizacào do repositório é executado pois neste processo tenta-se escolher um par que esteja mais perto e por conseguinte obter uma vizinhança de pares que também estejam mais perto (ver Seção j.2.3). Por exemplo. podemos observar que cuando um par entra en uma rede com 500 nos. to deles sato espalhados. mas 


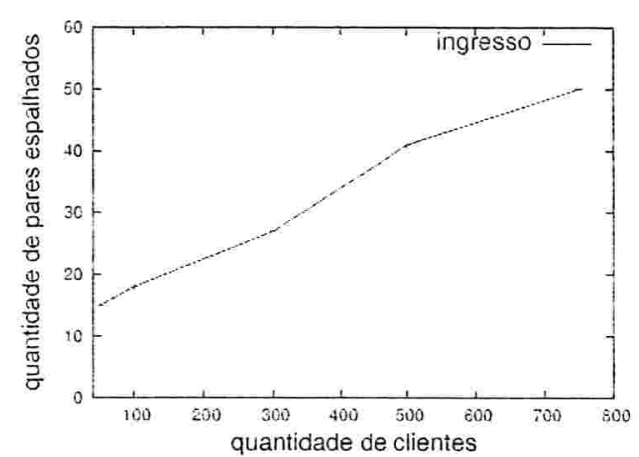

(a) Quantidade de pares espalhados no processo de entrada dos pares na rede

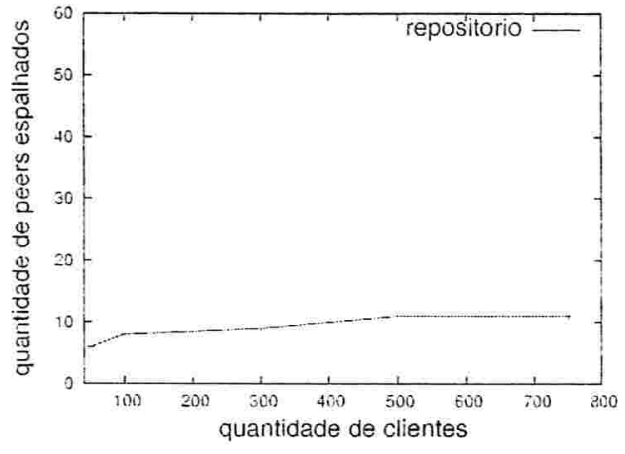

(b) Quantidade de pares espalhados quando executado o processo de Atualizaçâa do Repositório

Figura 8.2: Quantidade de pares espalhados nos processos de entrada de um par e de atualização do repositório.

diminui a 10 quando executado o processo de atualização do repositório.

\subsubsection{Largura de Banda Usada}

Definimos a largura de banda usada como a quantidade de bytes que um par envia pela rede em um certo momento. O consumo da largura de banda usada por uma aplicação é um tema muito importante em recentes pesquisas que testam a escalabilidade dos protocolos Par-a-Par. Podemos observar na Figura 8.3(a) que o consumo de largura de banda por par, quando se está executando o processo de ingresso de um par na rede, que demora 13 segundos, é quase constante. Isso devido ao fato de que. quando um par entra na rede. é necessário: (1) escolher o par de menor laténcia. dado uma quantidade constante de pares; (2) enviar uma quantidade de mensagens ignal à quantidade de roteadores entre ele e o escolhido. Essas quantidades de bytes enviados pela rede (ping e traceroute) é praticamente constante.

O consumo da largura de banda feito pela atualização do repositório, mostrado na Figura 8.3(b), também é constante. Como apresentado na Seção 5.2.3. isso se deve ao fato de o repositório fazer requisiços somente a uma quantidade limitada de vizinhos. Com isso. a quantidade de mensagens trocadas entre pares é constante. 


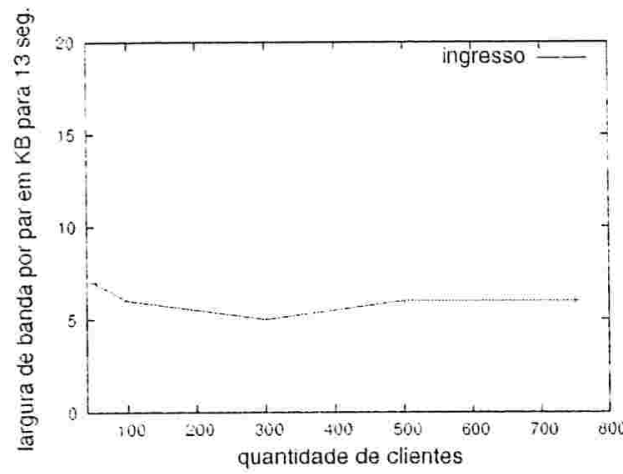

(a) Largura de banda usada no processo de entrada de um par na rede

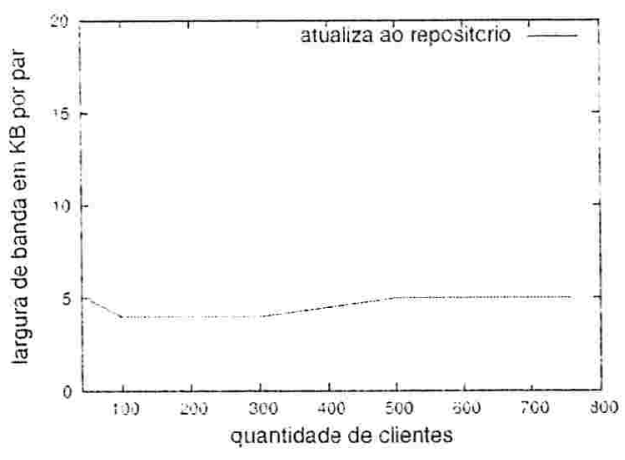

(b) Largura de banda usada no processo de Atualização do Repositório

Figura 8.3: Consumo de largura de banda usada nos processos de entrada de um par na rede e de atualização do rẹositório.

\subsection{Resultados Experimentais da Localização}

Nesta seção, avaliaremos o Protocolo de Localização apresentado na Seção 6 através de uma simulação. Nestes experimentos, o dado utilizado será a quantidade de memória RAM de uma máquina e o intervalo de valores estará definido por todos os números inteiros positivos possiveis para esse recurso. Para realizar os experimentos, nosso protocolo foi implementado em Java, usando Bamboo [Bam] como a implementação da tabela de hash distribuída e o seu simulador.

\subsubsection{Ambiente de Teste}

A simulação foi executada em um $\mathrm{PC}$ de $2.4 \mathrm{GHz}, 2$ GByte de memória RA\I e sistema operacional GNL Linux. O simulador foi adaptado para estimar; a partir da troca de mensagens, a largura de banda usada pelos pares.

\subsubsection{Custo de Inserir um Recurso}

A estrutura LBI é modificada cada rez que um recurso é inserido. O processo de inserir um recurso é um dos mais importantes na LBI pois reflete diretamente em quantos recursos será executado o processo de Estabilizaçồo (ou seja a atualizaçâo do predecessor e o sucessor de um recurso). como mostrado na Seçào 6.3.6.

Veste experimento. adicionamos 1000 recursos com ralores incrementais conserutivos. com o objetivo de obter o pior caso de custo de registro. onde cata recurso 
será adicionado ao final da $\mathrm{LBI}^{1}$ e com um interralo de tempo entre cada inserção. Teste contexto, temos duas alternativas a analisar: (1) É utilizada a tabela de fingers na busca da posição onde inserir o recurso. (2) A tábela de fingers não é utilizada.

A Figura 8.4 mostra o efeito de se usar ou não usar a tabela de fingers. Cada ponto do gráfico representa a quantidade de recursos aos quais será necessário aplicar o processo de Estabilização.

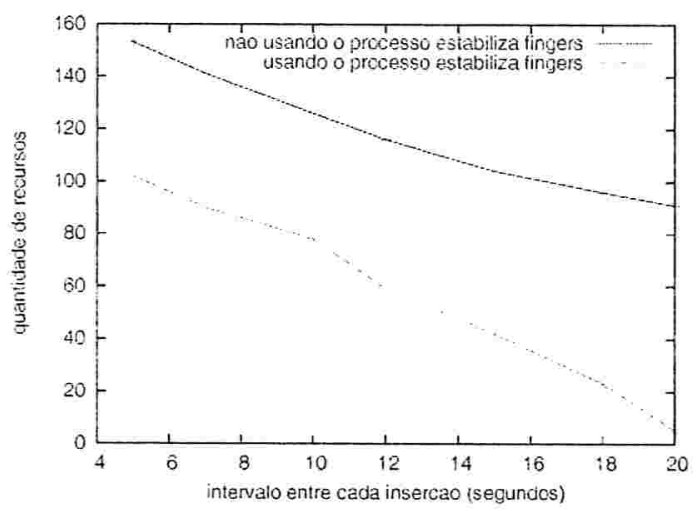

Figura 8.4: Custo de inserir um recurso usando ou não a tabela de fingers.

Podemos observar que a quantidade de recursos a serem estabilizados diminui quando: (1) o tempo entre cada inserção aumenta, (2) é utilizada a tabela de fingers.

Em (1), a mensagem que procura a posição final onde o recurso tem que ser adicionado não é influenciada pelos efeitos de sobrecarga de um par que pode estar processando uma outra mensagem. Em (2), a quantidade de recursos por onde a mensagem passa diminui logaritmicamente, como vimos na Seção 6.3.2, pois os recursos da tabela de fingers estão atualizados.

\subsubsection{Número de Recursos Visitados em uma Busca}

A quantidade de recursos visitados por onde uma mensagem passa até encontrar o recurso procurado é muito importante para verificar a escalabilidade e o desempenho do protocolo.

Cada ponto da Figura 8.5 representa a quantidade de recursos visitados até encontrar o recurso procurado. Por exemplo, para 1000 recursos adicionados na LBI com ralores incrementais. para encontrar o recurso com valor 300 é necessario risitar 10 recursos com seis fingers e 14 recursos con cinco fingers. Esses valores são

\footnotetext{
Como a LBI nio tem um ponteiro ao final da lista. para adicionar um recurso no final è necessario percorrer toda a lista.
} 


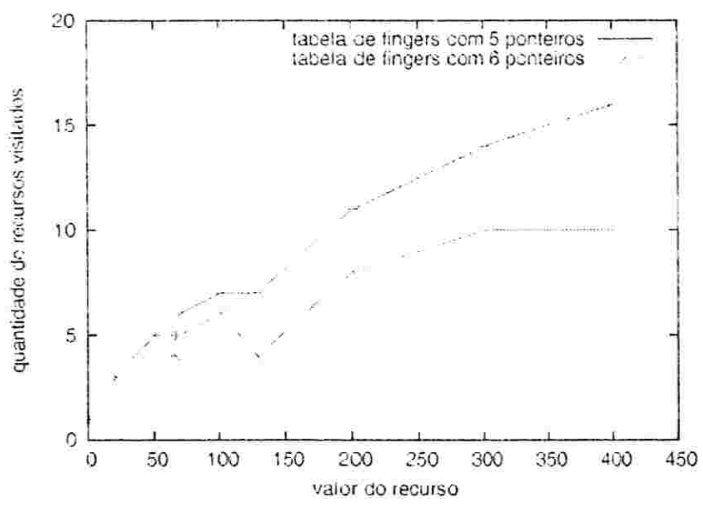

Figura 8.5: Quantidade de recursos risitados ein uma busca.

muito razoáreis. se comparados com a busca linear que visitaria 300 recursos e está de acordo com a análise teórica de que a quantidade de recursos visitados deve ser $O(\log n)$.

\subsubsection{Largura de Banda usada pelo Protocolo}

Teste experimento. adicionamos à rede 1000 pares os quais disponibilizavam os recursos que eram armazenados na LBI. Cada par disponibiliza somente um recurso, e foram adicionados um a um até completar os 1000. As medidas foram feitas quando a rede tinha $100,500,700$ e 1000 recursos, tomando a quantidade de bytes recebidos e enviados pelos pares e dividindo pela quantidade de pares pertencentes à rede.

Podemos ver na Figura 8.6(a) que o consumo total de largura de banda por par: quando executada a inserção de um recurso, é uma função linear crescente, mas que não é um valor muito alto. Por exemplo. se temos 1000 recursos o consumo médio por par será de 10 KBytes. A Figura \$.6(b) mostra o consumo de largura de banda. por par. quando executados os processos de estabilização da Seção 6.3.6. Podemos observar que a largura de banda por par diminui pois, depois que a LBI está estabilizada, esses processos não são executados. É importante destacar que, na quantidade de KBytes necessários para executar a inserção e estabilização da LBI estão incluidos também os KBytes necessários para adicionar um recurso na tabela de hash distribuida.

\subsubsection{Buscas por Intervalo}

Ĺm dos objetivos da LBI é estruturar os recursos de forma a poder localizar e devolver os recursos com ralores compreendidos en un certo interralo. Este experimento 


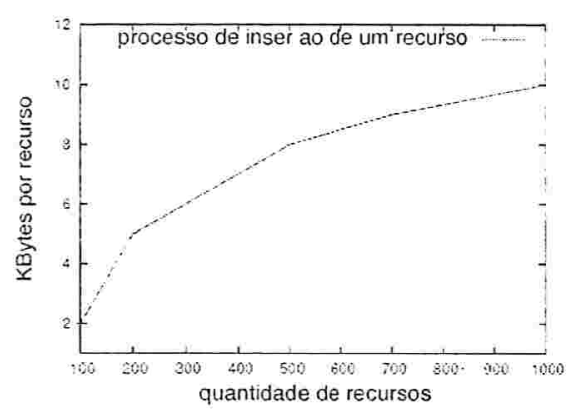

(a) Consumo de largura de banda na inserçào de um recurso

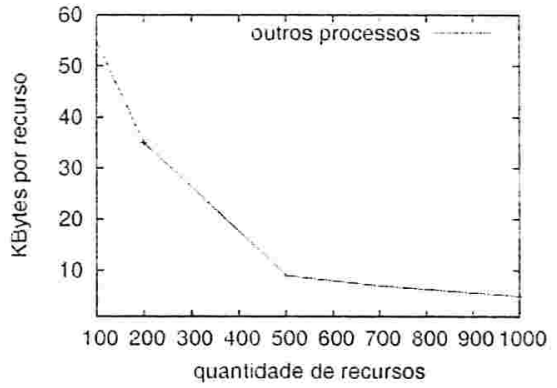

(b) Consumo de largura de banda quando executado os outros processos

Figura 8.6: Largura de banda usada pelos processos de registro e estabilização.

mede como a quantidade de recursos devolvidos em uma busca se comporta com o aumento do tempo da busca.

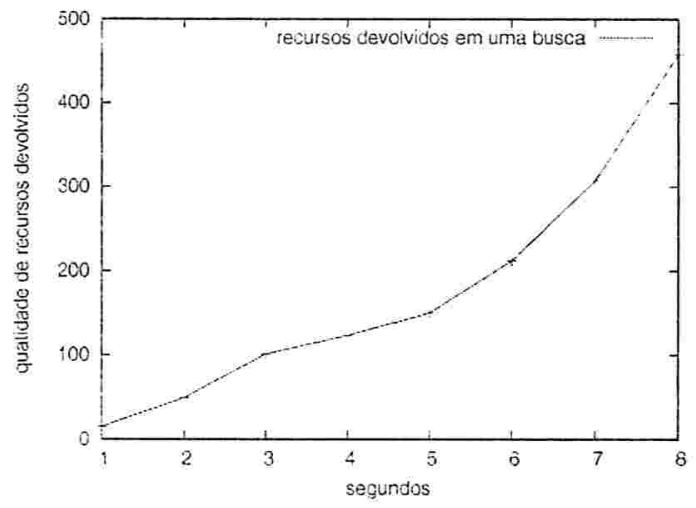

Figura 8.7: Quantidade de recursos devolvidos dada uma busca por intervalo.

Para esse experimento adicionamos 1000 recursos e fizemos uma busca por todos os ralores dos recursos que pertencem à LBI. Cada ponto da Figura S.i representa a quantidade de recursos devolridos em um determinado momento. Por exemplo, se a busca dura 1 segundo. serào derolvidos 15 recursos e se dura jo segundos. scrão devolvidos 150 recursos. Como o comportamento da busca lexperimentalmente) corresponde a uma funçào exponencial (ruma funçào linear derolveria aos 5 segundos $7 . j$ recursos o tempo total para obter todos os valores do inter- 
valo será de $O(\log n)$. obtido da fómula: se quantidade devolvidos $=O\left(e^{t \in m u \omega}\right)$ então tempototil $=O\left(\log \left(\right.\right.$ todos $\left.\left._{\text {itenolvidos }}\right)\right)$. Com esse resultado, mantemos o desempenho das estruturas baseadas nas árvores distribuidas mostradas na próxima seção. 


\section{Capítulo 9}

\section{Integração dos Protocolos ao InteGrade}

Veste capítulo será apresentado como o Protocolo de Interligação e o Protocolo de Localização podem ser integrados para tratar das requisições feitas pelos usuários do sistema InteGrade.

A seguir vamos analisar o seguinte exemplo: um usuário quer executar um programa e para isso precisa localizar 128 máquinas onde cada uma delas tenha disponível no mínimo 64 MBytes de memória RAM, $15 \%$ de utilização do processador (CPL) e 50 MBytes de disco rígido.

\subsection{Visão Geral}

Antes de responder como localizar os LR.Ms do InteGrade para executar a aplicação. vamos descrever como está composta a rede Par-a-Par em um momento dado. Para isso, vamos analisar a estrutura da rede segundo o Protocolo de Interligação e do Protocolo de Localização.

\subsubsection{Protocolo de Interligação}

Cada circulo da Figura 9.1 corresponde a um GRM e cada quadrado corresponde a um LR.I. Tossa rede está composta por 100 GR\Is e cada um deles possui 16 LRMIs. Graças ao Protocolo de Interligação, cada GRMI $g$ possui uma vizinhança (armazenada no repositório local de pares) ordenada pela latencia e que permite conhecer GRIIs que estejam próximos a $g$. 


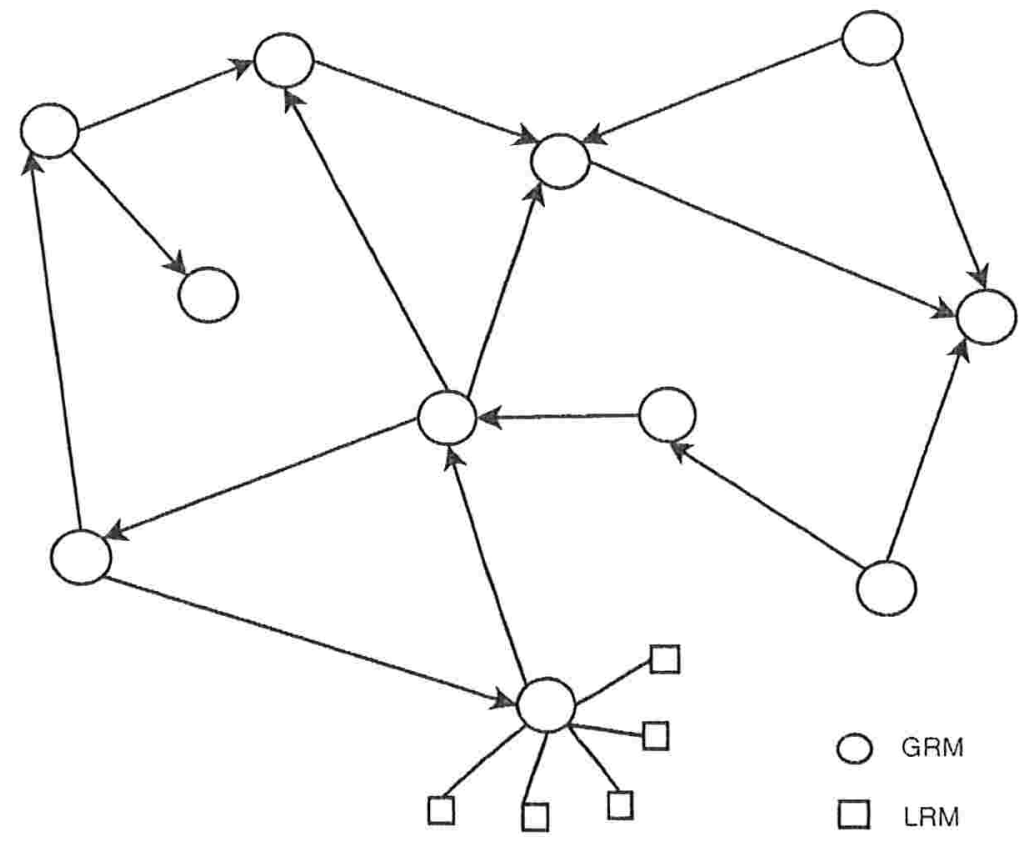

Figura 9.1: Configuração da rede formada pelos GR.Ms.

\subsubsection{Protocolo de Localização}

Para o caso do Protocolo de Localização, cada LRM que deseje compartilhar um recurso, em nosso caso a memória RAM, o processador e o disco rigido disponível, colocará o recurso na estrutura LBI e armazenada na DHT. A estrutura do recurso é definida como mostrado na Figura 9.2. A definição dos atributos da estrutura é:

- indexKey contém a chave com a qual o tipo de recurso foi armazenado, no nosso caso seria "RA.V", "CPL" on "HD".

- value corresponde ao valor numérico que o recurso disponibilizado pelo LRAI apresenta em um dado momento.

- ID contém o identificador do LRII. O identificador pode ser o endereço IP com a porta. um certificado digital ou a IOR do LRII. O importante é que esse identificador seja único entre todos os LR.Is da rede.

- LRM corresponde a IOR do LRMí.

- GRM correponde à IOR do GRM que gerencia o LRM. 


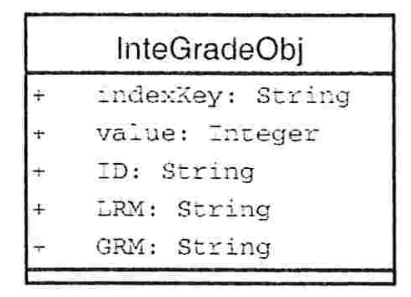

Figura 9.2: Estrutura do Recurso armazenado na LBI.

Em nosso exemplo, como são très os tipos de recursos que estão sendo compartilhados, teremos tres LBIs, uma para a RA.M, outra para a CPL e outra para o HD, como mostrado na Figura 9.3. É importante destacar que um LRM não necessariamente tèm que estar nas très LBIs. Por exemplo, se um LRM deseja compartilhar somente a memória RA.I e o CPL, mas não o HD, ele estará presente nas LBIs com chave "RA.I", "CPL" e não na LBI com chave "HD".
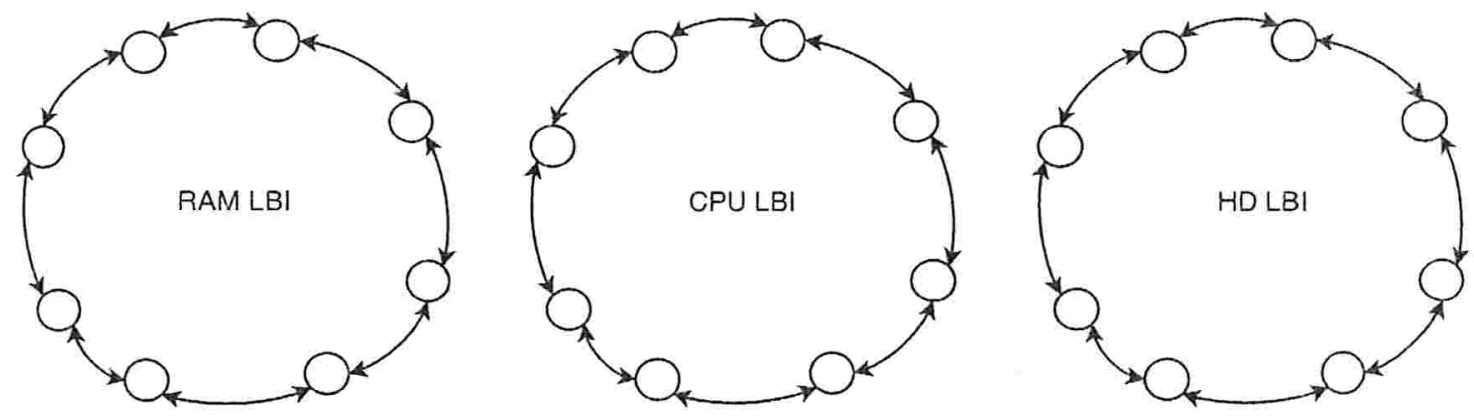

Figura 9.3: Três LBI, uma para a memória R.A.M, uma para o processador e outra para o disco rígido.

\subsection{Obtendo os LRMs}

Como mencionado no começo do apendice, o usuário precisa encontrar 128 LR.Ms que cumpram com os requisitos de RA.I. CPU e HD disponivel. Para isso, o usuário da grade faz a requisição que é encaminhada para o GR.M que está administrando o seu aglomerado. O GRM utilizará então a vizinhança e as LBI para obter os $12 \mathrm{~S}$ Lfilis. Primeiro centancio obter esses LRAís de sua vizinhança (Seção 9.2.1) e no caso de não conseguir os 128 LRIIs. tenta obter os restantes das LBI (Seçào 9.2.2) ate completar com a culantidade total. 


\subsubsection{Utilizando a Vizinhança}

O primeiro passo é obter o máximo número de LRMs da vizinhança, isso porque segundo nosso Protocolo de Interligação: esses LRMs estão mais próximos em termos de latencia e portanto a comunicação entre eles será mais eficiente.

Para isso, faz-se uma requisição aos GRMs definidos nas primeiras entradas do repositório local de pares, os quais devolverão os LRMs disponiveis no momento. Isto é possível pois, segundo explicado na Seção 2.1, o GRM é responsável por coletar várias informações dos LRM e portanto conhece quais os LRMIs que cumprem com os requisitos da busca.

\subsubsection{Utilizando as LBIs}

A Seção anterior obtém os LRMs da vizinhança, mas ainda assim pode ser que a quantidade de LRMs necessários para executar uma aplicação nāo seja atingida. Para completar com os LRM que faltam, utilizaremos as LBIs apresentarlas na Seção 9.1 .2 .

Na Figura 9.4 vemos o Algoritmo utilizado para obter os LRMs, das LBIs, que atendem os requisitos de uma certa requisição. Os passos do algoritmo são:

1: ObterLRMs()

2: grmHash $\leftarrow \emptyset$;

3: head_ram - dht.super_head("RA.N");

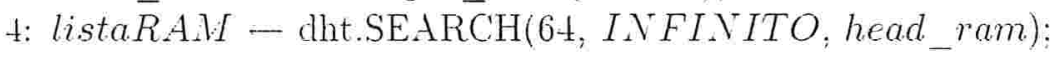

5: head_cpu $\leftarrow$ dht.super_head("CPL"):

6: listaCPU - dht.SEARCH(15. 100, head_cpu):

i: head_hd - dht.super_head("HD"):

8: lista $\bar{H} D-$ dht.SEARCH(50, INFINITO, head_hd);

9: lista_lrm_validos - filtraLista(listRAM. lista $\bar{C} P U$. lista $H D)$;

10: indexa(grm.Hash. lista_lrm_validos);

11: devolve grmHash:

Figura 9.4: Algoritmo utilizado para buscar os LR.Is nas LBIs dado um requisito para a execução de uma tarefa.

1. Obter da LBI. com chave RAMI. os LR.Is que tenham uma memória R.A.I disponivel maior que 64 MB

2. Obrer da LBI. com chave CPC, os LR.Ms que renham uma porcentagem de wo de processador disponvel maior que 1.j. (Linha 6). 
3. Obter da LBI, com chave HD, os LRMs que tenham uma quantidade de disco rígido disponível maior que 50 MB

4. Fazer um emparelhamento entre os LRII das listas obtidas e devolver somente os que estão contidos nas très LBIs (Linha 9). Se o LRM não pertencer a uma LBI quer dizer que não cumpre com todos os requisitos.

J. Indexar em uma estrutura (hash) esses LRWs válidos pelo GR.M que o gerencia. Com isso, poderemos observar quantos LRMs tèm o mesmo GRM (Linha 10).

6. Devolver ao usuário a estrutura hash que poderá escalonar a aplicação de diferentes maneiras (Linha 11). Por exemplo, uma heurística é utilizar os LRMs que estejam gerenciados pelo GRM que tenha o maior número de LRMs. 


\section{Capítulo 10}

\section{Conclusões e Trabalhos Futuros}

Após a descrição dos protocolos e dos resultados obtidos no desenvolvimento deste trabalho, apresentamos as conclusões e os trabalhos futuros que poderão ser desenvolvidos com base nesta pesquisa.

\subsection{Conclusões}

O objetivo deste trabalho foi desenvolver protocolos Par-a-Par que permitam estruturar os pares de uma rede, baseado na latencia entre eles, e localizar os recursos disponibilizados por esses pares. Esses protocolos, foram desenvolvidos visando sua utilização em sistemas de Computação em Grade. como o InteGrade.

Acreditamos que tais objetivos foram atingidos: nossos protocolos podem se adequar aos sistemas de Computação em Grade por serem independentes de um administrador central, possuírem suporte para buscas dos recursos baseadas em seus atributos e manterem a escalabiliclade.

A adoção de tecnologias Par-a-Par já implementadas como base para a comunicação e localização de um determinado recurso nos pares da rede se mostrou muito eficiente considerando o tempo e a facilidade de desenvolvimento do protocolo. A estrutura utilizada foi a tabela de hash distribuída e a implementação usada foi o Bamboo. Bamboo permitiu, de forma simples através de sua API simular recursos em redes de grande área sem termos que nos preocupar com essa implementação e funcionamento.

Sobre o Protocolo de Interligaçao. o principal objetivo é conectar os pares de forma que a comunicaço entre eles. em termos de latencia. seja a mais rapida possivel. A utilizaça da camada de rede. para encontrar noros pares. foi una ajuda 
muito grande em dois sentidos: primeiro, a obtenção dos caminhos entre dois pares já foi feita e calculada por essa camada e segundo, existem muitos caminhos entre os pares que se entrecruzam.

Para explicar isso, no primeiro ponto devemos destacar que, mesmo que a camada de rede não consiga obter "o melhor caminho" entre dois pares, ela consegue obter um bom caminho com o qual começar a procura por novos pares sem ter que implementar essa funcionalidade. No segundo ponto, quando os caminhos se entrecruzam, esses cruzamentos correspondem geralmente aos roteadores intermediários obtidos da camada de rede os quais, em nosso protocolo, foram utilizados para armazenar o par mais próximo desse roteador.

Com a simulação desse protocolo, podemos concluir que o tempo gasto para ingresso e atualização da rede é constante. Outro ponto importante é que na primeira iteração para atualizar a rede já se tinha uma estrutura onde a conexão entre os pares era muito boa. Finalmente, a quantidade de largura de banda consumida é linear em relação ao número de pares, devido ao uso da tabela de hash distribuída. Mesmo com essa deficiència, investigaçōes sobre o desempenho dessa estrutura asseguram que ela é totalmente escalável para centena de milhares de pares conectados.

Sobre o Protocolo de Localização, o objetivo é permitir a busca de recursos por um intervalo de valores, de forma eficiente e utilizando a tabela de hash distribuída. Para isso, foi proposta uma estrutura simples e eficiente baseada em uma lista distribuída e ordenada, para o registro e buscas dos recursos. Esses recursos podem possuir valores repetidos e, pelo nosso conhecimento, este é o primeiro trabalho que resolve esse problema.

De acordo com os resultados obtidos nas simulações deste protocolo, a nossa estrutura é tão eficiente quanto as propostas que usam árvores distribuídas, com a rantagem de utilizar uma estrutura mais simples de administrar.

\subsection{Trabalhos Futuros}

Pesquisas a serem realizadas a partir deste trabalho podem se diridir em duas áreas: na interligaçào dos pares e na localizaçăo dos recursos disponibilizados por eles.

Sugestóes de melhoria no Protocolo de Interligação dizem respeito à hargura de banda consumida e a integração da tabela de hash distribuída com um sistema 
de Computação em Grade.

A largura de banda consumida pode ser diminuida se nào utilizarmos a tabela de hash distribuida. Com essa abordagem, o acesso aos objetos roteadores que possibilitam conhecer novos pares, será uma tarefa difícil de conseguir.

Em relação à integração do nosso protocolo (baseado em uma implementação de uma tabela de hash distribuida) com um sistema de Computação em Grade, ela pode ser feita somente no nível de comunicação. Para isso podemos utilizar sistemas de middleware. como CORBA. que permitem a comunicação entre objetos através de chanadas remotas.

Considerando o Protocolo de Localização, existem algumas pesquisas que podem ser efetuadas. Por exemplo, o custo da inserção pode ser diminúdo usando alguns recursos que sejam réplicas dos identificadores mais visitados.

Outro análise pode ser na quantidade de troca de mensagens para realizar uma busca por intervalo. Ela pode ser diminuída utilizando a propagação dos pares que já foram visitados em uma requisição. Isto pode trazer problemas de largura de banda consumida que terão que ser analisados.

Finalmente. podemos sugerir uma pesquisa no compartilhamento de arquiros de dados em Grades Computacionais utilizando técnicas Par-a-Par. Para isso. seria interessante que a transferencia desses arquivos fosse com os aglomerados mais próximos em termos de latência. 


\section{Referências Bibliográficas}

[AS03] James Aspnes and Gauri Shah. Skip Graphs. In SODA 03: Proceedings of the Fourteenth Annual ACM SIAM Symposium on Discrete Algorithms, 2003.

[ASSW03] Tom Anderson, Scott Shenker, Ion Stoica, and David Wetherall. Design guidelines for robust Internet protocols. SIGCOMM Computer Communication Review, 33(1):125-130, 2003.

[AX02] Artur Andrzejak and Zhichen Xu. Scalable, Efficient Range Queries for Grid Information Services. In Proceedings of the Second IEEE International Conference on Peer-to-Peer Computing, 2002.

[Bam] The Bamboo Distributed Hash Table. http://www bamboo-dht.org. Ĺltimo acesso em Junho 2005.

[BBK02] Magdalena Balazinska, Hari Balakrishnan, and David Karger. INS/Twine: A Scalable Peer-to-Peer Architecture for Intentional Resource Discovery. In International Conference on Pervasive Computing 200\%, Zurich, Switzerland, August 2002.

[BV04] Rajkumar Buyya and Srikumar Venugopal. The Gridbus Toolkit for Service Oriented Grid and Ltility Computing: An Overview and Status Report. In Proceedings of the First IEEE International Workshop on Grid. Economics and Business Models (GECON), pages 19-36. IEEE Press. Abril 2004.

[BZH03] Ali Raza Butt, Rongmei Zhang; and Y. Charlie Hu. A self-organizing flock of condors. In Proceedings of the ACM IEEE Conference on Supromputing. IEEE Computer Sociotr: 2003.

[CFFK01] K. Czajkowski. S. Fitzgerald. I. Foster. and C. Tiesselman. Grid Information Serrices for Distributed Resource Sharing. In Proceedings of the 10th. IEEE International Symposium on High Performance Distributed 
Computing. page 1S1. Washington. DC. LS.A. 2001. IEEE Computer Society:

[Cho] The Chord Project. http://www.pdos.Ics.mit.edu/chord. Eltimo acesso em Junho 2005.

[C.JK-01] Mignel Castro, Michael B. Jones, Anne-Marie Kermarrec, Antony Rowstron, Marvin Theimer, Helen Wang, and Alec Wolman. An Evaluation of Scalable Application-level Multicast Built Lsing Peer-to-peer overlays. In ACM SIGCOMM 2001, Agosto 2001.

[CLL02] Jacky Chu, Kevin Labonte, and Brian Yeil Levine. Availability and Locality Measurements of Peer-to-Peer File Systems. In Proceedings of ITCom: Scalability and Traffic Control in IP Networks II Conferences. 2002.

[Con] The Condor Project. http://www.cs.wisc.edu/condor. Ĺltimo acesso em Julho 2005.

[Cos97] P. R. Cosway. Replication control in distributed b-trees. Technical report, Cambridge. NA, LSA, 1997.

[dIB59] Renee de la Briandais. File Searching Using Variable Length Keys. In Proceedings of the Western Joint Computer Conference, volume 15, 1959.

[eA01] Velson Minar et Al. Peer-to-Peer-Harnessing the Power of Distuptive Technologies. O'Reilly, 2001.

[FK97] I. Foster and C. Kesselman. Globus: A metacomputing infrastructure toolkit. The International Journal of Supercomputer Applications and High Performance Computing, 11(2):11j-128, 1997.

[GDS-03] Krishna P. Gummadi. Richard J. Dumn, Stefan Saroin, Steren D. Gribble. Henry M. Levy; and John Zahorjan. Measurement. modeling. and analysis of a peer-to-peer file-sharing workload. In SOSP '03: Proceedings of the ninetcenth $A C M$ symposinm on Operating systems principles. pages 311-329. New York. NY. L'SA. 2003. ACA Press.

[GKG-1)甘] Andrei Goldchleger, Fabio Kon, Alfredo Goldman. Marcelo Finger, and Germano Capistrano Bezerra. InteGrade: Object-Oriented Grid Micidleware Lereraging Idle Computing Power of Desktop Machines. Concurrency and Computation: Practice and Experience. 16:449-4.59. 2004. 
[Gilo] The Globus Alliance. http://www.globus.org. Cltimo acesso em Abril 2005.

[gnua] Gnutella 2 Protocol. http://www.gnutella2.com/index.php/Main_ Page\#The_Protocol. Cltimo acesso em Julho/2005.

[gnub] Gnutella Project. http://www.gnutella.com. Último acesso em Junho 2005.

[Gol04] Andrei Goldchleger. InteGrade: a Middleware System for Opportunistic Grid Computing. Master's thesis, Department of Computer Science University of São Paulo, Dezembro 2004. in Portuguese.

[gri] The Gridbus Project. http://www.gridbus .org. Cltimo acesso em Junho 2005 .

[Gro02] Object Management Group. CORBA v3.0 Specification. OMG Document 02-06-33, 2002.

[GS04] Jun Gao and Peter Steenkiste. An Adaptive Protocol for Efficient Support of Range Queries in DHT-Based Systems. In Proceedings of the 12th IEEE International Conference on Network Protocols (ICNPQ004), 2004.

[HHB $\left.{ }^{+} 03\right]$ Ryan Huebsch, Joseph M. Hellerstein, Nick Lanham Boon, Thau Loo, Scott Shenker, and Ion Stoica. Querying the Internet with PIER. In Proceedings of 19th International Conference on Very Large Databases., sep 2003.

[IF`02] Adriana Iamnitchi, Ian Foster, and Daniel Nurmi. A peer-to-peer approach to resource location in grid environments. In Proceedings of the 11 th IEEE International Symposium on High Performance Distributed Computing. page 419. Washington. DC. LSA, 2002. IEEE Computer Society.

[Int] InteGrade. http://integrade.incubadora.fapesp.br. Cltimo acesso em Dezembro 200j.

[Jun0t] Jun Gao and Peter Steenkiste. An Adaptive Prococol for Efficient Support of Range Queries in DHT-based Systems. 1:th IEEE International Conference on Netuork Protocols IICAP 2004). 2004.

[jxt] JATA. http://W's .jxta.org. Ültino acesso em Março 2005. 
[Kat02] Daishi Kato. GISP: Global Information Sharing Protocol. A Distributed Index for Peer-to-Peer Systems. In P2P OD: Proceedings of the Second International Conference on Peer-to-Peer Computing. page 65. IEEE Computer Society, 2002.

[kaz] Kazaa. http://www.kazaa.com. Ultimo acesso em Julho, 2005.

[KCM ${ }^{+}$)0] Fabio Kon, Roy H. Campbell, M. Dennis Mickunas, Klara Nahnstedt, and Francisco J. Ballesteros. 2K: A Distributed Operating System for Dynamic Heterogeneous Environments. In Proceedings of the 9th IEEE International Symposium on High Performance Distributed Computing (HPDC'9), pages 201-208. Pittsburgh, Agosto 2000.

[Knu73] D. E. Knuth. The Art of Computer Programming. Volume 3: Sorting and Searching. Addison-Wesley, 1973. Section 6.2.4.

[IR04] David R. Karger and Matthias Ruhl. Simple efficient load balancing: algorithms for peer-to-peer systems. In SPAA '04: Proceedings of the Sixteenth. Annual ACM Symposium on Parallelism in Algorithms and Architectures, pages 36-43. ACגI Press, 2004.

[Leu02] Bo Leuf. Peer to Peer. Addison-Wesley, 2002.

[LLMS8] Michael Litzkow, Miron Livny, and Matthew Mutka. Condor - a hunter of idle workstations. In Proceedings of the 8th International Conference of Distributed Computing Systems, Junho 1988.

[Lui04] Luis Garces-Erice and Pascal A. Felber and Ernst W. Biersack and Guillaume Lrvoy-Keller and Keith IV. Ross. Data Indexing in Peer-to-Peer DHT Networks. In Proceedings of the 24th IEEE International Conference on Distributed Computing Systems (ICDCS), pages 200-208, 2004.

[Min01] Nelson Winar. Distributed Systems Topologies, 2001. http://www. openp2p.com/pub/a/p2p/2001/12/14/topologies_one.html.

[nap] Sapster. http://ww. napster. com. Ĺltimo acesso em Julho 200.5.

[Pos 81] J. Postel. Internet Protocol - DARPA Internet Program Protocol Specification RFC 792. 1981. http://ww. ietf.org/rfc/rfc792.txt.

[Pug89] William Pugh. Skip Lists: A Probabilistic Alternative to Balanced Trees. In Workshop on Algorithms and Data Structures, pages 4:3i-449. $19 \$ 9$. 
[RD01] Antony Rowstron and Peter Druschel. Pastry: Scalable, decentralized object location, and routing for large-scale peer-to-peer systems. In Middleware 2001: Proceedings of the IFIP/ACM International Conference on Distributed Systems Platforms Heidelberg, pages 329-350, London, UK, 2001. Springer-Verlag.

$\left[\mathrm{RFH}^{+} 01\right]$ Sylvia Ratnasamy, Paul Francis, Mark Handley; Richard Karp, and Scott Schenker. A scalable content-addressable network. In Proceedings of the 2001 Conference on Applications, Technologies, Architectures, and Protocols for Computer Communications, pages 161-172, 2001.

[RGRK04] Sean Rhea, Dennis Geels, Timothy Roscoe, and John Kubiatowicz. Handling Churn in a DHT. In USENIX Annual Technical Conference, Junho 2004.

[RHS03] S. Ratnasamy; J. Hellerstein, and S. Shenker. Range Queries over DHTs. In Technical Report IRB-TR-03-009, Intel Corp., june 2003.

[Rit01] Jordan Ritter. Why Gnutella Can't Scale, 2001. http://www. darkridge.com/ jpr5/doc/gnutella.html.

[RLS+03] Ananth Rao, Karthik Lakshminarayanan. Sonesh Surana, Richard Karp, and Ion Stoica. Load Balancing in Structured P2P Systems. In 2nd International Workshop on Peer-to-Peer Systems (IPTPS '03)., 2003.

[RR05] Vladimir Rocha and Eric Ross. Uma Estrutura Escalável e Eficiente Para buscas por Intervalo sobre DHTs nas Redes P2P. In WP2P - I Peerto-Peer Workshop of the Brazilian Symposium on Computer Networks $(S B R C)$, Maio 2005 .

[SGG02] S. Saroiu, P. Gummadi. and S. Gribble. A Measurement Study of Peerto-Peer File Sharing Systems. In Proceedings of Multimedia Computing and Networking, 2002.

[S.MK-03] Ion Stoica, Robert Morris, David Karger, M. Frans Kaashoek, and Hari Balakrishnan. Chord: A Scalable Peer-to-peer Lookup Service for Internet Applications. In Infocom 03, Abril 2003.

[Sta03] William Stallings. Data and Computer Communication. Maxwell Macmillan International. serenth edition. 200:3.

[STDG01] Clay Shirky. Kelly Truelore. Rael Dornfest. and Lncas Gonze. P:P Neturking: The Energent P:P Platform of Presence. Identity. and Edye Resources. OReilly: 2001. 
[Tan102] Andrew Tanenbaum. Computer Networks. Prentice Hall, 2002.

[Va190] Leslie G. Valiant. A bridging model for parallel computation. Commun. ACM, 33(8):103-111, 1990.

[VTW02] A. Vahdat, K. Yocum, K. Walsh, P. Mahadevan, D. Kostic, J. Chase, and D. Becker. Scalability and Accuracy in a LargeScale Network Emulator. In Proceedings 5th OSDI, Dec. 2002., 2002.

[YB04] Praveen Yalagandula and James C Browne. Solving Range Queries in a Distributed System. In Technical Report TR-04-18. Department of Computer Science. The University of Texas at Austin. may 2004.

[YTB03] Jia Yu. Srikumar Venugopal. and Rajkumar Buyya. A Market-Oriented Grid Directory Service for Publication and Discovery of Grid Service Providers and their Services. Technical report, Grid Computing and Distributed Systems (GRIDS) Laboratory. The Lniversity of Melbourne, Australia. Janeiro 2003. GRIDS-TR-2003-0.

[ZSO4] X. Zhang and J. Schopf. Performance Analysis of the Globus Toolkit Monitoring and Discovery Service. MDS2. In Proceedings of the International Workshop on Middleware Performance (MP 2004), part of the 23ird International Performance Computing and Communications Conference. 2004. 